NBER WORKING PAPER SERIES

\title{
DOES PRIVATE EQUITY INVESTMENT IN HEALTHCARE BENEFIT PATIENTS? EVIDENCE FROM NURSING HOMES
}

\author{
Atul Gupta \\ Sabrina T. Howell \\ Constantine Yannelis \\ Abhinav Gupta \\ Working Paper 28474 \\ http://www.nber.org/papers/w28474 \\ NATIONAL BUREAU OF ECONOMIC RESEARCH \\ 1050 Massachusetts Avenue \\ Cambridge, MA 02138 \\ February 2021
}

We are grateful to Abby Alpert, Pierre Azoulay, Zack Cooper, Liran Einav, Matthew Grennan, Arpit Gupta, Jarrad Harford, Steve Kaplan, Holger Mueller, Aviv Nevo, Adam Sacarny, Albert Sheen, Arthur Robin Williams, and participants at the NBER Aging Summer Institute, American Economics Association, UBC Winter Finance Conference, Whistler Junior Health Economics Summit, Virtual Corporate Finance Seminar, ESSEC, Norwegian School of Economics, Oklahoma Price, PE Research Consortium (PERC) Annual Symposium, Tulane, NYU Stern, U Penn Wharton, Yale Health Policy, Oregon Lundquist, and Johns Hopkins Carey for their comments and suggestions. Jun Wong, Mei-Lynn Hua, and Sarah Schutz provided excellent research assistance. We thank Christianna Williams of Abt Associates for insights into CMS quality measures, Liz Liberman for industry information, and Mohan Ramanujan at NBER for assistance with the CMS data. Funding from the Wharton Dean's Research Fund and the Mack Institute (Gupta), the Kauffman Foundation (Howell), and the Fama Miller Center at the University of Chicago (Yannelis) is greatly appreciated. We gratefully acknowledge funding through National Institute of Aging pilot grant P01AG005842-31. All remaining errors are our own. The views expressed herein are those of the authors and do not necessarily reflect the views of the National Bureau of Economic Research.

NBER working papers are circulated for discussion and comment purposes. They have not been peer-reviewed or been subject to the review by the NBER Board of Directors that accompanies official NBER publications.

(C) 2021 by Atul Gupta, Sabrina T. Howell, Constantine Yannelis, and Abhinav Gupta. All rights reserved. Short sections of text, not to exceed two paragraphs, may be quoted without explicit permission provided that full credit, including (C) notice, is given to the source. 
Does Private Equity Investment in Healthcare Benefit Patients? Evidence from Nursing Homes Atul Gupta, Sabrina T. Howell, Constantine Yannelis, and Abhinav Gupta

NBER Working Paper No. 28474

February 2021

JEL No. G3,G32,G34,G38,I1,I18

\section{ABSTRACT}

The past two decades have seen a rapid increase in Private Equity (PE) investment in healthcare, a sector in which intensive government subsidy and market frictions could lead high-powered forprofit incentives to be misaligned with the social goal of affordable, quality care. This paper studies the effects of PE ownership on patient welfare at nursing homes. With administrative patient-level data, we use a within-facility differences-in-differences design to address nonrandom targeting of facilities. We use an instrumental variables strategy to control for the selection of patients into nursing homes. Our estimates show that PE ownership increases the short-term mortality of Medicare patients by 10\%, implying 20,150 lives lost due to PE ownership over our twelve-year sample period. This is accompanied by declines in other measures of patient well-being, such as lower mobility, while taxpayer spending per patient episode increases by $11 \%$. We observe operational changes that help to explain these effects, including declines in nursing staff and compliance with standards. Finally, we document a systematic shift in operating costs post-acquisition toward non-patient care items such as monitoring fees, interest, and lease payments.

Atul Gupta

Wharton Health Care Management 3641 Locust Walk, CPC 306

Philadelphia, PA 19104

atulgup@wharton.upenn.edu

Sabrina T. Howell

NYU Stern School of Business

KMC 9-93

44 West 4th Street

New York, NY 10012

and NBER

showell@stern.nyu.edu
Constantine Yannelis

Booth School of Business

University of Chicago

5807 S. Woodlawn Avenue

Chicago, IL 60637

and NBER

constantine.yannelis@chicagobooth.edu

Abhinav Gupta

New York University

agupta4@stern.nyu.edu 


\section{Introduction}

The U.S. spends more than other developed countries on healthcare, yet has worse health outcomes (Garber and Skinner, 2008). In light of evidence from other sectors, private equity (PE) ownership of healthcare providers could improve productivity (Kaplan, 1989; Davis et al., 2014; Bloom et al., 2015b; Bernstein and Sheen, 2016). PE ownership can affect firm performance because it confers distinct incentives to quickly and substantially increase firm value. ${ }^{1}$ However, PE's success in other sectors may not be relevant to healthcare, which suffers from unique market frictions. For example, patients cannot accurately assess provider quality, they typically do not pay for services directly, and a web of government agencies act as both payers and regulators (Cutler, 2011; Skinner, 2011). These features weaken the natural ability of a market to align firm incentives with consumer welfare and could mean that high-powered incentives to maximize profits have detrimental implications for consumer welfare (Hansmann, 1980; Hart et al., 1997; Chandra et al., 2016).

Policymakers appear increasingly concerned about this possibility given the rapid growth of PE in healthcare. For example, in 2019 U.S. Senators asked about "the role of PE firms in the nursing home care industry, and the extent to which these firms' emphasis on profits and short-term return is responsible for declines in quality of care," while a member of the British Parliament argued that PE-owned nursing homes in the UK pursue "profiteering, cost and corner cutting, all the while their owners are loading them up on debt with high interest rates and expecting the taxpayer to pay when it fails" (Brown et al., 2019; Hodgson, 2020). ${ }^{2}$ Meanwhile, voices from the private sector often paint a different picture; for example, a 2019 report from consulting firm EY concluded that "Not only is PE perceived to have a beneficial overall impact on health care businesses, it is also considered to positively influence the focus on quality and clinical services" (Saenz, 2019).

This debate has come to the fore in part because of rising PE activity in U.S. healthcare

\footnotetext{
${ }^{1}$ See Section 2.2 for an explanation of PE and its incentive structure.

${ }^{2}$ Policymaker concern has focused not only on nursing home quality (Doggett et al., 2020), but also surprise medical bills (Cooper et al., 2020) and predatory acquisitions of physician practices (King, 2020), among other areas. Also see Flood (2019) and Lewis (2019).
} 
over the last two decades, with total investment increasing from less than $\$ 5$ billion in 2000 to more than $\$ 100$ billion in 2018 (Appelbaum and Batt, 2020). PE-owned firms provide the staffing for more than one-third of emergency rooms, own large hospital and nursing home chains, and are rapidly expanding ownership of physician practices. ${ }^{3}$ Thus far, evidence to inform the animated policy discussion is limited and inconclusive.

We focus on nursing homes in the U.S., which represent a large sector with spending at $\$ 166$ billion in 2017 projected to grow to $\$ 240$ billion by 2025 (Martin et al., 2018). Nursing homes offer an attractive setting in which to examine the impact of PE in healthcare. First, they have historically had a high rate of for-profit ownership (about 70\%), allowing us to study the effects of PE ownership relative to for-profit ownership more generally. Second, PE firms have acquired both large chains and independent facilities, enabling us to make progress in isolating the effects of PE ownership from the related phenomenon of corporatization in medical care (Eliason et al., 2020). We use patient- and facility-level administrative data from the Centers for Medicare \& Medicaid Services (CMS), which we match to PE deal data. The data include 18,485 unique nursing homes between 2000 and 2017. Of these, 1,674 were acquired by PE firms in 128 unique deals. We observe about 7.4 million unique Medicare patients.

We overcome two empirical challenges to estimating causal effects of PE ownership. The first is non-random selection of acquisition targets. To address this we include facility fixed effects, which also eliminate cross-sectional differences in the types of locations where PE firms tend to buy nursing homes. The second challenge is unobserved changes in patient composition following PE ownership, perhaps reflecting new advertising, hospital ties, or patient reactions to quality. We control for the patient-facility match with a differential distance instrumental variables (IV) strategy (McClellan et al., 1994; Grabowski et al., 2013; Card et al., 2019), exploiting patient preference for a nursing facility close to their home (the median distance is 4.6 miles). To our knowledge, no national study on PE or on ownership in healthcare has simultaneously addressed both challenges.

A key measure of patient welfare is short-term survival. We find that going to a PE-

\footnotetext{
${ }^{3}$ See Bruch et al. (2020); Brown et al. (2020); Casalino (2020).
} 
owned nursing home increases the probability of death during the stay and the following 90 days by 1.7 percentage points, about $10 \%$ of the mean. This estimate implies about 20,150 Medicare lives lost due to PE ownership of nursing homes during our sample period. We use the observed age and gender distribution of Medicare decedents to estimate the corresponding implied loss in life-years - 160,000. Using a conventional value of a lifeyear from the literature, this estimate implies a mortality cost of about $\$ 21$ billion in 2016 dollars. To put this in perspective, this is about twice the total payments made by Medicare to $\mathrm{PE}$ facilities during our sample period, about \$ 9 billion.

The mortality effect is concentrated among older patients, especially those with relatively low disease burdens. Exploring treatment effect heterogeneity more formally using Marginal Treatment Effect (MTE) analysis, we find evidence of reverse selection on treatment gains, i.e., patients with the lowest unobserved resistance to going to a PE-owned facility experience the highest increase in mortality (nearly $4 \mathrm{pp}$ ). We estimate an unconditional Average Treatment Effect (ATE) of about $1.3 \mathrm{pp}$. Hence, the conclusion that patients are worse off at PE-owned facilities can be generalized beyond compliers to the average Medicare patient. However, we also estimate negative MTE values for patients with the highest unobserved resistance, implying that a small fraction of patients are better off receiving care at such facilities.

The effect on mortality is robust to a battery of specification checks, and does not appear in a placebo analysis testing for pre-buyout effects. It also remains intact when we restrict our attention to PE acquisitions of the largest chains, in which chain size remained constant over the sample period, implying that the effect reflects the nature of ownership rather than consolidation or corporatization more broadly. To ensure the effect is not spurious, we study other measures of patient well-being using the same IV approach. We find that going to a PE-owned nursing home increases the probability of taking antipsychotic medications - discouraged in the elderly due to their association with greater mortality - by $50 \%$. Similarly, patient mobility declines and pain intensity increases post-acquisition. Finally, the amount billed per 90 -day episode increases by $11 \%$. Taken together, these results suggest that PE ownership decreases nursing home productivity, as 
measured by our proxies for quality output per dollar spent.

To explore mechanisms for the effect on mortality, we assess operational changes using facility-level data. Here we are limited to using a differences-in-differences research design, which has been standard in the literature on PE effects. We find negative effects on facility Five Star ratings, which are constructed by CMS to provide summary information on quality of care. We next consider nurse availability, which is the most important determinant of quality of care (Zhang and Grabowski, 2004; Lin, 2014). We find that PE ownership leads to a $3 \%$ decline in hours per patient-day supplied by the frontline nursing assistants who provide the vast majority of caregiving hours and perform crucial well-being services such as mobility assistance, personal interaction, and cleaning to minimize infection risk and ensure sanitary conditions. Overall staffing declines by $1.4 \%$.

The loss of front-line staff is most problematic for older but relatively less sick patients, who drive the mortality result. There may be less scope to reduce the costs of care for the sicker patients, as they have explicit medical needs. Elevated antipsychotic use could also be partly explained as a substitution response to lower nurse availability (Cawley et al., 2006). We can explain about a third of the mortality effect using previously published mortality effects of antipsychotics and lower nurse availability and assuming these factors are additive (Schneider et al., 2005; Tong, 2011). However, this may be an understatement if these factors are more harmful when they interact.

Finally, we assess facility finances to shed light on how the financial strategies particular to the PE industry affect operations. A puzzle is why nursing homes are attractive targets given their low and regulated profit margins, often cited at just 1-2\%. Using CMS cost reports, we find that there is no effect of buyouts on net income, raising the question of how PE firms create value. There are three types of expenditures that are particularly associated with PE profits and tax strategies: "monitoring fees" charged to portfolio companies, lease payments after real estate is sold to generate cash flows, and interest payments reflecting the importance of leverage in the PE business model (Metrick and Yasuda, 2010; Phalippou et al., 2018). We find that all three types of expenditures increase after buyouts, with interest payments rising by over $300 \%$. These results, along with the decline in nurse availability, 
suggest a systematic shift in operating costs away from patient care.

This paper contributes to three strands of the literature. First, we provide new evidence on the effects of PE ownership on target firm operations (Boucly et al., 2011), product quality (Lerner et al., 2011; Fracassi et al., 2020), and value (Gupta and Van Nieuwerburgh, 2019; Bernstein et al., 2019; Biesinger et al., 2020). We overcome most limitations of previous studies on PE in healthcare, such as limited geographies, a short sample period, a lack of patient-level data, or a small number of deals (Stevenson and Grabowski, 2008; Harrington et al., 2012; Pradhan et al., 2013, 2014; Cadigan et al., 2015; Huang and Bowblis, 2019; Gondi and Song, 2019; Casalino, 2020; Gandhi et al., 2020).

In contrast with much of the existing literature, and likely reflecting the considerable market frictions in healthcare, our results suggest that PE owners may breach implicit contracts with stakeholders to maximize profits (Shleifer and Summers, 1988). Eaton et al. (2019) come to the same conclusion in their study of PE ownership of colleges. It is noteworthy that nursing homes operate under much more intense regulatory scrutiny of their daily operations than do colleges. Hence, our results raise concerns about the effectiveness of the elaborate state and federal oversight infrastructure in place to ensure nursing home quality.

Second, this paper adds to the literature on how provider ownership interacts with price incentives and regulation in healthcare Duggan (2000); Grabowski and Hirth (2003); Grabowski et al. (2013); Clemens and Gottlieb (2014); Adelino et al. (2015); Hill et al. (2019); Curto et al. (2019). ${ }^{4}$ Some work points to non-pecuniary objectives of nonprofits as one reason nonprofit providers can outperform for-profits. Our results appear consistent with this theme, potentially raising questions about whether antitrust regulators should prospectively review PE deals in healthcare. While the large deals in our sample did not soften competition, they may have hurt consumers. ${ }^{5}$

\footnotetext{
${ }^{4}$ There is also a related literature on competition in healthcare markets Bloom et al. (2015a), Curto et al. (2021); Grabowski and Hirth (2003); Dafny et al. (2012); Cooper et al. (2018); Pelech (2018); Ho and Lee (2019).

${ }^{5}$ The largest deals in our sample involved purchases of nursing home chains owning hundreds of facilities already and which remained stable in size. Both the US House and Senate are considering expanding the scope of the prevailing anti-trust laws. As example, see https: //wWw . cnbc . com/2021/02/04/klobuchar-unveils-sweeping-antitrust-bill-laying-out-
} 
Third, this paper contributes to the emerging literature on the industrial organization of the nursing home sector, which has received less attention than hospitals in economics (Lin, 2015; Hackmann and Pohl, 2018; Hackmann, 2019). Previous work has focused on the role of competition and payment rates in determining quality. Our results imply that owner incentives are of first-order importance, which may be helpful for policymakers as they consider regulatory actions to improve transparency and accountability. For example, in light of prior work showing how PE increases performance when incentives between investors and consumers are well-aligned, government reimbursements targeting outcomes could potentially improve patient welfare. These issues have become more urgent as the COVID-19 pandemic has exposed flaws in the regulation and financing of long-term care facilities, which have accounted for nearly $40 \%$ of U.S. deaths from the virus. ${ }^{6}$

The paper proceeds as follows. Section 2 provides institutional background. Section 3 describes the data. The strategy for patient-level analysis is explained in Section 4, and the results are in Section 5. The facility-level estimation is in Section 6. Section 7 concludes.

\section{Institutional Background}

\subsection{The Economics of Nursing Homes}

Nursing homes provide both short-term rehabilitative stays - usually following a hospital procedure - as well as long-term custodial stays for patients unable to live independently. There are two unique features of the long-term care market in the U.S. relative to other healthcare subsectors. First, government payers (Medicaid and Medicare) account for $75 \%$ of revenue, while private insurance plays a much larger role in other subsectors (Johnson, 2016). ${ }^{7}$ Second, about $70 \%$ of nursing homes are for-profit, which is a much larger share than other subsectors. For example, fewer than one-third of hospitals are for-profit.

her-vision-as-new-subcommittee-chair- html.

${ }^{6}$ Source: The New York Times Coronavirus Tracker, as of October 2020.

${ }^{7}$ Medicaid is a means-tested insurance program targeted at low income and disabled non-elderly individuals. It is the primary payer for custodial care and accounts for about $60 \%$ of nursing home patientdays in our data. Medicare is an entitlement health insurance program for individuals older than age 65, and it covers limited short-term rehab care following hospital inpatient care, accounting for $15 \%$ of patient-days. 
Policymakers have long been concerned about low-quality care at nursing homes in the U.S. and for-profit ownership has often been proposed as a causal factor (Institute of Medicine, 1986; Grabowski et al., 2013). ${ }^{8}$

As with any business, the economics of nursing homes are shaped by the nature of demand, the cost structure, and the regulatory environment. On the demand side, nursing homes serve elderly patients but are paid by third-party, largely government payers. Over 95\% of facilities treat both Medicare and Medicaid patients (Harrington et al., 2018). Both programs pay a prospectively set amount per day of care for each covered patient ('per diem'), which does not incorporate quality of care, reputation, or other determinants that would be considered by a well-functioning market. These rates are non-negotiable, and facilities simply choose whether they will accept beneficiaries of these programs. Medicare fee-for-service pays much more, at roughly $\$ 515$ per patient day relative to $\$ 209$ per patient day from Medicaid. ${ }^{9}$ Overall profit margins are in the low single digits (MedPAC, 2017), a topic we return to at the end of the paper. Payments are adjusted for patient complexity, so there is an incentive to overstate their severity-a practice known as 'up-coding.' This makes it difficult to use risk as an outcome.

Nursing homes provide institutional care and so have high fixed costs, making the occupancy rate an important driver of profitability. Nursing staff represent the largest component of operating cost, at about 50\% (Dummit, 2002). Broadly speaking, there are three types of nurses. Low-skill Certified Nurse Assistants (CNAs) account for about $60 \%$ of total staff hours and provide most of the direct patient care. Licensed Practical Nurses (LPNs) have more training and experience than CNAs but cannot manage patients independently. Registered Nurses (RNs) have the highest skill and experience levels, and can independently determine care plans for patients. LPNs and RNs each account for about

\footnotetext{
${ }^{8}$ This concern is frequently reflected in the popular media, including as a reason for high death rates from Covid-19 in nursing homes. For example, a New York Times article in December, 2020 asserted that: "Long-term care continues to be understaffed, poorly regulated and vulnerable to predation by for-profit conglomerates and private-equity firms. The nursing aides who provide the bulk of bedside assistance still earn poverty wages, and lockdown policies have forced patients into dangerous solitude" (Kim, 2020).

${ }^{9}$ https://skillednursingnews.com/2019/03/medicare-advantage-eats-into-margingains-for-skilled-nursing-facilities/. Medicaid still pays more than the marginal cost of treatment per day. Hackmann (2019) calculates that the marginal cost of treatment per-day is about $\$ 160$ on average.
} 
$20 \%$ of nurse hours. Nurse availability is crucial to the quality of care and there is a consensus that low ratios of nursing staff to residents are associated with higher patient mortality and other adverse clinical outcomes (Tong, 2011; Lin, 2014). Staffing ratios are therefore standard metrics to examine nursing home quality (Hackmann, 2019).

Economists have long emphasized the importance of information asymmetry between patients and healthcare providers (McGuire, 2000). It is difficult for patients to assess nursing home quality and compare it to available alternatives, and as discussed above, price is not a helpful quality signal in this setting. Reputation is therefore likely to have an unusually large influence on demand for nursing homes (Arrow, 1963). Profit maximizing facilities should optimally invest in building and sustaining their reputation. This creates a dynamic incentive problem where they could generate higher profits in the short-term by cutting patient care costs (nursing staff, for example), but they may optimally sacrifice these short-term profits in order to maintain their reputation and safeguard patient demand for the long-term. It remains unclear which factor inputs affect nursing home reputation, but evidence from prior studies suggests that patient demand does not respond to poor quality scores on government mandated report cards (Grabowski and Town, 2011; Werner et al., 2012).

\subsection{The Economics of Private Equity Control}

PE firms conduct leveraged buyouts (LBOs), in which a target firm is acquired primarily with debt financing - which is placed on the target firm's balance sheet - and a small portion of equity. ${ }^{10} \mathrm{PE}$ is associated with particularly high-powered incentives to maximize profits because fund managers are compensated through a call option-like share of the profits, employ large amounts of leverage collateralized with target firm assets, aim to liquidate investments within a short time frame, and do not have existing relationships with target firm stakeholders (Kaplan and Stromberg, 2009). Specifically, the compensation of the General Partners (GPs) who manage PE funds stems primarily from increasing

\footnotetext{
${ }^{10}$ Kaplan and Stromberg (2009) provide a detailed discussion of the PE business model and review the academic evidence on their effects. In the interest of brevity, we limit our discussion.
} 
portfolio company value between the time of the buyout and an exit, when the company is sold to another firm or taken public. GPs typically receive $20 \%$ of profits after a hurdle rate, which the fund's investors (Limited Partners) are guaranteed before GPs receive any profits. GPs also receive transaction and monitoring fees, which are not tied to performance. Overall, however, PE managers typically do not earn returns if the business continues as-is, motivating aggressive value-creation strategies. In contrast, a traditional business owner running the firm as a long-term going concern with a lower debt burden may prefer lower but more stable profits.

A large literature in finance beginning with Kaplan (1989) and Kaplan and Schoar (2005) has shown that in part due to the call option-like nature of GP compensation, PE buyouts increase productivity, operational efficiency, and generate higher returns. Kaplan and Stromberg (2009) argue that PE owners increase firm value through three channels, which they call financial, governance, and operations engineering. The first channel includes the alleviation of credit constraints (Boucly et al., 2011), which may lead to increases in investment and improved operations, and exploiting the favorable tax code treatment of debt financing (Spaenjers and Steiner, 2020), which may increase financial stress and the chances of default.

Governance engineering includes a number of changes to the compensation, benefits, and composition of the management team at the target firm to align their incentives with those of the PE owners. For example, in addition to frequently changing key managers, PE owners also increase the equity stake of the management team and introduce performancebased compensation (Gompers et al., 2016). Bloom et al. (2015b) show that PE-owned firms are better managed than similar firms that are not PE-owned.

Operations engineering refers to the more recent practice of PE firms applying their industry expertise to add value to their investments. PE owners identify both strategic and operational opportunities, such as re-branding, organization restructuring, investing in new technology, expanding to new markets, and cost-cutting (Gadiesh and MacArthur, 2008; Acharya et al., 2013; Bernstein and Sheen, 2016). Davis et al. (2014) show that PE buyouts are linked to greater labor churn, the expansion of efficient operations and the closure of 
inefficient operations.

Considering these changes in the context of nursing homes, the effects on patients are theoretically ambiguous. On the one hand, better management, stronger incentives, and access to credit may lead to improvements in care quality. On the other hand, three forces could adversely affect quality. The first is that cost cutting measures and a focus on capturing subsidies could come at the expense of quality improvement efforts. The second is that the nursing home incurs a large debt obligation as part of the buyout, and the resulting interest payments can reduce the cash available for care. A related additional cost is leasing property that formerly was owned by the nursing home. PE owners often sell real estate assets shortly after the buyout, which generates cash that can be returned to investors. Such cash flows early in the deal's lifecycle boost ultimate discounted returns. For example, in one of the largest PE deals in our sample, the Carlyle Group bought HCR Manorcare for about $\$ 6.3$ billion in 2007 , of which roughly one quarter was equity and three-quarters were debt. Four years later, Carlyle sold the real estate assets for $\$ 6.1$ billion, offering investors a substantial return on equity (Keating and Whoriskey, 2018). Afterward, HCR Manorcare rented its facilities; the monthly lease payments are essentially another debt obligation, and a Washington Post investigation found that quality of care deteriorated following the real estate sale (Keating and Whoriskey, 2018).

Finally, the third force is the relatively short-term time horizon of PE investments, which could push managers to focus on maximizing short-term profits even if they come at the expense of long term reputation and performance. In the case of HCR Manorcare, the nursing home chain was ultimately unable to make its interest and lease payments and entered bankruptcy proceedings in the spring of 2018. Carlyle sold its stake to the landlord.

\section{Data and Descriptive Statistics}

In this section we briefly summarize our data sources and provide descriptives about the sample, including an analysis of PE targeting. In Appendix A, we describe these elements in comprehensive detail. 


\subsection{Data}

We obtained facility-level annual data between 2000 and 2017 from publicly-available CMS sources. In each year we observe about 15,000 unique skilled nursing facilities (we use the term "nursing home" interchangeably), for a total of approximately 280,000 observations. These data include variables such as patient volume, nurse availability, and various components of the Five Star ratings. The ratings first appear in 2009. Fortunately, half of the PE deals in our sample occurred after 2009.

Our second data source consists of patient-level data for Medicare beneficiaries from 2004 to 2016. We use the Medicare enrollment and claims files (hospital inpatient, outpatient, and nursing homes) for the universe of fee-for-service Medicare beneficiaries. We merge these files with detailed patient assessments recorded in the Minimum Data Set (MDS) to obtain additional clinical insights. These data are confidential and were accessed under a data use agreement with CMS. They include patient enrollment details, demographics, mortality, and information about care in nursing homes and hospitals during this period.

In patient-level analysis, the unit of observation is a nursing home stay for a Medicare beneficiary that begins during our sample period, which we begin in 2005 in order to have at least one look-back year. We consider only the patient's first nursing home stay in our entire sample period so that we can unambiguously attribute outcomes to one facility and make our patient sample more homogeneous. This produces a sample of more than seven million patients over 12 years. We are most interested in the effect on mortality, which is an unambiguously bad outcome, has little measurement error, and is difficult to "game" on the part of a facility or a government agency. For these and other reasons, short-term mortality (with suitable risk adjustment) has become the gold-standard measure of provider quality in the health economics and policy literature (McClellan and Staiger, 1999). We use an indicator for death during the stay or within 90 days following discharge, based on death dates recorded in the Medicare master beneficiary summary file. There is a high level of short-term mortality—one in six patients die within three months of discharge-indicating 
the general morbidity of this patient cohort.

We use two measures of spending: the amount billed to Medicare for the patient stay, and the amount for the stay plus the following 90 days, in case better quality care leads to lower subsequent spending (both in 2016 dollars). Medicare covers the entire cost until the $21^{\text {st }}$ day of stay, at which point the patient begins paying a coinsurance. Consequently, about $90 \%$ of total payments in our data are made by Medicare and patients bear the remainder. We complement the mortality analysis by examining some ancillary measures of patient well-being using the clinical assessments. We study four outcomes that CMS uses when computing the Five Star quality ratings for nursing homes. The first is an indicator for the patient starting antipsychotic medication during the stay. Antipsychotic use in the elderly is known to increase mortality, and non-pharmaceutical interventions such as music and breathing exercises have been shown to be more effective (Taragano et al., 1997; Kuehn, 2005; Sink et al., 2005; Schneider et al., 2005; Banerjee et al., 2011; Press and Alexander, 2013). The second is an indicator for the patient's self-reported mobility score declining during the stay. The third is an indicator for developing a pressure ulcer. The fourth is an indicator for the patient's self-reported pain intensity score increasing during the stay.

To identify nursing homes acquired in PE deals, we make use of a proprietary list of transactions in the "elder and disabled care" sector compiled by Pitchbook Inc., a leading market intelligence firm in this space. The deals span 2004 to 2015, so that we will have sufficient time to evaluate outcomes. We match the target names to individual nursing facilities using name (facility or corporate owner) and address as recorded in the CMS data. This process yields 128 deals, which correspond to a change in ownership to PE for 1,674 facilities. The vast majority of deals in Pitchbook are not at hazard of matching, as they concern assisted living or other elder care companies that are not Medicare-accepting skilled nursing facilities. (See Appendix A for details.)

Figure B.1 shows the number of deals in each year; the deals are spread over time, and no part of the business cycle dominates. The deals are also spread across PE firms. In total, our data contain 136 unique PE firms that acquired nursing homes. Most deals are syndicated and involve multiple PE firms. Table B.1 presents the top 10 deals by number 
of facilities acquired. On average, we observe PE-owned facilities for eight years postacquisition. Hence the results should be interpreted as medium to long-term effects of PE ownership. It is difficult to ascertain whether we comprehensively capture PE activity in this sector. While there is no 'official' tally of PE-owned nursing homes to benchmark against, our sample size compares favorably against an estimate of 1,876 nursing homes reportedly acquired by PE firms over a similar duration, 1998-2008 (GAO, 2010). The PE investors in our sample include very large funds, smaller funds, and specialized healthcare PE investment funds. The funds which account for the greatest number of deals are Onex, Fillmore Capital Partners, The Hillview Group, The Carlyle Group, Cammeby International, Heritage Partners, Lydian Capital, Formation Capital, and Oaktree.

\subsection{Descriptive Statistics}

Overall, PE investment in healthcare has increased dramatically in recent decades, as shown using Pitchbook data in Panel A of Figure 1. Panel B focuses on the Elder and Disabled Care sub-sector, which includes the nursing homes that we study as well as assisted living and other types of care. The shaded areas in the graphs correspond to years after our sample ends, and indicate that deal activity continued to accelerate beyond 2015. The bottom two panels describe the skilled nursing facilities in our CMS data that are PE-owned. As of 2015, PE-owned facilities represented about $9 \%$ of all nursing facilities in the data, corresponding to an annual flow of about 100,000 patients. Note that the large spike in the mid-2000s seen in all the graphs reflects an economy-wide PE boom during this period, and is not specific to healthcare. Similarly, the flat lining in Panels C and D starting in 2010 reflects the lull in deal activity due to the Great Recession. Given the patterns in Panel B, the share of facilities that are PE-owned is likely substantially higher today.

Table 1 Panel A presents summary statistics on key variables used in the analysis at the facility-year level, where a facility is a single nursing home. Panel B presents summary statistics at the unique patient level on the final Medicare patient sample (recall we focus on a patient's first stay). PE targets are slightly larger, have fewer staff hours per resident, 
and a lower Overall Five Star rating. At the sector level, ratings and staffing have secularly increased over time. For staffing, this reflects more stringent standards from regulators over time. As the PE deals occurred primarily later in the sample, it is therefore remarkable that they have lower measures of quality on average. Panel B shows that demographic measures are similar across the types of facilities, such as patient age and a high-risk indicator. ${ }^{11}$ PE-owned facilities bill about $10 \%$ more per stay than non-PE facilities.

We describe which characteristics are associated with buyouts in Table A.1. Facilities in more urban counties and in states with higher elderly population shares are more likely to be targeted. ${ }^{12}$ County-level income, race, and home ownership do not predict buyouts. Chain-owned facilities are more likely to be acquired than independent facilities, likely reflecting the fixed costs of a PE deal. A higher share of Medicare patients (the omitted group) is positively associated with being targeted. Finally, the Five Star overall rating has a negative relationship with buyouts, indicating that PE firms target relatively low-performing nursing homes. These factors remain statistically significant predictors when included simultaneously in the same model, shown in column 5. These results highlight the need to estimate the effects of PE ownership within-facility.

\section{Empirical Strategy for Patient-Level Analysis}

There are two primary concerns related to measuring the causal effects of PE ownership on patient-level outcomes. First, PE funds may target facilities that are different in ways the econometrician cannot observe. To address this concern, we include facility fixed effects, eliminating time invariant differences across facilities. Second, following a PE buyout, the composition of patients may change, confounding the analysis. Differential customer selection following PE ownership could reflect both supply-side channels such as changes in advertising and hospital referrals, or patient perceptions about PE ownership.

\footnotetext{
${ }^{11}$ We use the Charlson Comorbidity Index, a standard measure of patient mortality risk based on comorbidities. We create a high-risk indicator that is equal to one if the previous-year Charlson score is greater than two.

${ }^{12}$ The map in Figure B.2 shows that deals are not excessively concentrated in particular areas of the country.
} 
Recent studies have documented that nursing homes can select patients based on patient characteristics, only some of which are observable to CMS (Hackmann and Pohl, 2018; Gandhi, 2020). We see evidence of changes in patient risk following PE ownership in our data. Table B.5 Panel A presents point estimates from differences-in-differences models that exploit variation in the timing of the PE deals across facilities. We test for changes in patient risk (assessed at the time of admission) following acquisition. We examine effects on a mix of acute and chronic conditions to broadly capture changes in patient risk. The coefficients indicate that patients are less likely to suffer from Dementia and Alzheimers or from acute conditions like Hip Fractures at the time of admission. However, they are also more likely to have a Urinary Tract Infection (UTI). Figure B.3 presents the corresponding event study plots, which generally suggest flat or declining trends in patient risk around the time of the acquisition. We are concerned that if there is a similar decline in unobserved patient risk following PE ownership, it will bias downward mortality and spending effects obtained via OLS. Therefore, we develop an instrument for the match between patients and nursing homes.

\subsection{Distance Instrument}

We use a differential distance instrument (McClellan et al., 1994) to control for endogenous patient selection into nursing homes. The instrument exploits the well-known patient preference for nearby healthcare providers (Einav et al., 2016; Card et al., 2019; Currie and Slusky, 2020). This is especially true for nursing homes; for example, Hackmann (2019) finds that the median distance between a senior's residence and her nursing home is under 4.3 miles. This is also evident in our data-the median and 90th percentile distances between a patient and her nursing home are 4.6 and 18 miles, respectively. About $35 \%$ of all patients choose the facility located closest to them (see Figure B.4). ${ }^{13}$ As a result of these patterns, this instrument has been useful in the nursing home setting to control for patient selection (Grabowski et al., 2013; Huang and Bowblis, 2019).

\footnotetext{
${ }^{13}$ Distance patterns remain remarkably stable over time in our sample. Mean distance to facility is unaffected by PE buyout, as shown in Figure B.4D.
} 
We compute the difference (in miles) between two distances: from a patient's home zip code to the closest PE-owned facility zip code; and from the patient's residence to the nearest non-PE facility zip code. A positive value indicates the patient is closer to a non-PE facility. A lower differential distance value implies the nearest PE-owned facility is closer to the patient. PE ownership evolves over time as more deals take place (and some PE funds exit their investments), creating variation across years in differential distance for individuals residing in the same zip code. Following convention in the literature, we drop patients with outlier differential distance values. ${ }^{14}$

The first stage is estimated using Equation (1), and the second stage is estimated using Equation (2). The endogenous regressor of interest $P E_{i, j, r, t}$ is an indicator set to one if patient $i$ in Hospital Referral Region (HRR) $r$ chooses PE-owned facility $j$ in year $t$. We instrument with linear and squared differential distance, $D_{i}$ applicable to patient $i$ based on her zip code, $z$, and when the nursing home stay began.

$$
\begin{gathered}
P E_{i, j, r, t}=\alpha_{j}+\alpha_{r, t}+\zeta_{1} D_{i}+\zeta_{2} D_{i}^{2}+X_{i, z}^{\prime} \xi+v_{i, j, r, t} \\
Y_{i, j, r, t}=\alpha_{j}+\alpha_{r, t}+\phi P E_{i, j, r, t}+X_{i, z}^{\prime} \gamma+\varepsilon_{i, j, r, t}
\end{gathered}
$$

Our preferred model controls for facility, $\alpha_{j}$, and patient HRR by year fixed effects, $\alpha_{r, t}$. The vector $X_{i, z}$ denotes patient risk controls including age, indicators for gender, marital status, dual eligible, and 17 disease categories. ${ }^{15}$ We conduct multiple robustness checks, which include adding time-varying socioeconomic variables at the patient's zipcode-year level and omitting all controls. ${ }^{16}$ Standard errors are clustered by facility to account for unobserved correlation in outcomes across patients treated at the same nursing home.

The instrument is strongly predictive of choice of nursing home type. The first stage results are reported in Table 2. Column 2 presents the estimates from our preferred

\footnotetext{
${ }^{14}$ Specifically, we drop patients with a differential distance value beyond 70 miles, which is approximately the 95th percentile (i.e., the nearest PE facility is 70 miles further than the nearest non-PE facility). The concern here is that these patients are plausibly located in a different market which PE facilities do not operate in, and hence could differ in unobserved ways correlated with health or spending outcomes. To be symmetric, we also drop (the very few) patients who have a differential distance value below -70 .

${ }^{15}$ To construct these indicators, we use diagnoses codes recorded in claims billed over the three months prior to the index nursing home stay (hospital stays, ED visits, and outpatient visits).

${ }^{16}$ The socioeconomic variables, from the American Community Survey, are annual median household income, the share of the population that are white, that are renters rather than home-owners, and that are below the Federal poverty line.
} 
specification. A five mile decrease in differential distance $(0.3$ s.d.) increases the probability of going to a PE-owned nursing home by 2.3 percentage points ( $\mathrm{pp}$ ), a quarter of the mean level. The F-statistic exceeds 200, well above conventional rule-of-thumb thresholds for weak instruments.

\subsection{Instrument Assumptions and Validation Tests}

IV estimation differs from randomized controlled trials because the randomization of patients to treatment is indirect rather than deliberate. As in all such analyses, we must rely on two untestable identification assumptions. The first is conditional random assignment, which requires that after conditioning on covariates, unobserved characteristics correlated with the outcomes of interest are not correlated with differential distance. This assumption subsumes the exclusion restriction, that the instrument affects outcomes only through its effect on the patient's probability of going to a PE facility. The second assumption is monotonicity, which assumes that a decrease in differential distance makes all patients more likely to choose a PE-owned facility. This is true on average, but the assumption is at the patient-level which is untestable. Monotonicity is necessary to interpret the IV estimate as a well-defined local average treatment effect (LATE).

An important test for randomization examines whether differential distance is correlated with covariates, particularly those which may affect health outcomes, such as risk. Comparing the estimates reported in columns 1 and 2 of Table 2, the coefficients on differential distance are nearly unaffected by including patient-level controls, consistent with random assignment. Figure 2 Panel A visually presents the relationship between patient risk and the instrument and indicates little or no correlation. ${ }^{17}$

Additional evidence for random assignment is that patient characteristics are similar for high and low values of differential distance. We document this in Table 3, where we summarize 21 patient characteristics for above- and below-median differential distance

\footnotetext{
${ }^{17}$ We project the high-risk indicator (see Section A.2) on the controls we use in our main regression, and collapse the residuals into twenty bins. Similarly, we run a regression of differential distance on the controls and collapse the residuals into twenty bins. We plot the means of each bin, with the risk residuals on the Y-axis and distance residuals on the $\mathrm{X}$-axis. The figure also presents a fitted line and the slope coefficient.
} 
values. The top two rows of the table show that, consistent with a strong instrument, below-median differential distance average is 2.7 miles, while the above-median average is 27 miles. The associated probability of going to a PE-owned facility declines from $17 \%$ to $2 \%$. The patient characteristics in the subsequent rows are extremely similar across the two groups. For example, $64 \%$ of each group are women, and about a quarter of the patients in both groups have diabetes. While differential distance is highly predictive of going to a PE-owned facility, it appears to randomize patients with respect to observed covariates.

PE funds may strategically target nursing homes located in places with certain desired demographic and risk profiles. We account for stable differences in the patient catchment of facilities by including facility fixed effects. However, it is possible that PE firms strategically target geographic markets with desirable trends, for example with increasing household income. To address this concern, we show robustness to including time-varying zip code-level socioeconomic controls. We document that these controls do not affect the first stage in Column 3 of Table 2. The use of HRR-specific year fixed effects further mitigates the possibility of differential market trends biasing the effects.

A related concern may be that HRRs are too large and do not sufficiently control for unobserved heterogeneity in trends across markets. Hence, we also test robustness to using the more granular market definition of Health Service Areas (HSA) and counties. ${ }^{18}$ There are nearly 800 HSAs and 3,000 counties, respectively, while there are only about 300 HRRs. Columns 4 and 5 of Table 2 present results using these finer market definitions, respectively, with slightly smaller estimates.

We provide evidence consistent with the monotonicity assumption in Figure 2 Panel B, which contains a binscatter plot of the first stage, showing that the likelihood of going to a PE-owned facility increases nearly linearly with differential distance. It is estimated in the same way as Panel A described above, except that the outcome is an indicator for the facility being PE-owned. The monotonicity assumption also implies that the first stage should be

\footnotetext{
${ }^{18}$ HSAs were developed by the National Center for Health Statistics of the Centers for Disease Control in the mid 1990s. They are designed to identify a single county or contiguous sets of counties where Medicare patients seek hospital care within the area. We use a slightly modified version developed by the SEER program of the National Cancer Institute, available for download at https://seer.cancer.gov/ seerstat/variables/countyattribs/hsa.html.
} 
negative when estimated on sub-samples of patients with different characteristics. Table B.2 shows that when we estimate the relationship between below-median differential distance and PE ownership (a simplified first stage), we recover coefficients that are very similar to the full-sample result and all are significant at the .01 level for a variety of sample splits by age, gender, race, and zipcode income level.

Table B.2 also helps characterize compliers relative to the average patient at a PE facility. The ratio of the first stage coefficient for a subsample with a specific attribute to that obtained for the full sample provides the likelihood of compliers having that particular attribute relative to the average PE patient. ${ }^{19}$ Compliers appear to have a very similar age distribution and the probability of being male, married, or white. Intuitively, distance-based compliers are more likely to be from a low-income zipcode.

\section{Patient-Level Effects}

This section presents the main results of the paper. We focus on the effects of PE ownership on short-term mortality and spending per patient, discussing the LATE, heterogeneity in treatment effects, as well as tests for the mechanism and robustness.

\subsection{Main Effects on Mortality and Spending}

Table 4 presents the results obtained by estimating Equation (2). These models include 22 patient-level controls (described in Section 4.1), facility fixed effects, and patient HRRby-year fixed effects. Column 1 indicates that receiving care at a PE-owned nursing home increases the probability of death during the stay and the following 90 days by $1.7 \mathrm{pp}$, about $10 \%$ of the mean. In the context of the health economics literature, this is a very large effect. This estimate remains stable in magnitude at about $10 \%$ of the mean regardless of the time horizon studied (see Table B.3).

\footnotetext{
${ }^{19}$ This follows from Bayes rule and the use of a discrete instrument in this model of the first stage. The coefficient from a subsample with attribute $X$ is $P(M \mid X)=P(X \mid M) P(M) / P(X)$ where $M$ denotes a marginal PE patient. Dividing by the first stage coefficient for the full sample, $P(M)$, gives us $P(X \mid M) / P(X)$, the relative likelihood.
} 
We calculate the implied cost in statistical value of life-years in Table B.4 Panel A. We translate the IV coefficients into lives and life-years lost based on the number of index stays by patients of PE-owned nursing homes during our sample period. Accordingly, we compute about 20,150 additional deaths due to PE ownership over our twelve-year sample period. To estimate life-years lost, we rely on observed survival rates for Medicare patients at all nursing homes. This leads to an estimate of about 160,000 lost life-years. ${ }^{20}$ Applying a standard estimate of statistical value of a life-year of $\$ 100,000$ (Cutler and McClellan, 2001), inflated to 2016 dollars, this implies a mortality cost of $\$ 20.7$ billion.

The next two columns of Table 4 Panel A consider spending per patient. In our data, more than $90 \%$ of the billed amount is paid by taxpayers through Medicare and patients pay the balance. The amount billed per nursing home stay increases by $19.5 \%$ (column 2; note it is necessary to exponentiate coefficients larger than .1 when the outcome is logged). As Table 1 shows, on average PE-owned nursing homes bill $\$ 14,800$ per stay, while non-PE nursing homes bill $\$ 13,500$. This does not seem to reflect additional preventive care that is compensated for by lower subsequent needs, because the total amount billed for both the stay and the 90 days following the stay (the episode) increases by about $11 \%$.

The most important robustness test we conduct is a placebo analysis, which probes whether spurious trends rather than the ownership change might explain the results. We use Medicare patient-level data from 2002-07, a period with little PE ownership of nursing homes and little overlap with our main sample. We randomly set the PE dummy to turn on in 2004 or 2005 for facilities that eventually were acquired by PE firms later. Further, we discard data for any facility starting with the year it actually got acquired. We recompute differential distances under these 'placebo' assignments and estimate our main IV models. Table 4 Panel B presents these placebo estimates and reassuringly finds small and

\footnotetext{
${ }^{20}$ As life expectancy differs substantially between men and women, we estimate the effect separately by gender. We calculate the average life expectancy at discharge by gender by observing the actual life span for each patient in our data. For patients still alive at the end of our sample period, we approximate the year of death based on patient gender and age using Social Security actuarial tables. We adjust this downward to account for the fact that decedents tend to be older on average (by about 2 years). We then applied this mean life expectancy to the number of deaths computed above and obtained the number of life-years lost. This approach may overstate the true value if the incremental deaths at PE facilities are of older patients. This approach also understates the true value since we don't account for the loss in longevity not resulting in death.
} 
insignificant effects, implying a lack of differential trends prior to acquisition.

Our IV estimates imply that the reduced form effect on mortality and spending should decline as differential distance grows larger (i.e., relative to the nearest alternative, a PE facility is farther away). Figure 3 visually confirms this pattern. The figure plots coefficients from regressing each outcome on indicators for quintile of differential distance, with the furthest quintile as the reference group using our preferred controls as in the main specification. By using quantile dummies, this specification is flexible and does not impose linearity with respect to differential distance. We find the largest effects among patients in the bottom two quintiles of differential distance, i.e., those located nearest to PE-owned facilities.

Results from OLS models are presented in Table B.5 and the corresponding event studies are in Figure B.5. They suggest no pre-trends, consistent with the parallel trends assumption that underlies our empirical model (i.e., target facilities and control facilities would continue on parallel trends in the absence of the buyout). We observe a statistically significant, but much smaller increase in mortality in the OLS model $(0.3 \mathrm{pp})$. This is only one-sixth the size of the IV estimate, consistent with unobservedly lower risk patients matching with PEowned facilities. In a similar vein, we also find small, negative effects on spending (1-2\% decrease) and length of stay (not presented).

\subsection{Heterogeneity in the Mortality Effect}

This section explores heterogeneity both on observed attributes and on unobserved resistance to treatment, using a Marginal Treatment Effects (MTE) framework.

\subsubsection{Observed attributes}

To assess heterogeneity in the IV analysis, we split the sample based on observed characteristics. We first consider four groups based on patient risk and age. We expect that higher age is associated with a greater need for attentive but not necessarily high-skill or complex care, for example helping patients to use the toilet and minimizing infection risk. 
Higher risk - a measure constructed from disease burdens - should be associated with more need for high-skill, medicalized RN care. Older, high risk patients require the most intensive and high-skill care. Therefore, we split the sample into four groups around the median age of 80 and around the high-risk indicator (Charlson score above two). The results, shown in Table 5 Panel A, document that the effect on mortality is driven by patients who are low risk, with the most robust result among patients who are low risk but above-median age. This group accounts for nearly half of the sample. The high risk, above-median age group also has a large, positive coefficient, but it is noisy. In contrast, the point estimate for high-risk but below-median age patients is negative and marginally significant. This suggests that PE-owned nursing homes are able to take better care of more complex patients, especially when they are on the younger side. But lower risk or older patients suffer.

We find positive effects among both men and women, but the effect is larger and much more robust among female patients, who represent $65 \%$ of the sample and are on average older. The effect is also larger among patients from above-median income zip codes. ${ }^{21}$ It is also larger among White patients. Finally, the last set of results divide the sample into three categories corresponding to the patient's reason for hospitalization prior to the nursing home stay; we find the largest effect for patients who were hospitalized due to cardiovascular disease.

There is evidence that for-profit incentives generally and PE ownership specifically are associated with lower quality of care in more concentrated markets (Gandhi et al., 2020), so we examine in Panel B whether the effects vary by market competition, using the HerfindahlHirschman Index (HHI) of the hospital referral region (HRR). We find that the coefficient is larger among nursing homes in below-median HHI areas, but the coefficient is more precise among nursing homes in above-median HHI areas. As both coefficients are relatively close to our main estimate, concentration does not appear to be a driving factor.

\footnotetext{
${ }^{21}$ We do not observe beneficiary income directly, so we assign individuals to above-median and belowmedian income neighborhoods based on their zip code.
} 


\subsubsection{MTE Theory and Estimation Approach}

The LATE may mask treatment effect heterogeneity across different types of patients. For example, some patients may benefit from the type of care that is offered by PE-owned facilities, even though we estimated negative impacts on average for the complier group. It also ignores the possibility of patient selection on treatment gains. The MTE framework allows us to examine these dimensions (Heckman and Vytlacil, 2005; Heckman et al., 2006). It enables us to compute treatment effect parameters of economic interest such as the Average Treatment Effect (ATE) and Treatment on the Treated (ATT). Unlike the LATE, these parameters are not specific to the complier group and allow us to make more general statements regarding the causal effects of PE ownership.

We denote $Y_{0, i}$ and $Y_{1, i}$ as potential outcomes for individual $i$ in the untreated $(k=0)$ and treated $(k=1)$ states, respectively. Treatment in our setting is receiving care at a PE-owned facility, $P E_{i}$. We model these potential outcomes $Y_{k, i}$ as a function of observed control vector $X_{i}$ and dummies for facility, $F_{j}$ and market-year interactions, $R_{r, t} . U_{k, i}$ denotes all unobserved factors. ${ }^{22}$

$$
Y_{k, i}=X_{i}^{\prime} \beta_{k}+F_{j}+R_{r, t}+U_{k, i}, \quad k=0,1
$$

We then propose a latent selection model of how patients choose a PE-owned facility based on observed and unobserved factors.

$$
\begin{aligned}
& P E_{i}=Z_{i}^{\prime} \delta-V_{i}, \\
& P E_{i}=1 \text { if } P E_{i}^{\geq} 0, P E_{i}=0 \quad \text { otherwise, }
\end{aligned}
$$

where $Z=\left(X, F, R, D, D^{2}\right)$ is a vector including all the controls listed above in Equation (3) and the differential distance instruments excluded from the outcome equation, $D_{i}$ and $D_{i}^{2}$. We interpret $V_{i}$ as the unobserved resistance to going to a PE-owned facility. This selection model imposes monotonicity by using a constant parameter $\delta$ for all individuals. Following the MTE literature, we transform the selection equation into the quantiles of the distribution of $V$ rather than its absolute values:

\footnotetext{
${ }^{22}$ Following Brinch et al. (2017), we assume that the error term $U_{k, i}$ is normalized to be conditional mean zero, i.e., $\mathbb{E}[U \mid X=x, F=f, R=r]=0$.
} 


$$
Z_{i}^{\prime} \delta-V_{i} \geq 0 \Longrightarrow Z_{i}^{\prime} \delta \geq V_{i} \Longrightarrow \Phi\left(Z_{i}^{\prime} \delta\right) \geq \Phi\left(V_{i}\right)
$$

where $\Phi$ is the cumulative distribution function of $V_{i}$. We interpret $\Phi\left(Z_{i}^{\prime} \delta\right)$ as the propensity score, the probability that an individual with observed characteristics $Z_{i}$ chooses a PE nursing home, and denote it as $P(Z) . \quad \Phi\left(V_{i}\right)$ represents the quantiles of unobserved resistance to treatment, and is denoted as $U_{D}$.

Omitting subscripts for simplicity, the MTE is defined as $\operatorname{MTE}\left(X=x, U_{D}=u\right)=\mathbb{E}\left[Y_{1}-\right.$ $\left.Y_{0} \mid X=x, U_{D}=u\right]$. The MTE is the treatment gain for an individual with characteristics $X=$ $x$, who is in the $u^{\text {th }}$ quantile of the resistance distribution. Such individuals are indifferent to receiving treatment when their propensity score $P(Z)$ equals $u$.

We make two untestable assumptions to estimate the MTE. The first, as in Section 4.2, is random assignment of the instrument, conditional on observables. The second assumption is of functional form. Following the convention in the recent MTE literature (Brinch et al., 2017; Cornelissen et al., 2018), we assume that the MTE is additively separable into an observed and unobserved component. This allows the MTE to be identified over the unconditional support of $P(Z)$ across all values of $X$ rather than the support of $P(Z)$ conditional on $X=x$, easing the burden of identifying variation needed from the data (Carneiro et al., 2011).

$$
\begin{aligned}
\operatorname{MTE}\left(X=x, U_{D}=u\right) & =\mathbb{E}\left[Y_{1}-Y_{0} \mid X=x, U_{D}=u\right] \\
& =\underbrace{x\left(\beta_{1}-\beta_{0}\right)}_{\text {observed }}+\underbrace{\mathbb{E}\left[U_{1}-U_{0} \mid U_{D}=u\right]}_{\text {unobserved }}
\end{aligned}
$$

Another implication of this assumption is that treatment effect heterogeneity due to $X$ affects the MTE curve in $u$ only through the intercept. The slope of the MTE curve in $u$ does not depend on X, facilitating estimation. The potential outcomes model described above produces the following outcome equation as a function of observables and $P(Z)$ (Carneiro et al., 2011).

$$
\mathbb{E}[Y \mid X, F, R, P(Z)=p]=X^{\prime} \beta_{0}+F+R+X^{\prime}\left(\beta_{1}-\beta_{0}\right) p+K(p),
$$

where $K(p)$ is a nonlinear function of the propensity score. The derivative of this outcome equation with respect to $p$ estimates the marginal treatment effect at $X=x$ and $U_{D}=p$ 
(Heckman et al., 2006).

We first estimate the selection model in Equation (4) using a linear probability model and obtain $\hat{p}=Z^{\prime} \hat{\delta}$. Figure 4 Panel A presents the variation in the estimated propensity score. We collapse the data to percentiles of differential distance, $D$ and plot a non-parametric fit of $P(Z)$ values against the corresponding percentile means of $D$. This shows a similar pattern first observed in Figure 2 - the probability of going to a PE-owned facility declines nearly monotonically as differential distance increases. However, this figure masks the full support of the distribution of $P(Z)$, which extends over the entire unit interval. Figure 4 Panel B highlights the overlap in distribution of the propensity scores for treated and untreated patients by plotting histograms for the two groups against $P(Z)$ on the $\mathrm{X}$-axis. We use $\log$ scales on the Y-axes since there are large numbers of observations at the two extremes of propensity score. The figure confirms that the treated and untreated groups overlap in distributions over nearly the entire unit interval, enabling the estimation of the unconditional ATE without the need for extrapolation (Basu et al., 2007). We then estimate the outcome Equation (8) below, assuming $K(p)$ is a polynomial in $p$ of degree $S$.

$$
Y=X^{\prime} \beta_{0}+F+R+X^{\prime}\left(\beta_{1}-\beta_{0}\right) \hat{p}+\sum_{s=2}^{S} \rho_{s} K(\hat{p})+\epsilon .
$$

The MTE curve is the derivative of Equation (8) with respect to $\hat{p}$. In our baseline model we set $S=2$, but test robustness to using higher order polynomials. Standard errors are obtained by block bootstrap, clustering by facility.

\subsubsection{MTE Results}

We estimate Equation (8) and confirm the presence of selection on unobserved resistance by testing the joint significance of the coefficients $\rho_{s}$ on the higher order terms of the polynomial in $p$ (Heckman et al., 2006). The coefficient on $p^{2}$ is highly statistically significant ( $p$ value $<0.01$ ), confirming patient selection into PE facilities on unobserved resistance.

Figure 4 Panel C presents the MTE curve along with $90 \%$ confidence intervals. Our primary approach uses a second degree polynomial, so the MTE curve is linear in unobserved resistance $(u)$. Since it is downward sloping, there is reverse selection on 
treatment gains; that is, individuals with the least resistance to going to a PE facility experience the worst mortality effects of nearly $4 \mathrm{pp}$. In contrast, individuals with the highest resistance experience marginally negative (i.e., beneficial) effects. The MTE values are not statistically significant for individuals with above median resistance to treatment. The figure also plots the ATE, which is $1.3 \mathrm{pp}$ (s.e. $1.4 \mathrm{pp}$ ). To test sensitivity to the linearity assumption, we also estimate the MTE curve with 3rd, 4th, and 5th degree polynomials. Figure B.6 Panel B shows that the curve remains downward sloping regardless of the polynomial.

We aggregate the marginal treatment effects using the appropriate weights to obtain various treatment effect parameters such as the unconditional ATE and ATT (Cornelissen et al., 2016). Given the downward sloping nature of the MTE curve, we expect the average effect on the treated to be higher than that for the untreated. Figure 4 Panel D presents the weights to apply to the MTE values to compute the ATT and ATUT. Accordingly, we estimate an ATT of $3.1 \mathrm{pp}$ (s.e. $0.9 \mathrm{pp}$ ) and an ATUT of $1.0 \mathrm{pp}$ (0.9 pp). Only the ATT is statistically significant among the three treatment effect parameters.

There are two key takeaways from this analysis. First, the ATE implies that a randomly chosen Medicare patient from our sample would experience an increase of $1.3 \mathrm{pp}$ in the probability of short-term mortality if she chose a PE-owned nursing home. While about a third lower than the LATE estimate, it nevertheless implies a large number of deaths in a counterfactual where all Medicare short-stay patients receive care at a PE-owned facility. Second, the MTE curve implies reverse selection on gains and that some patients - those with greater resistance to treatment - experience improvements in mortality if they choose a PE-owned facility, though the negative MTE values are not statistically significant. This pattern is consistent with the heterogeneity in treatment effects on observed attributes. For example, we find a large and statistically significant increase in mortality for individuals residing in zip codes with greater than median income (see Table 5 row 3). Individuals in richer neighborhoods are also about $20 \%$ more likely to choose PE-owned facilities - their mean propensity score is $12 \mathrm{pp}$ versus $10 \mathrm{pp}$ for patients from neighborhoods with income below the median. In contrast, we find a smaller and statistically insignificant effect for 
individuals in lower income neighborhoods.

\subsection{Patient Well-Being and Mechanism Tests}

If the effect on short-term mortality is related to lower patient welfare, we expect to see consistent evidence using other wellbeing measures. Therefore, we also use the IV model to assess effects on the four clinical measures of wellbeing that CMS uses as outcomes for short-stays when computing Five Star ratings (surprisingly, mortality is not one of them). The first is whether a patient starts taking antipsychotic drugs. As discussed in Section 3, antipsychotics are discouraged in the elderly due to their association with mortality and the greater efficacy of behavioral interventions. We find that going to a PE-owned nursing home increases the chances of starting antipsychotics by $3 \mathrm{pp}$, or $50 \%$ of the mean (Table 6 column 1). Using an estimate from the literature on how antipsychotic medications affect mortality, this coefficient implies that about $15 \%$ of the total effect on mortality is potentially attributable to starting antipsychotics. ${ }^{23}$

We also find a positive effect on experiencing worsening mobility, which increases by $4.3 \mathrm{pp}$, or about $8 \%$ of the mean (Table 6 column 2). We do not find a significant effect on the third measure - developing ulcers - though the coefficient is positive (column 3). Fourth, there is a positive effect on increasing pain intensity of $2.7 \mathrm{pp}$, which is $10 \%$ of the mean. Figure B.5 presents the corresponding event studies and indicate no differential pretrends. ${ }^{24}$ Overall, the evidence of harmful effects on other measures of patient wellbeing are comfortingly consistent with the estimated effects on mortality.

Thus far we have assumed that ownership type explains any effects of PE buyouts. Alternatively, PE ownership could bring economies of scale or corporatization, which are

\footnotetext{
${ }^{23}$ Several clinical studies have examined the harmful effects of antipsychotic prescribing for the elderly. The most relevant study for our purposes is by Schneider et al. (2005), who perform a meta-analysis of fifteen randomized controlled trials (11 from nursing homes) that studied the effects of antipsychotics on mortality for elderly patients. They report a $50 \%$ increase in mortality. The trials evaluated mortality at durations averaging about 3 months, coincidentally matching our mortality measure. Applying a 50\% increase in mortality to our setting implies an $8 \mathrm{pp}$ increase in 90-day mortality on a mean of $17 \mathrm{pp}$. We apply this elevated mortality effect to the 3 percent additional patients at PE facilities who receive antipsychotics. This implies an increase in mortality of $8 \times 0.03=0.24 \mathrm{pp}$ for PE patients on average.

${ }^{24}$ Results using OLS models are in Table B.5B. They are typically smaller in magnitude (except ulcers), consistent with selection leading to downward bias in OLS.
} 
the explanation that Eliason et al. (2020) propose for negative effects of dialysis center mergers. To test this hypothesis, we conduct three tests in Table 7. The first adds to our main model a control for being a chain versus an independent facility. If our effects are explained by the "rolling-up" of independent facilities into more efficient chains, the estimates should attenuate. Instead, they are essentially unchanged. The second test excludes the top two deals - the buyouts of the very large Genesis Healthcare and Golden Living chains (both have more than $300+$ facilities). The coefficient is larger, implying that our result is not driven by the very largest chains. The most important test is in row 4, where we use only the top five deals to define PE ownership. In these deals, the target chains already owned more than 100 facilities and stayed nearly the same size over the sample period. Therefore, in this model chain size is held constant and we evaluate the effect of a change in ownership. Again, the effect is larger than in the full sample. In sum, it does not seem that chain corporate structures or synergies in large firms explain our results.

Another concern is whether the results are spuriously capturing the quality difference between for-profit and nonprofit nursing facilities. About $20 \%$ of the patients receive treatment at a non-profit facility. By definition these facilities are part of the control group. We test the sensitivity of our main estimate to excluding these facilities from the sample altogether. Row 5 presents the corresponding results and shows that the estimate reduces about $20 \%$ in magnitude but remains statistically significant.

The remaining rows of Table 7 report robustness tests that vary the controls and market definitions. If the instrument does not randomly assign patient risk, we expect patient controls to substantially affect the results. Instead, the results are robust to alternative controls, consistent with random assignment. The first test in this group (row 6) includes zip-year socioeconomic controls. The coefficients decline only slightly. The next two rows use the more granular HSAs and counties, respectively, to define patient markets instead of HRRs. The final row omits all patient controls, estimating larger effects, but well within two standard errors of the main estimate. Overall, the results are quite stable. 


\section{Operational Changes}

This section uses facility-level data to explore operational changes that could help explain the adverse patient welfare effects described in the previous section.

\subsection{Empirical Strategy}

For outcomes available only at the nursing home level, we cannot instrument for patient selection and the best possible research design therefore is differences-in-differences. We use variants of the following specification:

$$
Y_{j, t}=\alpha_{j}+\alpha_{t}+\beta P E_{j, t}+P_{j, t}^{\prime} \gamma_{1}+M_{j, t}^{\prime} \gamma_{2}+\varepsilon_{j, t}
$$

$P E_{j, t}$ takes a value of one if facility $j$ is PE-owned in year $t$. The coefficient of interest is $\beta$, which captures the relationship between PE ownership and the outcome $Y_{j, t}$. We include facility $\left(\alpha_{j}\right)$ and year fixed effects $\left(\alpha_{t}\right)$. We retain all facilities in our preferred specification, but the results are robust to limiting the sample to for-profit facilities. The vector $P_{j, t}$ includes three controls for facility-level patient mix and $M_{j, t}$ includes five county-level controls for time-varying market attributes. ${ }^{25}$ As there may be concern that control variables could be affected by PE ownership, we also present results without any controls.

The identifying assumption is that PE targets and control facilities would continue on parallel trends in the absence of the acquisition. We assess whether there are differential pre-trends using event study figures, which plot the coefficients $\beta_{s}$ from estimating Equation (10) below.

$$
Y_{j, t}=\alpha_{j}+\alpha_{t}+\sum_{s \neq 0} \beta_{s} \text { Deal } \text { Year }_{\mathrm{j}, \mathrm{s}}+P_{j, t}^{\prime} \gamma_{1}+M_{j, t}^{\prime} \gamma_{2}+\varepsilon_{j, t}
$$

\footnotetext{
${ }^{25}$ Patient mix controls: Case Mix Index (CMI) is a composite measure of patient risk based on medical history of diagnosis or treatment for a large number of conditions. Second, Acuity index is a measure of patient risk computed using the patient's assessed Activities of Daily Living (ADL) scores. In both cases, a greater value indicates a riskier patient cohort for the nursing home. We winsorize both the CMI and Acuity Index at the $1 \%$ and $99 \%$ level in each year. The third control is the share of the facility's patients who are Black. County-level controls: Herfindahl Hirschman Index (HHI) based on shares of beds, number of for-profits, number of chain-owned, number of hospital-based, and number of overall facilities. These are calculated using a leave-one-out procedure from the facility-level data.
} 
Deal Year $_{\mathrm{j}, \mathrm{s}}$ is an indicator that is one in year $s$ relative to the buyout year for facility $j$, and zero otherwise. The remaining terms are as defined above for Equation (9).

\subsection{Results}

We consider three types of operational channels. The first two explicitly concern facility quality, while the last pertains to financial strategies particular to the PE industry. All the results are presented in Table 8 . For each outcome, the top row of coefficients are from specifications with only facility and year fixed effects, while the bottom row adds the full set of patient and market controls. Event studies are in Figures 5 and 6.

\subsubsection{Compliance With Standards and Staff Availability}

First, we consider compliance with care protocols in Panel A of Table 8. Our outcome of interest is the facility-level Five Star rating, which varies from one (worst) to five (best). After PE buyouts, the Deficiency rating declines by 0.08 points (column 1), which is about $3 \%$ of the mean and $7 \%$ of the standard deviation (the most relevant measure given how this variable is constructed). This rating reflects whether the facility is satisfying care protocols such as storing and labeling drugs properly, disinfecting surfaces, as well as other aspects of care such as ensuring resident rights and avoiding patient abuse. The Overall rating similarly declines (column 2). Figure 5 presents event studies for each outcome. There are no pre-trends, consistent with the identifying assumption, and the negative effects appear immediately after the change in ownership and persist for at least five years. ${ }^{26}$

In Panel B, we assess effects on nursing staff hours per patient-day, a well-established measure of nursing home quality that accounts for changes in patient volume. Column 1 shows a modest decline of 0.05 hours in aggregate staff hours (1.4\% of the mean). This aggregate effect masks larger changes for different types of nurses that offset each other. There is a decrease in 'front line' caregivers (CNAs and LPNs), shown in columns 2 and

\footnotetext{
${ }^{26}$ The Overall rating has three components: the Deficiency rating, a Quality rating based on metrics computed using claims data and clinical assessments, and a Staffing rating, which is based on staffing measures evaluated in Panel B. Since we assess quality and staffing changes more granularly, we do not present the effects on these components, but we find negative, significant effects of equal or larger magnitudes there as well.
} 
3, respectively. Together there is a decline of around 0.09 hours for these two groups (3\% of the mean). In contrast, there is an increase in use of Registered Nurses (RNs) by about 0.04 hours $(8 \%)$. The event studies in Figure 5 again reveal no pre-trends and indicate more immediate declines after the deal in front-line staffing, while the increase in RN staffing appears starting in the third year after the buyout. ${ }^{27}$ The increase in RN staff hours does not compensate for the decline in lower skilled nurse hours because RNs account for a small fraction of all staff hours. Medicare cost reports indicate that CNAs and LPNs receive an hourly wage that is about $40 \%$ and $70 \%$ respectively of the wage paid to RNs, which is around $\$ 35$ per hour. Unfortunately, we cannot observe whether facilities are taking cost reduction steps such as using more part-time labor and reducing individual shifts.

The existing literature helps to connect the effects on nurse availability with the estimated effect on mortality. Tong (2011) exploits an increase in minimum nurse staffing regulation in California and finds a decline in on-site patient mortality due to greater availability of frontline nurses. Applying her estimates in our setting, the estimated decline in frontline nurse staffing predicts an increase in mortality of $0.25 \mathrm{pp}^{28}$ The findings on increased use of antipsychotics and lower nurse availability may be related. Grabowski et al. (2011) note that antipsychotics are believed to substitute for nurse care and show that when nursing homes increase wages, inappropriate use of antipsychotics decreases. Therefore, it is intuitive that lower staffing - in particular low-skill staffing - would be associated with increases in adverse conditions related to lack of attention, such as more use of antipsychotics and lower mobility. The two channels additively predict an increase in mortality of $0.5 \mathrm{pp}$ in our setting (about $30 \%$ of our mortality effect). However, this may be an underestimate if they produce larger effects when they interact.

The increase in RN availability is consistent with the negative effects on mortality being driven by older rather than more complex patients. RN staff are most relevant for the more

\footnotetext{
${ }^{27} \mathrm{We}$ report the results of robustness tests in Table B.6, which include controls for chains, excluding the top two deals, and including only for-profit nursing homes.

${ }^{28}$ Tong (2011) reports a $15 \%$ decline in mortality due to an increase in nurse availability of one hour per resident-day. Since we estimate a decline of 0.09 hours, this predicts an increase of $0.09 \times 15=1.4 \%$ of the mean, or 0.24 pp. More recently, Ruffini (2020) exploits variation in minimum wage requirements to isolate the effects of nurse staffing changes on quality and also finds mortality effects.
} 
medicalized aspects of care, while front line nurses support daily living activities such as preventing infections and turning patients in bed. One possibility is that managers may have looked for ways to cut overall labor costs while changing the mix of nursing staff capability to maintain quality and patient experience, as RNs are crucial to nursing home quality (Zhang and Grabowski, 2004; Lin, 2014). An alternative explanation is the regulatory focus on RNs. For example, CMS uses the availability of RNs to determine eligibility for Medicare reimbursement. ${ }^{29}$ Given the tight regulatory scrutiny of RN availability, it is difficult to reduce staffing levels in this category.

To explore whether the declines in staff availability and quality are related, we compare changes in staff availability and Five Star ratings within target facilities around the PE buyout event. This analysis recovers correlations and does not imply causality, so we present the raw data in bin-scatter plots. Figure B.7 shows the change in Five Star rating over the three years around PE acquisition on the Y-axis against the change in aggregate staff hours per patient day during the same period on the X-axis. The plots show that facilities which experienced larger declines in staff availability also experienced greater declines in ratings. The patterns are consistent across rating types and suggest that cuts to nursing staff may be an important channel to explain the quality declines.

\subsubsection{Finances and Operations}

Our final analysis uses CMS cost reports to analyze key sources of expenditure related to the PE business model. We begin by noting that nursing homes are widely known to have relatively low and regulated profit margins, often cited at just $1-2 \% .{ }^{30}$ Our data on nursing home cost reports submitted to CMS indicate that nursing homes report negative operating margins on average, and PE-owned nursing homes are not on average more profitable. In unreported analysis, we see no effect of buyouts on net income or overall revenue or costs.

\footnotetext{
${ }^{29}$ Specifically, such facilities are defined by having "an RN for 8 consecutive hours a day, 7 days a week (more than 40 hours a week), and that there be an RN designated as Director of Nursing on a full time basis." See https://www.cms.gov/Regulations-and-Guidance/Guidance/Manuals/ Downloads/som107c07pdf.pdf.

${ }^{30} \mathrm{http}$ ://www. medpac.gov/docs/default-source/data-book/jun17_databookentirereport_ sec.pdf
} 
This raises the question of how PE firms create value from nursing home investments.

There are three types of firm expenditures that the academic literature and popular press particularly associates with profits for PE owners. The first is what are often termed "monitoring fees" charged to portfolio companies. In the CMS cost reports, these are listed as "management fees"- charges to the nursing home for being owned and managed by a PE firm. ${ }^{31}$ Metrick and Yasuda (2010) note that these are thought to be between 1-5\% of EBITDA. Our data suggest that they increase over time after buyouts, as shown in Figure 6 Panel A, where the fees are flat before the buyout, and then rise dramatically afterwards. Table 8 Panel $\mathrm{C}$ column 1 indicates that on average, management fees increase by $7.7 \%$ after acquisition (we exponentiate coefficients in this panel as the outcomes are in logs).

The second type of expenditure is lease payments. The value of underlying real estate is frequently cited as a reason that nursing homes and other typically low-margin assets can be profitable investments, because the investor can sell the real estate to a related company or to a third party (Dixon, 2007; Keating and Whoriskey, 2018; Brown, 2019). Cash from the real estate sale can be disbursed as profits to the PE fund. A cash inflow early in the life of the investment is particularly beneficial to the fund's Internal Rate of Return, a key performance metric. The nursing home assumes the obligation of future rent payments. As an example, a New York Times report on the nursing home industry notes that:

"[PE] investors created new companies to hold the real estate assets because the buildings were more valuable than the businesses themselves, especially with fewer nursing homes being built. Sometimes, investors would buy a nursing home from an operator only to lease back the building and charge the operator hefty management and consulting fees" (Goldstein et al., 2020). ${ }^{32}$

\footnotetext{
31 In their summary of buyout fund economics, Metrick and Yasuda (2010) write that "we think of monitoring fees as just another way for BO funds to earn a revenue stream." These fees should not be confused with the usual $2 \%$ of fund value that General Partners earn each year for managing Limited Partners' capital, before profits from investments.

${ }^{32}$ Two examples further illuminate these types of transaction. First, the HCR Manorcare deal discussed in Section 2.2, where the chain's real estate assets were spun off and sold shortly after the acquisition by the Carlyle Group. Second, at a Congressional hearing the executive director of the Long-Term Care Community Coalition said "more and more with entities buying up nursing homes, they have no experience in the business, they sell out the underlying property" (Brown, 2019).
} 
Consistent with this strategy, column 2 shows that facility building lease payments increase dramatically by about $75 \%$ after PE acquisitions. Figure 6 Panel B confirms the lack of pre-trends and the increase post-buyout.

The third type of expenditure is interest on debt. While not a direct source of PE profits, debt is tightly related to the overall PE model for creating value. Metrick and Yasuda (2010) note that the ratio of debt to equity in a buyout deal is typically around 5:1. The interest payments become a cost to the portfolio company. In Figure 6 Panel C, we see that like the previous two outcomes, interest payments are flat before the buyout and then rise dramatically afterwards. Column 3 indicates that the increase is about $325 \%$.

Finally, we find that cash on hand declines after the buyout by $38 \%$. Unlike the other outcomes, the event study in Figure 6 Panel D indicates that cash on hand initially increases after the buyout as profits increase and cash is injected, perhaps to invest in efficiency improvements. However, as the strategies for returning profit to the investors are implemented, such as selling the real estate and thus requiring the operator to take on lease payments, the cash on hand turns negative. This could make the nursing home less well-equipped to manage sudden shocks such as, for example, needing to buy personal protective equipment following an infectious disease breakout.

Taking the results on nurse availability together with the estimated effects on interest, lease, and management fees payments, we infer that PE ownership shifts operating costs away from staffing towards costs that are profit drivers for the PE fund. To our knowledge, this paper offers the first instance in the literature on PE in which these three profit drivers have been documented systematically.

The final outcome we explore is patient capacity and volume. Table B.7 column 1 finds no measurable change in the number of beds, which may partly reflect state regulations restricting expansions. Admissions increase by 3.5\%, or 6.5 patients per year for the average facility (column 2). However, we interpret this effect with caution since the corresponding event study suggests a pre-trend (Figure B.8B). The apparent disconnect between demand and quality of care may reflect information frictions in observing nursing home quality, as discussed earlier (Arrow, 1963; Grabowski and Town, 2011; Werner et al., 2012). 
Higher admissions raise the question of whether PE ownership increases overall access to nursing home care, providing care for individuals who would not otherwise have gone to a nursing home. To test whether this is the case, we assess the effects of PE entry into a nursing home market, using the HRR definition. Table B.7 column 3 shows that there is no effect of initial PE entry on admissions at the market level, corroborated by flat patterns in the event study (Figure B.8C). Hence, the data are more consistent with the facility-level admissions increase reflecting business stealing.

\section{Conclusion}

This paper studies PE buyouts in healthcare, an important sector where PE activity has increased dramatically, generating policy debate. Nursing homes are a useful setting because they have particularly high levels of for-profit ownership and subsidy and have experienced extensive PE investments. In an instrumental variables design incorporating facility fixed effects, we address both targeting and patient selection challenges to identification. We find that going to a PE-owned facility increases 90-day mortality by about $10 \%$ for short-stay Medicare patients, while taxpayer spending over the 90 days increases by $11 \%$. Furthermore, we document declines in nurse availability per patient and in measures of compliance with Medicare's standards of care. We also find a corresponding increase in operating costs that tend to drive profits for PE funds.

There are many channels for future work. Although our results imply PE ownership reduces productivity of nursing homes, it may have more positive effects in other sectors of healthcare with better functioning markets. Beyond healthcare, there has been significant PE investment in sectors such as education, defense and infrastructure, which like healthcare rely on high levels of government subsidy but are characterized by opaque product quality. Further work is needed to determine how government programs can be redesigned to align the interests of PE-owned firms with those of taxpayers and consumers. 


\section{References}

Acharya, Viral V, Oliver F Gottschalg, Moritz Hahn, and Conor Kehoe, "Corporate governance and value creation: Evidence from private equity," The Review of Financial Studies, 2013, 26 (2), 368-402.

Adelino, Manuel, Katharina Lewellen, and Anant Sundaram, "Investment decisions of nonprofit firms: Evidence from hospitals," The Journal of Finance, 2015, 70 (4), 15831628.

Appelbaum, Eileen and Rosemary Batt, "Private equity buyouts in healthcare: Who wins, who loses?," Institute for New Economic Thinking Working Paper Series, 2020, (118).

Arrow, Kenneth J, "Uncertainty and the welfare economics of medical care," The American Economic Review, 1963, 53 (1/2), 941-973.

Banerjee, Sube, Jennifer Hellier, Michael Dewey, Renee Romeo, Clive Ballard, Robert Baldwin, Peter Bentham, Chris Fox, Clive Holmes, Cornelius Katona et al., "Sertraline or mirtazapine for depression in dementia (HTA-SADD): a randomised, multicentre, double-blind, placebo-controlled trial," The Lancet, 2011, 378 (9789), 403411.

Basu, Anirban, James J Heckman, Salvador Navarro-Lozano, and Sergio Urzua, "Use of instrumental variables in the presence of heterogeneity and self-selection: an application to treatments of breast cancer patients," Health Economics, 2007, 16 (11), $1133-1157$.

Bernstein, Shai and Albert Sheen, "The operational consequences of private equity buyouts: Evidence from the restaurant industry," Review of Financial Studies, 2016, 29 (9), 2387-2418.

_ , Josh Lerner, and Filippo Mezzanotti, "Private equity and financial fragility during the crisis," Review of Financial Studies, 2019, 32 (4), 1309-1374.

Biesinger, Markus, Cagatay Bircan, and Alexander Ljungqvist, "Value creation in private equity," EBRD Working Paper, 2020.

Bloom, Nicholas, Carol Propper, Stephan Seiler, and John Van Reenen, "The Impact of Competition on Management Quality: Evidence from Public Hospitals," Review of Economic Studies, 2015, (82), 457-489.

_, Raffaella Sadun, and John Van Reenen, "Do private equity owned firms have better management practices?," The American Economic Review, 2015, 105 (5), 442-446.

Boucly, Quentin, David Sraer, and David Thesmar, "Growth LBOs," Journal of Financial Economics, 2011, 102 (2), 432-453.

Brinch, Christian N, Magne Mogstad, and Matthew Wiswall, "Beyond LATE with a discrete instrument," Journal of Political Economy, 2017, 125 (4), 985-1039.

Brown, Benjamin, Eloise O'Donnell, and Lawrence $\mathbf{P}$ Casalino, "Private equity investment in behavioral health treatment centers," JAMA Psychiatry, 2020, 77 (3), 229230 .

Brown, Danielle, "Lawmakers pepper private equity firms on nursing home investments, quality issues," McKnight's Long-Term Care News, 2019. 
Brown, Sherrod, Mark Pocan, and Elizabeth Warren, "Letter to The Carlyle Group (KewsongLee and Glenn A. Youngkin)," November 2019.

Bruch, Joseph D, Suhas Gondi, and Zirui Song, "Changes in hospital income, use, and quality associated with private equity acquisition," JAMA Internal Medicine, 2020.

Cadigan, Rebecca Orfaly, David G Stevenson, Daryl J Caudry, and David C Grabowski, "Private investment purchase and nursing home financial health," Health Services Research, 2015, 50 (1), 180-196.

Card, David, Alessandra Fenizia, and David Silver, "The health impacts of hospital delivery practices," Technical Report, National Bureau of Economic Research 2019.

Carneiro, Pedro, James J Heckman, and Edward J Vytlacil, "Estimating marginal returns to education," American Economic Review, 2011, 101 (6), 2754-81.

Casalino, Lawrence P, "Private equity, women's health, and the corporate transformation of American medicine," JAMA Internal Medicine, 2020.

Cawley, John, David C Grabowski, and Richard A Hirth, "Factor substitution in nursing homes," Journal of Health Economics, 2006, 25 (2), 234-247.

Chandra, Amitabh, Amy Finkelstein, Adam Sacarny, and Chad Syverson, "Health care exceptionalism? Performance and allocation in the US health care sector," American Economic Review, 2016, 106 (8), 2110-44.

Charlson, Mary, Ted P Szatrowski, Janey Peterson, and Jeffrey Gold, "Validation of a combined comorbidity index," Journal of Clinical Epidemiology, 1994, 47 (11), 12451251.

Clemens, Jeffrey and Joshua D Gottlieb, "Do physicians' financial incentives affect medical treatment and patient health?," American Economic Review, 2014, 104 (4), 132049.

Cooper, Zack, Fiona Scott Morton, and Nathan Shekita, "Surprise! out-of-network billing for emergency care in the United States," Journal of Political Economy, 2020, 128 (9), 3626-3677.

_, Stuart V Craig, Martin Gaynor, and John Van Reenen, "The price ain't right? Hospital prices and health spending on the privately insured," The Quarterly Journal of Economics, 2018, 134 (1), 51-107.

Cornelissen, Thomas, Christian Dustmann, Anna Raute, and Uta Schönberg, "From LATE to MTE: Alternative methods for the evaluation of policy interventions," Labour Economics, 2016, 41, 47-60.

$\ldots,{ }_{-}$, and $\_,$"Who benefits from universal child care? Estimating marginal returns to early child care attendance," Journal of Political Economy, 2018, 126 (6), 2356-2409.

Currie, Janet and David Slusky, "Does the Marginal Hospitalization Save Lives? The Case of Respiratory Admissions for the Elderly," Technical Report, National Bureau of Economic Research 2020.

Curto, Vilsa, Liran Einav, Amy Finkelstein, Jonathan Levin, and Jay Bhattacharya, "Health care spending and utilization in public and private Medicare," American Economic Journal: Applied Economics, 2019, 11 (2), 302-32. 
_, _, Jonathan Levin, and Jay Bhattacharya, "Can health insurance competition work? evidence from medicare advantage," Journal of Political Economy, 2021, 129 (2), 570606.

Cutler, David M, "Where are the health care entrepreneurs? The failure of organizational innovation in health care," Innovation Policy and the Economy, 2011, 11 (1), 1-28.

_ and Mark McClellan, "Is technological change in medicine worth it?," Health Affairs, 2001, 20 (5), 11-29.

Dafny, Leemore, Mark Duggan, and Subramaniam Ramanarayanan, "Paying a premium on your premium? Consolidation in the US health insurance industry," American Economic Review, 2012, 102 (2), 1161-85.

Davis, Steven J, John Haltiwanger, Kyle Handley, Ron Jarmin, Josh Lerner, and Javier Miranda, "Private equity, jobs, and productivity," The American Economic Review, 2014, 104 (12), 3956-3990.

Dixon, Kim, “US senators probe nursing homes run by private equity," Reuters, 2007.

Doggett, Lloyd, Rosa DeLauro, Katie Porter, and Mary Scanlon, "Letter to Leonard Green and Partners (Jonathan Sokoloff),” June 2020.

Duggan, Mark G, "Hospital ownership and public medical spending," The Quarterly Journal of Economics, 2000, 115 (4), 1343-1373.

Dummit, Laura A, Nursing homes: Quality of care more related to staffing than spending, US General Accounting Office, 2002.

Eaton, Charlie, Sabrina Howell, and Constantine Yannelis, "When investor incentives and consumer interests diverge: Private equity in higher education," The Review of Financial Studies, 2019.

Einav, Liran, Amy Finkelstein, and Heidi Williams, "Paying on the margin for medical care: Evidence from breast cancer treatments," American Economic Journal: Economic Policy, 2016, 8 (1), 52-79.

Eliason, Paul J, Benjamin Heebsh, Ryan C McDevitt, and James W Roberts, "How acquisitions affect firm behavior and performance: Evidence from the dialysis industry," The Quarterly Journal of Economics, 2020, 135 (1), 221-267.

Flood, Chris, "US Congress examines private equity role in surging healthcare costs," The Financial Times, 2019.

Fracassi, Cesare, Alessandro Previtero, and Albert W Sheen, "Barbarians at the store? Private equity, products, and consumers," Technical Report, National Bureau of Economic Research WP 274352020.

Gadiesh, Orit and Hugh MacArthur, Lessons from private equity any company can use, Harvard Business Press, 2008.

Gandhi, Ashvin, "Picking your patients: Selective admissions in the nursing home industry," Available at SSRN, 2020.

_, YoungJun Song, and Prabhava Upadrashta, "Private Equity, Consumers, and Competition: Evidence from the Nursing Home Industry," 2020.

GAO, "Complexity of private investment purchases demonstrates need for CMS to improve 
the usability and completeness of ownership data," Technical Report september 2010.

Garber, Alan M and Jonathan Skinner, "Is American health care uniquely inefficient?," Journal of Economic Perspectives, 2008, 22 (4), 27-50.

Goldstein, Matthew, Jessica Silver-Greenberg, and Robert Gebeloff, "https://www.nytimes.com/2020/05/07/business/coronavirus-nursing-homes.html," The New York Times, 2020.

Gompers, Paul, Steven N Kaplan, and Vladimir Mukharlyamov, "What do private equity firms say they do?," Journal of Financial Economics, 2016, 121 (3), 449-476.

Gondi, Suhas and Zirui Song, "Potential implications of private equity investments in health care delivery," Journal of the American Medical Association, 2019, 321 (11), 1047-1048.

Grabowski, David C and Richard A Hirth, "Competitive spillovers across non-profit and for-profit nursing homes," Journal of Health Economics, 2003, 22 (1), 1-22.

Grabowski, David C. and Robert J. Town, "Does information matter? Competition, quality, and the impact of nursing home report cards," Health Services Research 46, 2011, 46 (6.1), 1698-1719.

Grabowski, David C, John R Bowblis, Judith A Lucas, and Stephen Crystal, "Labor prices and the treatment of nursing home residents with dementia," International Journal of the Economics of Business, 2011, 18 (2), 273-292.

_ , Zhanlian Feng, Richard Hirth, Momotazur Rahman, and Vincent Mor, "Effect of nursing home ownership on the quality of post-acute care: An instrumental variables approach," Journal of Health Economics, 2013, 32 (1), 12-21.

Gupta, Arpit and Stijn Van Nieuwerburgh, "Valuing private equity strip by strip," National Bureau of Economic Research Working Paper, 2019.

Hackmann, Martin B, "Incentivizing better quality of care: The role of Medicaid and competition in the nursing home industry," American Economic Review, 2019, 109 (5), 1684-1716.

_ and R Vincent Pohl, "Patient vs. provider incentives in long term care," Technical Report, National Bureau of Economic Research 2018.

Hansmann, Henry B, "The role of nonprofit enterprise," The Yale Law Journal, 1980, 89 (5), 835-901.

Harrington, Charlene, Brian Olney, Helen Carrillo, and Taewoon Kang, "Nurse staffing and deficiencies in the largest for-profit nursing home chains and chains owned by private equity companies," Health Services Research, 2012, 47 (1pt1), 106-128.

_, Helen Carrillo, Rachel Garfield et al., "Nursing facilities, staffing, residents and facility deficiencies, 2009 Through 2016," Menlo Park: The Henry J. Kaiser Family Foundation, 2018.

Hart, Oliver, Andrei Shleifer, and Robert W Vishny, "The proper scope of government: theory and an application to prisons," The Quarterly Journal of Economics, 1997, 112 (4), 1127-1161.

Heckman, James J and Edward Vytlacil, "Structural equations, treatment effects, and 
econometric policy evaluation 1," Econometrica, 2005, 73 (3), 669-738.

_ , Sergio Urzua, and Edward Vytlacil, "Understanding instrumental variables in models with essential heterogeneity," The Review of Economics and Statistics, 2006, 88 (3), 389432.

Hill, Elaine L, David JG Slusky, and Donna K Ginther, "Reproductive health care in Catholic-owned hospitals," Journal of Health Economics, 2019, 65, 48-62.

Ho, Kate and Robin S Lee, "Equilibrium provider networks: Bargaining and exclusion in health care markets," American Economic Review, 2019, 109 (2), 473-522.

Hodgson, Leah, "Pandemic deepens woes of UK's private equity-backed nursing homes," Pitchbook, 2020, September 21.

Huang, Sean Shenghsiu and John R Bowblis, "Private equity ownership and nursing home quality: an instrumental variables approach," International Journal of Health Economics and Management, 2019, 19 (3-4), 273-299.

Institute of Medicine, Improving the quality of care in nursing homes, Vol. 85, Natl Academy Pr, 1986.

Johnson, Richard W, "Who is covered by private long-term care insurance," Urban Institute. tinyurl. com/yxqklvdz. Retrieved December, 2016, 28, 2018.

Kaplan, Steven, "The effects of management buyouts on operating performance and value," Journal of Financial Economics, 1989, 24 (2), 217-254.

Kaplan, Steven $\mathbf{N}$ and Antoinette Schoar, "Private equity performance: Returns, persistence, and capital flows," The Journal of Finance, 2005, 60 (4), 1791-1823.

- and Per Stromberg, "Leveraged buyouts and private equity," Journal of Economic Perspectives, 2009, 23 (1), 121-46.

Keating, Dan and Peter Whoriskey, "Overdoses, bedsores, broken bones: What happened when a private-equity firm sought to care for society's most vulnerable," The Washington Post, 2018.

Kim, Tammy, "This is why nursing homes failed so badly," New York Times, 2020, December 31 .

King, Robert, "Private equity firms in Congress' crosshairs with legislation calling for transparency," Fierce Healthcare, 2020, February 12.

Kuehn, Bridget M, "FDA warns antipsychotic drugs may be risky for elderly," Journal of the American Medical Association, 2005, 293 (20), 2462-2462.

Lerner, Josh, Morten Sorensen, and Per Strömberg, "Private equity and long-run investment: The case of innovation," The Journal of Finance, 2011, 66 (2), 445-477.

Lewis, Adam, "Blackstone, KKR draw ire from Congress over surprise medical bills," 2019.

Lin, Haizhen, "Revisiting the relationship between nurse staffing and quality of care in nursing homes: An instrumental variables approach," Journal of Health Economics, 2014, $37,13-24$.

_ , "Quality choice and market structure: A dynamic analysis of nursing home oligopolies," International Economic Review, 2015, 56 (4), 1261-1290. 
Martin, Anne B, Micah Hartman, Benjamin Washington, Aaron Catlin, National Health Expenditure Accounts Team et al., "National health care spending in 2017: growth slows to post-Great Recession rates; share of GDP stabilizes," Health Affairs, 2018, pp. 10-1377.

McClellan, Mark and Douglas Staiger, "The quality of health care providers," Technical Report 7327, National Bureau of Economic Research Working Paper 1999.

_, Barbara J McNeil, and Joseph P Newhouse, "Does more intensive treatment of acute myocardial infarction in the elderly reduce mortality?: analysis using instrumental variables," Journal of the American Medical Association, 1994, 272 (11), 859-866.

McGuire, Thomas G, "Physician agency," Handbook of health economics, 2000, 1, 461536.

MedPAC, "Report to the Congress: Medicare payment policy," March 2017.

Metrick, Andrew and Ayako Yasuda, "The economics of private equity funds," The Review of Financial Studies, 2010, 23 (6), 2303-2341.

Pelech, Daria, "Paying more for less? Insurer competition and health plan generosity in the Medicare Advantage program," Journal of Health Economics, 2018, 61, 77-92.

Phalippou, Ludovic, Christian Rauch, and Marc Umber, "Private equity portfolio company fees," Journal of Financial Economics, 2018, 129 (3), 559-585.

Pradhan, Rohit, Robert Weech-Maldonado, Jeffrey S Harman, Alex Laberge, and Kathryn Hyer, "Private equity ownership and nursing home financial performance," Health Care Management Review, 2013, 38 (3), 224-233.

_, , , , and Kathryn Hyer, "Private equity ownership of nursing homes: implications for quality," Journal of Health Care Finance, 2014, 42 (2).

Press, Daniel and Michael Alexander, "Treatment of behavioral symptoms related to dementia," UpToDate. Available at: http://www. uptodate. com/contents/treatment-ofbehavioral-symptoms-related-todementia, 2013.

Ruffini, Krista, "Worker earnings, service quality, and firm profitability: Evidence from nursing homes and minimum wage reforms," Unpublished Mimeo, 2020.

Saenz, Andres, "How private equity can improve the health of healthcare," EY Global Private Equity Report, 2019.

Schneider, Lon S, Karen S Dagerman, and Philip Insel, "Risk of death with atypical antipsychotic drug treatment for dementia: meta-analysis of randomized placebocontrolled trials," Journal of the American Medical Association, 2005, 294 (15), 19341943.

Shleifer, Andrei and Lawrence H Summers, "Breach of trust in hostile takeovers," in "Corporate Takeovers: Causes and Consequences," University of Chicago Press, 1988, pp. 33-68.

Sink, Kaycee M, Karen F Holden, and Kristine Yaffe, "Pharmacological treatment of neuropsychiatric symptoms of dementia: a review of the evidence," Journal of the American Medical Association, 2005, 293 (5), 596-608.

Skinner, Jonathan, "Causes and consequences of regional variations in health care," in 
"Handbook of Health Economics," Vol. 2, Elsevier, 2011, pp. 45-93.

Spaenjers, Christophe and Eva Steiner, "Do private equity investors create value? Evidence from the hotel industry," Available at SSRN, 2020.

Stevenson, David G and David C Grabowski, "Private equity investment and nursing home care: is it a big deal?," Health Affairs, 2008, 27 (5), 1399-1408.

Taragano, Fernando E, Constantine G Lyketsos, Carlos A Mangone, Ricardo F Allegri, and Enrique Comesaña-Diaz, "A double-blind, randomized, fixed-dose trial of fluoxetine vs. amitriptyline in the treatment of major depression complicating Alzheimer's disease," Psychosomatics, 1997, 38 (3), 246-252.

Tong, Patricia K, "The effects of California minimum nurse staffing laws on nurse labor and patient mortality in skilled nursing facilities," Health Economics, 2011, 20 (7), 802-816.

Werner, Rachel M., Edward C. Norton, R. Tamara Konetzka, and Daniel Polsky, "Do consumers respond to publicly reported quality information? Evidence from nursing homes," Journal of Health Economics, 2012, 31 (1), 50-61.

Zhang, Xinzhi and David C Grabowski, "Nursing home staffing and quality under the nursing home reform act," The Gerontologist, 2004, 44 (1), 13-23. 


\section{Figures and Tables}

Figure 1: Private Equity Ownership in Healthcare

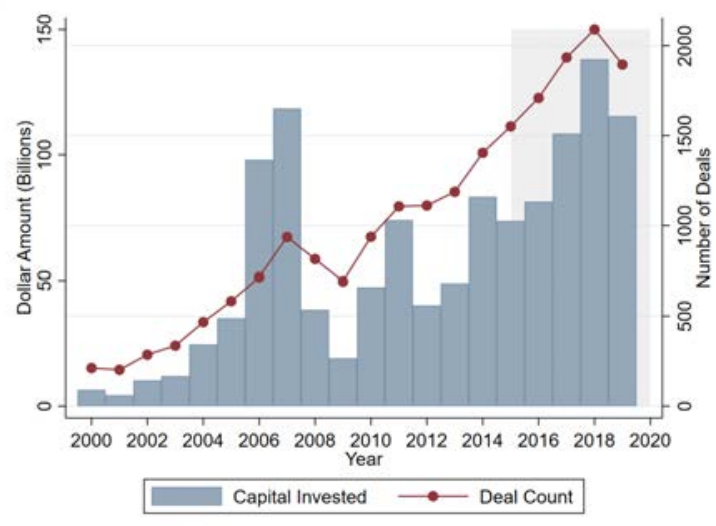

A: PE Deals in Healthcare

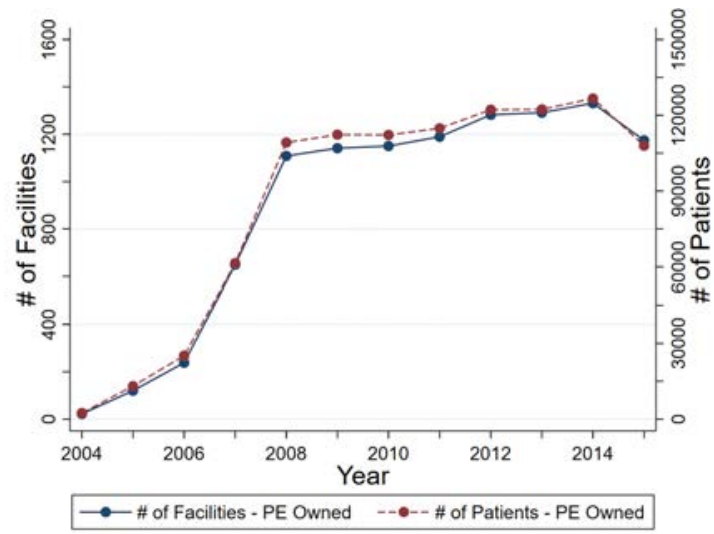

C: Number of Facilities and Patients Acquired

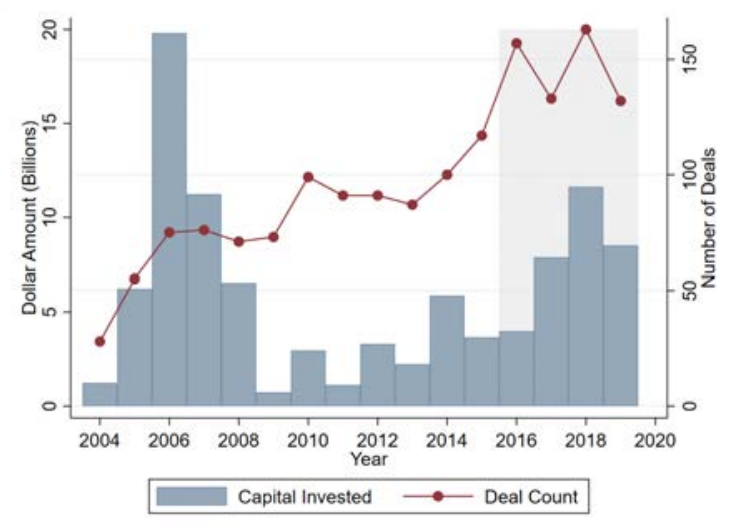

B: PE Deals in Eldercare

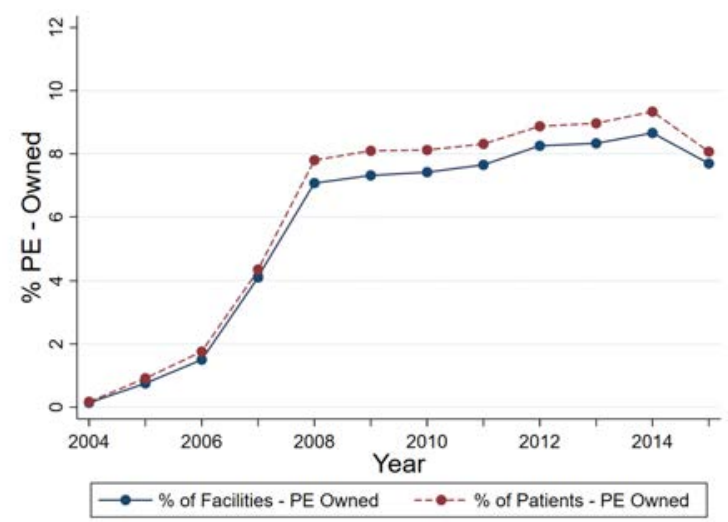

D: Percentage of Facilities and Patients Acquired

Note: This figure shows PE deals in health care over time. Panels A and B present the total capital invested (left axis) and number of transactions (right axis) by $\mathrm{PE}$ firms in healthcare and eldercare, by year. Panels $\mathrm{C}$ and $\mathrm{D}$ focus on the number of active nursing homes owned by PE firms in each year. Panel B presents the number of PE-owned facilities (left axis) and patients admitted at these facilities (right axis). Note that the total number of facilities ever bought by PE firms is larger $(1,674)$ than what is plotted here since some of these facilities closed or went back to non PE ownership over time. Panel D presents these trends as a percentage of total number of facilities and patients admitted, respectively. 
Figure 2: Patient Characteristics with Differential Distance

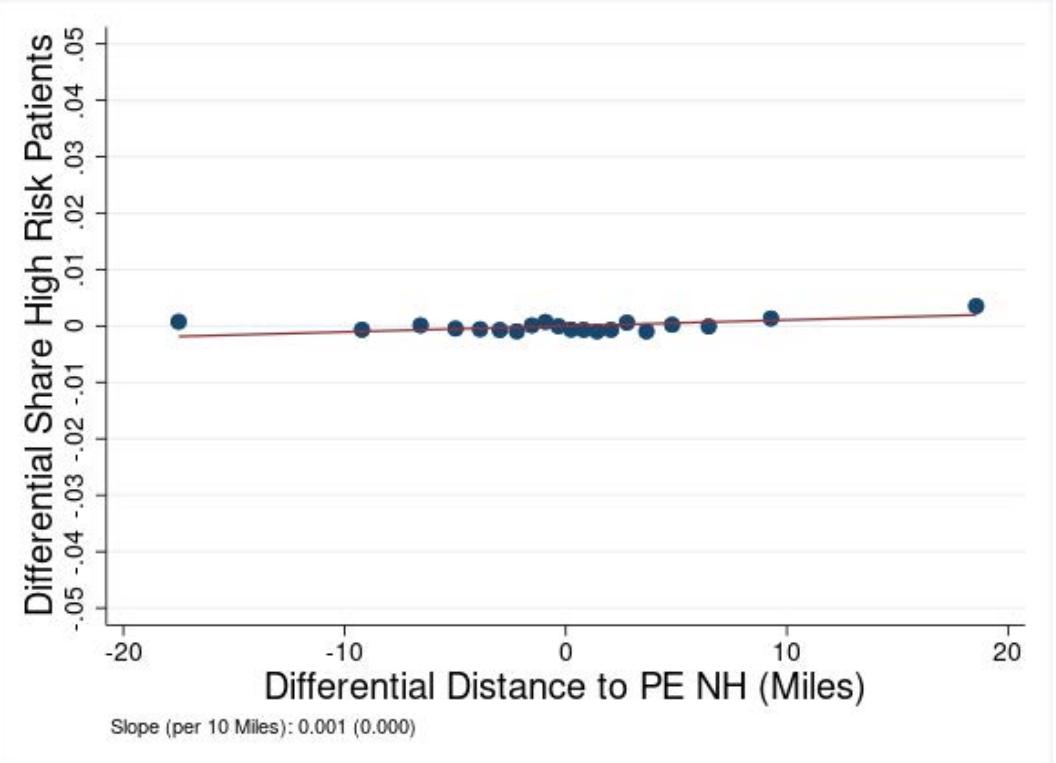

A: High Risk Patients

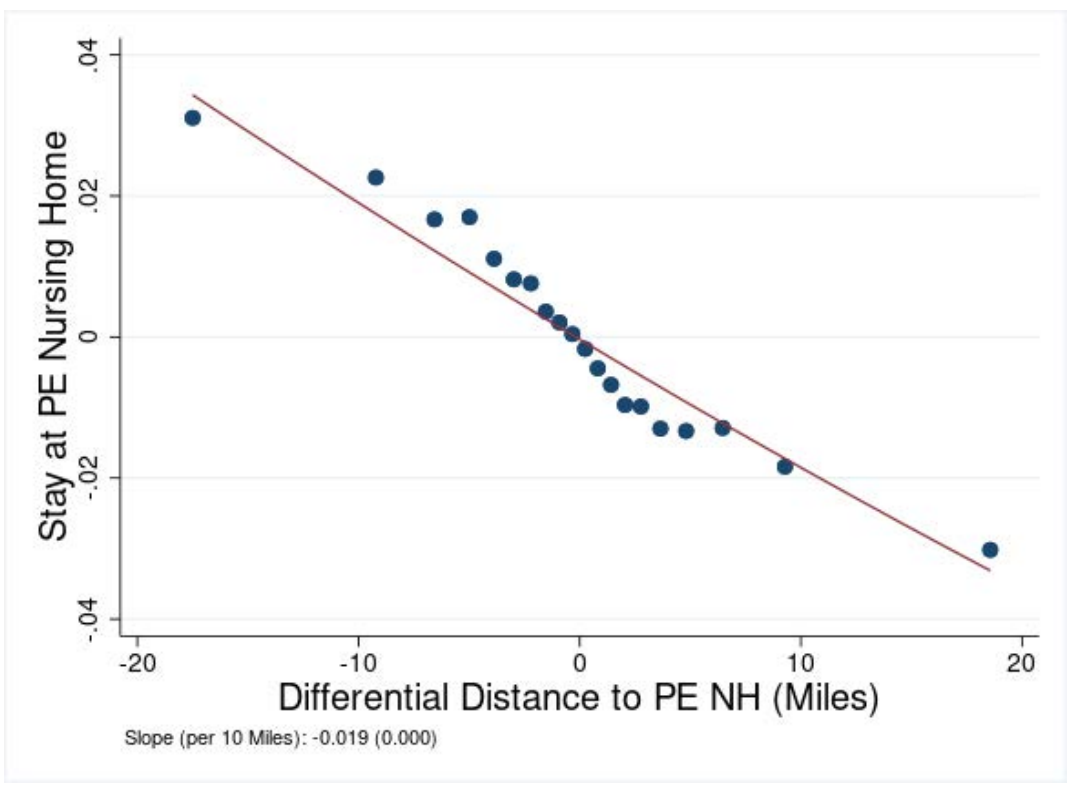

B: Stay at PE Nursing Home

Note: This figure presents scatter plots of patient characteristics against differential distance to the nearest PE facility. The independent variable is the difference in distance (in miles) of the nearest PE nursing home to the nearest non-PE nursing home for the patient. The dependent variable in Panel A is an indicator for the patient to have a Charlson Co-morbidity Index (based on diagnoses recorded in hospital inpatient and outpatient claims over the 3 months before admission to nursing home) greater than 2, and in Panel B is an indicator for the nursing home being PE-owned. The data was collapsed into 20 equal sized bins and we plot the means of residuals in each bin that were obtained from models including facility and patient HRR x Year fixed effects, and patient demographics: age, race, gender, maritial status, and an indicator if patient is dual eligible. The figures also present quadratic fitted lines for these plots. Each plot also presents the slope coefficient (per 10 miles of differential distance) with the corresponding standard error. Standard errors are clustered by facility. 
Figure 3: Patient Outcomes and Differential Distance

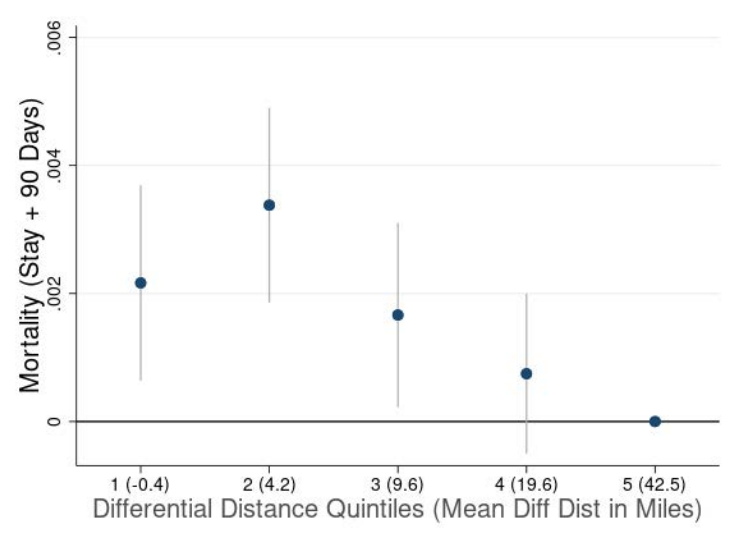

A: Mortality (Stay +90 Days)

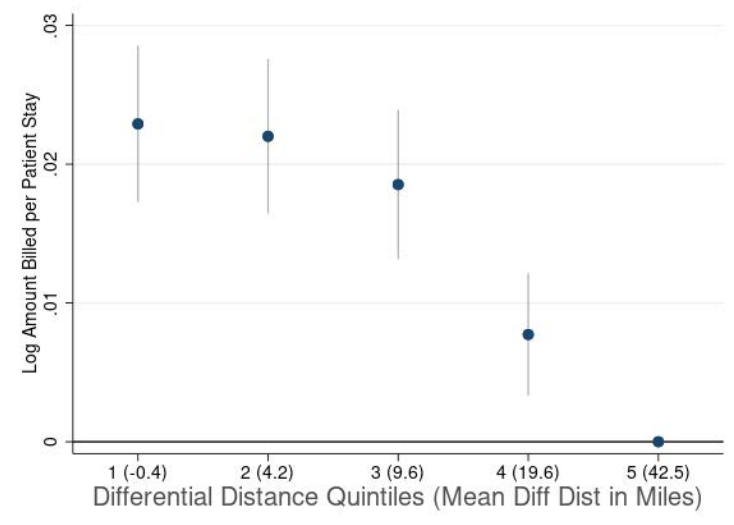

B: Log Amount Billed per Patient Stay

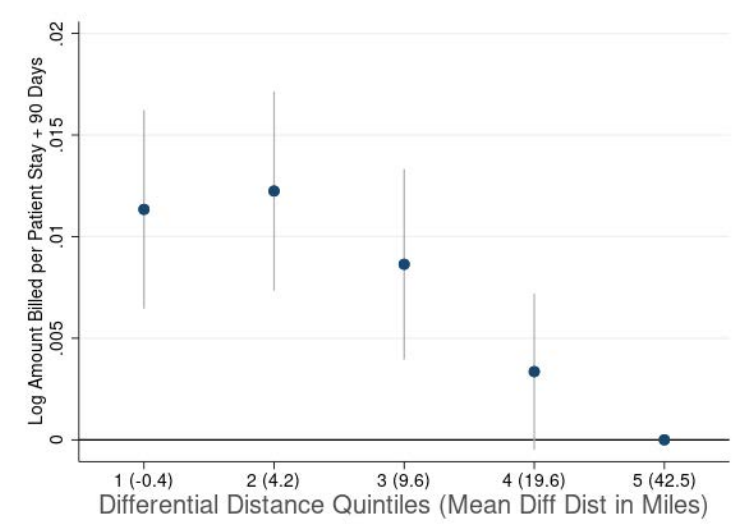

C: Log Amount Billed per Patient Stay + 90 Days

Note: This figure presents results from reduced form regressions for patient-level outcomes on the instrument, differential distance. Each blue point in the figure represents a coefficient $\beta_{s}$, obtained by estimating the equation $Y_{i}=\alpha_{m, t}+\alpha_{j}+\sum_{s=2}^{5} \beta_{s} 1\left(Q_{D D}=s\right)_{i}+\gamma_{1} X_{i}++\epsilon_{i}$, where $1\left(Q_{D D}=s\right)_{i}$ is an indicator for the $q^{\text {th }}$ quintile of differential distance. The highest quintile group, i.e., individuals relatively furthest away from a PE facility, is the reference group. Log total payment in Panel B refers to the total payment for the index nursing home stay. Standard errors are clustered by facility. 
Figure 4: Marginal Treatment Effects

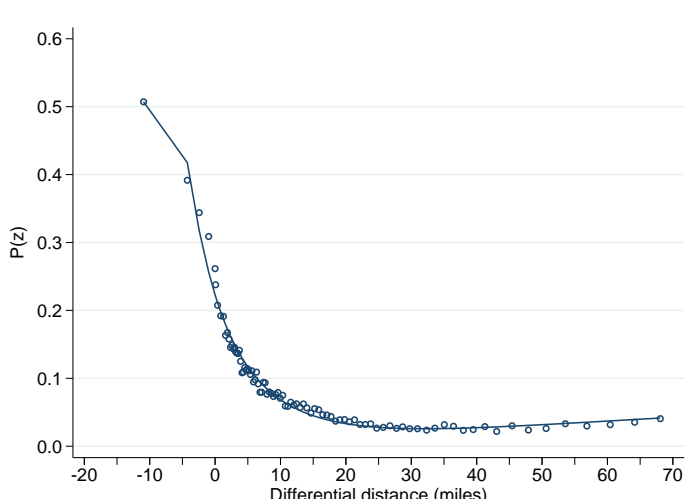

A: First stage

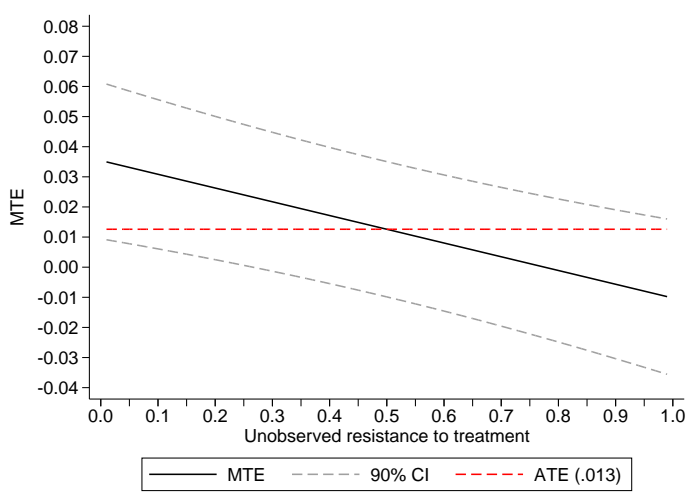

C: MTE curve



B: Common Support

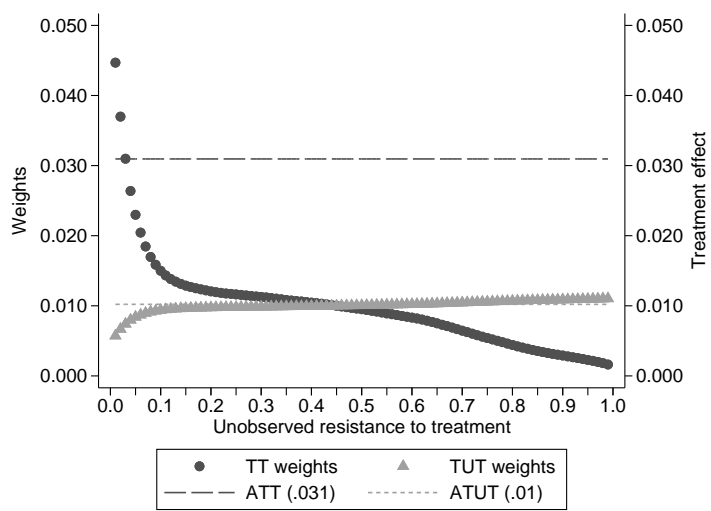

D: ATT and ATUT

Note: This figure presents results pertaining to Marginal Treatment Effects (MTE) analysis using the Medicare patient-level data. Panel A presents the 'first stage' fit of predicted probability of treatment or propensity score, w.r.t the instrument. Panel B presents the overlap in distributions of PE and non-PE groups by propensity score. This plot uses a log scale due to the large number of non-PE patients with low propensity. Appendix figure B.6A presents the corresponding plot using a linear scale. Panel C presents the MTE curve with $90 \%$ confidence intervals obtained using block bootstrap and the Average Treatment Effect (ATE) estimate. Panel D presents the weights for the Average Treatment on the Treated (ATT) and Average Treatment on the Untreated (ATUT) and the corresponding estimates. Section 5.2.2 presents details of the MTE estimation. 
Figure 5: Aggregate Quality and Staffing Outcomes

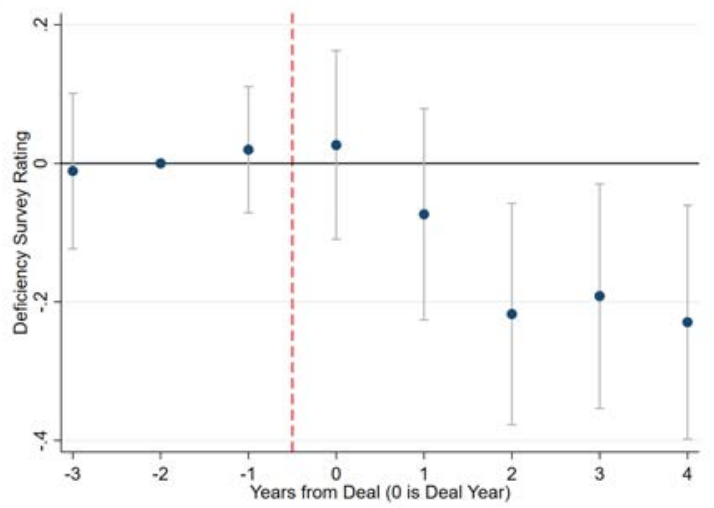

A: Deficiency Survey Rating

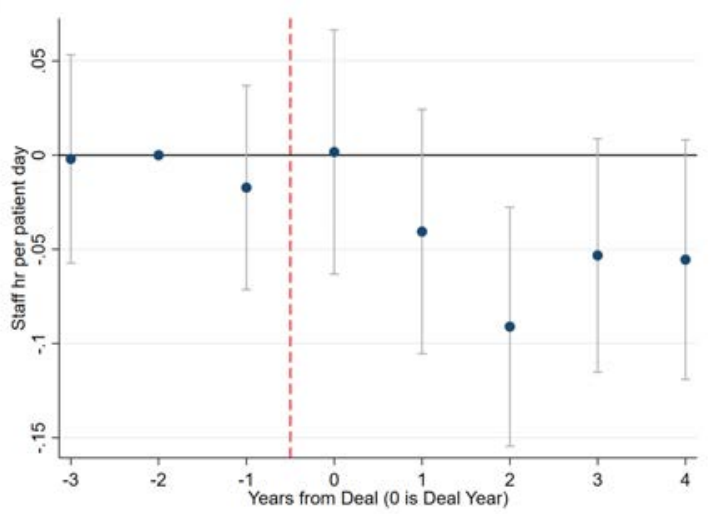

C: Staff Hour per Patient Day

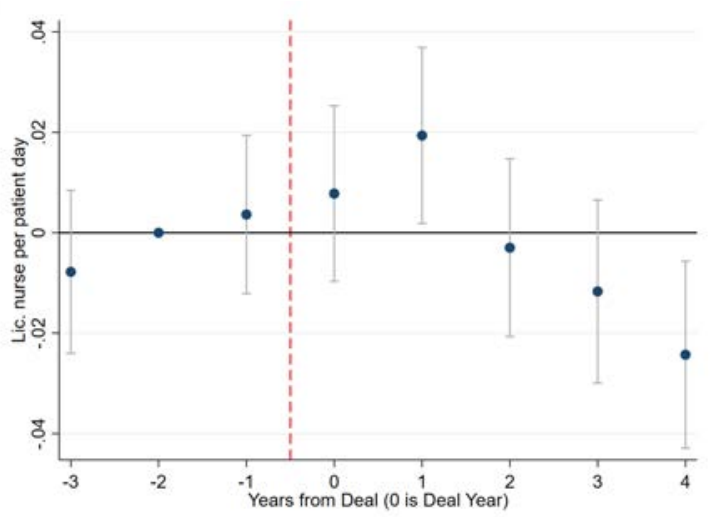

E: Lic. Nurse per Patient Day

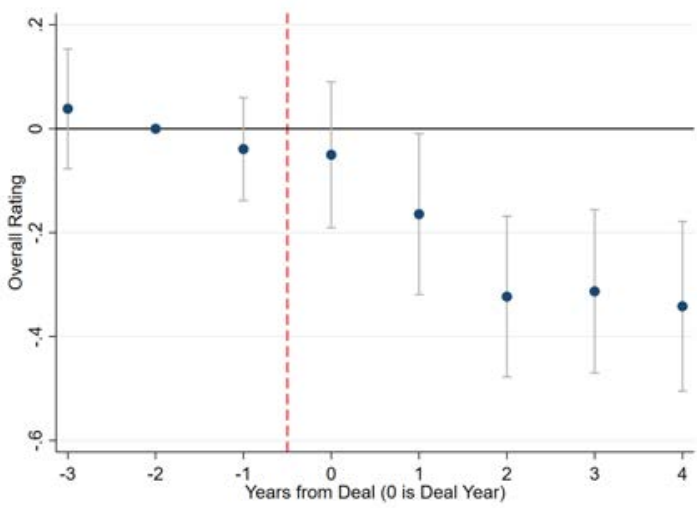

B: Overall Rating

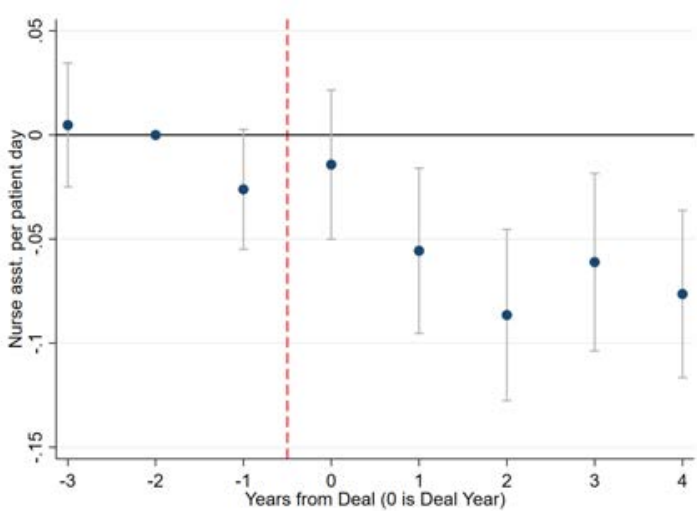

D: Nurse Asst. per Patient Day

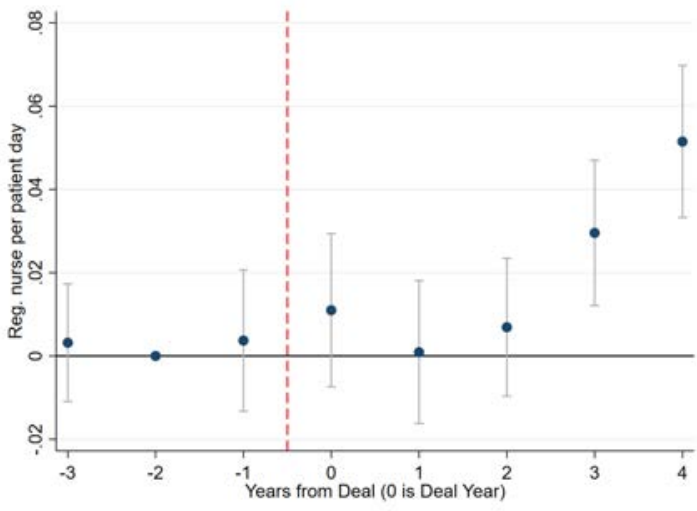

F: Registered Nurse per Patient Day

Note: This figure presents event studies on quality of care measures (Five Star ratings) and Staffing around the time a nursing home experiences a PE buyout. Each point in the figures represents the coefficient $\beta_{s}$ obtained by estimating Equation (10) as discussed in Section 6. Year $=-2$ is the omitted point. In Panels A and B, we present effects on the Five-star ratings awarded by CMS - deficiencies identified by independent contractors in audits and overall rating, respectively. A negative effect on ratings implies a decline in quality. Panels $\mathrm{C}$ to $\mathrm{F}$ present results on nurse staffing per-patient for all staff, nurse assistants, licensed nurses, and registered nurses respectively. All models include facility and year fixed effects, patient mix and market controls, as described in Section 6.1. All dependent variables are winsorized at 1 and $99 \%$ level. Standard errors are clustered by facility. 


\section{Figure 6: Facility Finances}

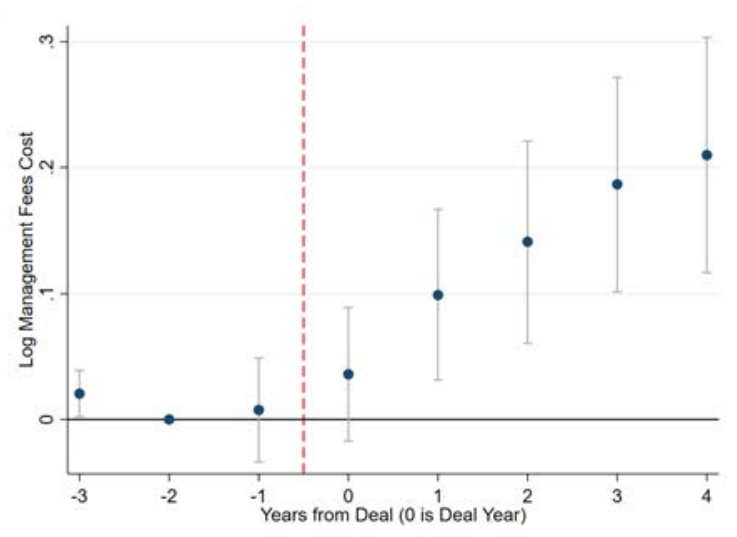

A: Log Management Fee Cost

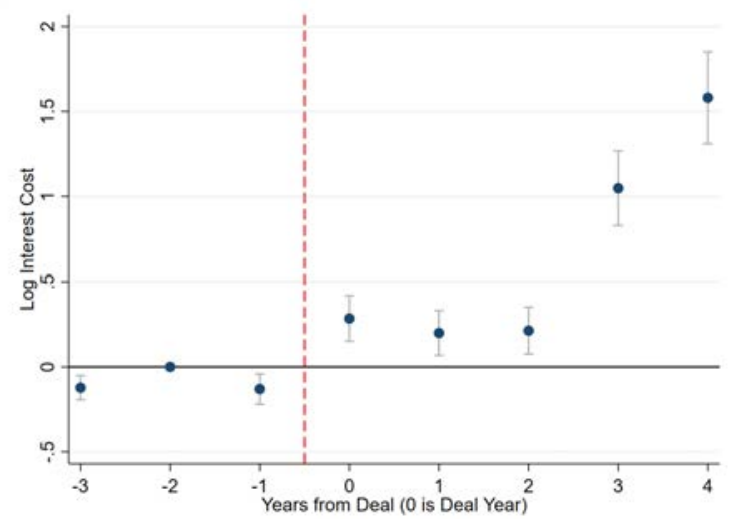

C: Log Interest Cost

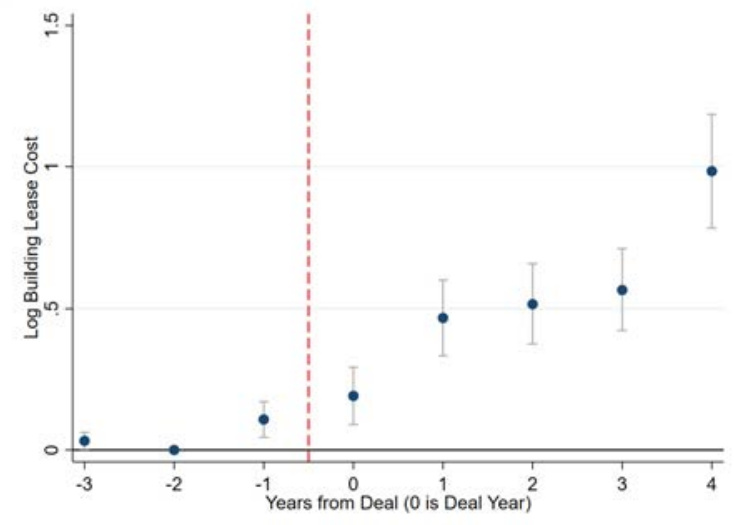

B: Log Building Lease Cost

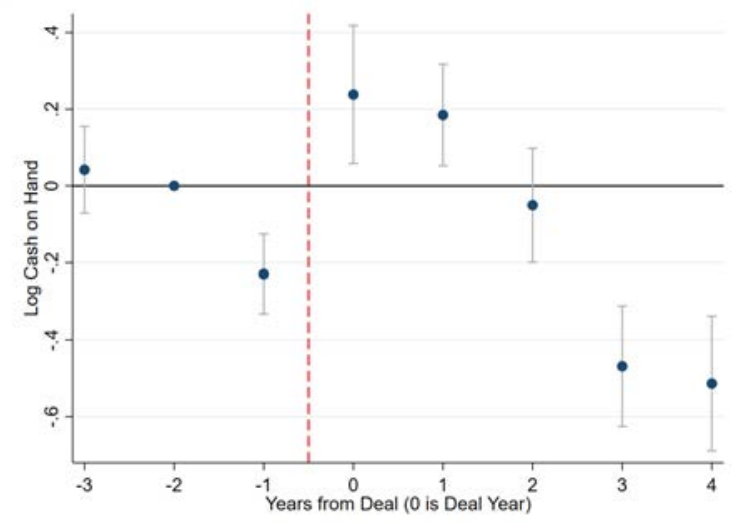

D: Log Cash on Hand

Note: This figure presents event studies on facility finances around the time a nursing home experiences a PE buyout. Each point in the figures represents the coefficient $\beta_{s}$ obtained by estimating Equation (10) as discussed in Section 6. Year $=-2$ is the omitted point. Panels A to D present results on the log of management fee cost, building lease cost, interest cost, and cash on hand, respectively. All models include facility and year fixed effects, patient mix and market controls, as described in Section 6.1. All dependent variables are winsorized at $1 \%$ and $99 \%$ levels. Standard errors are clustered by facility. 
Table 1: Descriptive Statistics

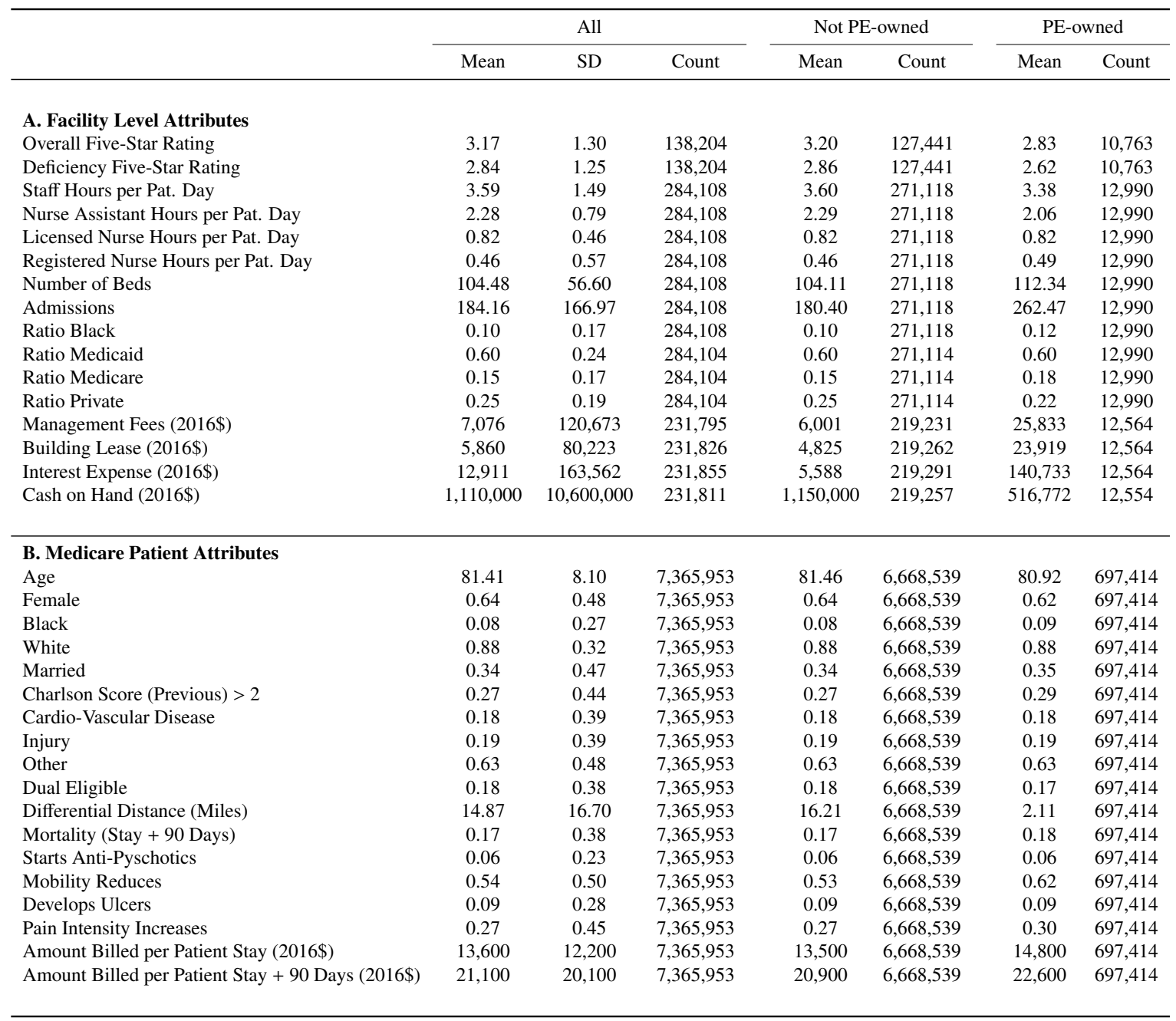

Note: This table presents descriptive statistics for key variables used in the analysis. Panel A presents descriptives on facility-level data for all nursing homes over the years 2000-17 while Panel B presents patientlevel data for Medicare patients with index stays over the years 2005-16. A unit of observation is a facility-year in Panel A and a unique patient in Panel B (since we retain only the first stay per patient). Columns 1,2 and 3 present means, standard deviations and number of observations for the full sample. We categorize facilities into two groups. Columns 4 and 5 present means and number of observations at facilities that never experienced a PE acquisition or before PE acquisition during our sample period. Columns 6 and 7 present corresponding values for facilities in the post-buyout period. For most variables, about $10 \%$ of the observations pertain to facilities that experienced a PE acquisition. Sample sizes differ across variables in Panel A since they were sourced from multiple sources or in some cases were reported only for more recent years. In Panel A, all continuously varying variables were winsorized at the $1 \%$ and $99 \%$ levels. We compute the Charlson Comorbidity Index using co-morbidities diagnosed in hospital inpatient and outpatient claims (first $10 \mathrm{dx}$ codes) over the 3 months prior to, but not including, the index stay. Spending values in Panel B are winsorized at the 99\% level and deflated to be in 2016 dollars. 'Total' billing includes hospital inpatient, outpatient including emergency department, and nursing home stay spending over the 90 days following discharge from the index stay and includes the index stay. The following patient-level variables were sourced from the Minimum Data Set (MDS): marriage, antipsychotics, mobility, and pressure ulcers. Medicare patients that could not be merged into the MDS (94\% match rate) were dropped from the sample. Facilities with less than 100 Medicare patients over the entire period were omitted from the patient-level sample. If any of the MDS variables was missing, then we set the respective indicator to zero. We exclude patients facing a differential distance of greater than 70 miles, approximately the $95^{\text {th }}$ percentile value, or below -70 miles. 
Table 2: Patient-Level Analysis: First Stage

\begin{tabular}{|c|c|c|c|c|c|}
\hline & $\begin{array}{c}(1) \\
1(\mathrm{PE})\end{array}$ & $\begin{array}{c}(2) \\
1(\mathrm{PE})\end{array}$ & $\begin{array}{c}(3) \\
1(\mathrm{PE})\end{array}$ & $\begin{array}{c}(4) \\
1(\mathrm{PE})\end{array}$ & $\begin{array}{c}(5) \\
1(\mathrm{PE})\end{array}$ \\
\hline $\begin{array}{l}\text { Differential Distance } \\
\text { (In } 10 \text { Miles) }\end{array}$ & $\begin{array}{c}-0.0480 * * * \\
(0.002)\end{array}$ & $\begin{array}{c}-0.0480 * * * \\
(0.002)\end{array}$ & $\begin{array}{c}-0.0479 * * * \\
(0.002)\end{array}$ & $\begin{array}{c}-0.0454 * * * \\
(0.002)\end{array}$ & $\begin{array}{c}-0.0419 * * * \\
(0.002)\end{array}$ \\
\hline $\begin{array}{l}(\text { Differential Distance })^{2} \\
(\text { In } 10 \text { Miles })\end{array}$ & $\begin{array}{l}0.0062 * * * \\
(0.000)\end{array}$ & $\begin{array}{c}0.0063 * * * \\
(0.000)\end{array}$ & $\begin{array}{c}0.0062 * * * \\
(0.000)\end{array}$ & $\begin{array}{l}0.0059 * * * \\
(0.000)\end{array}$ & $\begin{array}{l}0.0055^{* * *} * \\
(0.000)\end{array}$ \\
\hline Market Controls & & & Y & & \\
\hline Patient Controls & & $\mathrm{Y}$ & Y & Y & $\mathrm{Y}$ \\
\hline Facility FEs & $\mathrm{Y}$ & $\mathrm{Y}$ & $\mathrm{Y}$ & Y & $\mathrm{Y}$ \\
\hline Patient FEs Level & HRR x Year & HRR x Year & HRR x Year & HSA x Year & County x Year \\
\hline Observations & $7,365,934$ & $7,365,934$ & $7,358,129$ & $7,365,752$ & $7,365,246$ \\
\hline Y-Mean & 0.09 & 0.09 & 0.09 & 0.09 & 0.09 \\
\hline F-Stat & 224 & 224 & 222 & 220 & 203 \\
\hline
\end{tabular}

Note: This table presents estimates of the relationship between PE ownership of the nursing home and the patient's differential distance. Each cell presents the coefficient $\beta$ obtained by estimating Equation (1). The independent variable is the difference in distance (both linear and quadratic, in 10 miles) to the nearest PE nursing home and the nearest non-PE nursing home for the patient. This is calculated based on distances between the respective zip code centroids. The outcome variable is an indicator for whether the nursing home serving the patient is PE-owned ( $=1$ if PE-owned, 0 otherwise). Column 1 controls for facility and patient market (Hospital Referral Region) x Year fixed effects. Column 2 (our preferred specification) adds controls for patient risk controls (indicators for 17 pre-existing conditions used to define the Charlson Co-morbidity Index inferred from claims over the three months prior to admission, and sex, age, race, marital status, and an indicator if patients are dual eligible). Column 3 adds controls for patient zip-year characteristics: median household income, the shares of the population that are white, that are renters rather than home-owners, that are below the Federal poverty line, and that are enrolled in the medicare advantage program. Column 4 uses the same controls as in col. 2 but defines patient market using a narrower market definition: Health Service Area (HSA) instead of HRR. Column 5 uses the same controls as in col. 2 but defines patient market using a narrower market definition: County instead of HRR. Standard errors are clustered by facility. 
Table 3: Balance of Patient Characteristics

\begin{tabular}{|c|c|c|}
\hline Patient Attribute & $\begin{array}{c}(1) \\
\mathrm{DD}<\text { Median }\end{array}$ & $\begin{array}{c}(2) \\
\text { DD }>\text { Median }\end{array}$ \\
\hline Differential Distance & 2.70 & 27.04 \\
\hline PE-owned Nursing Home & 0.17 & 0.02 \\
\hline Age & 81.40 & 81.42 \\
\hline Female & 0.64 & 0.64 \\
\hline Black & 0.09 & 0.07 \\
\hline Married & 0.35 & 0.34 \\
\hline Dual Eligible & 0.16 & 0.19 \\
\hline AMI & 0.08 & 0.08 \\
\hline Congestive Heart Failure & 0.22 & 0.24 \\
\hline PVD & 0.05 & 0.05 \\
\hline CEVD & 0.13 & 0.14 \\
\hline Dementia & 0.04 & 0.05 \\
\hline COPD & 0.21 & 0.23 \\
\hline Rheumatoid Arthritis & 0.03 & 0.03 \\
\hline Peptic Ulcer & 0.02 & 0.02 \\
\hline Mild Liver Disease & 0.01 & 0.01 \\
\hline Diabetes & 0.21 & 0.22 \\
\hline Diabetes + Complication & 0.04 & 0.04 \\
\hline Paraplegia & 0.03 & 0.03 \\
\hline Renal Disease & 0.14 & 0.13 \\
\hline Cancer & 0.09 & 0.08 \\
\hline Severe Liver Disease & 0.01 & 0.01 \\
\hline Metastatic Cancer & 0.04 & 0.04 \\
\hline AIDS & 0.00 & 0.00 \\
\hline Number Of Patients & $3,683,135$ & $3,682,818$ \\
\hline
\end{tabular}

Note: This table presents the balance in patient attributes with respect to the instrument: differential distance. We divide patients into two groups based on whether their differential distance is below or above the median value (8.9 miles). Recall that differential distance (DD) is the difference between distance to the nearest PE nursing home and the nearest non-PE nursing home for the patient. Column 1 presents the means of patient characteristics for patients with DD below the median value, while Column 2 presents the means for patients with DD greater than the median. Characteristics include four demographics and 17 pre-existing co-morbidity indicators used to compute the Charlson Co-morbidity Index. Paraplegia includes both partial and complete paralysis. We generated indicators for the 17 disease groups using the 'charlson' command in Stata, available at http://fmwww.bc . edu/RePEc/bocode/c/charlson.html. We considered diagnosis codes on hospital inpatient and outpatient claims over the 3 months prior to, but not including, the index nursing home stay. 
Table 4: Patient-Level Analysis: IV Results

\begin{tabular}{|c|c|c|c|}
\hline & \multicolumn{3}{|c|}{ A: Main Results } \\
\hline & $\begin{array}{c}(1) \\
\text { Mortality } \\
(\text { Stay + } 90 \text { Days })\end{array}$ & $\begin{array}{c}(2) \\
\text { Log Amount Billed } \\
\text { Per Patient Stay }\end{array}$ & $\begin{array}{c}(3) \\
\text { Log Amount Billed } \\
\text { Per Patient Stay + 90 Days }\end{array}$ \\
\hline $1(\mathrm{PE})$ & $\begin{array}{c}0.0168 * * \\
(0.007)\end{array}$ & $\begin{array}{c}0.1777 * * * \\
(0.028)\end{array}$ & $\begin{array}{c}0.1054 * * * \\
(0.024)\end{array}$ \\
\hline $\begin{array}{l}\text { Observations } \\
\text { Y-Mean } \\
\text { F-Stat }\end{array}$ & $\begin{array}{c}7,365,934 \\
0.17 \\
224\end{array}$ & $\begin{array}{c}7,365,934 \\
9.07 \\
224\end{array}$ & $\begin{array}{c}7,365,934 \\
9.57 \\
224\end{array}$ \\
\hline \multirow{2}{*}{ F-Stat } & \multicolumn{3}{|c|}{ B: Placebo Analysis } \\
\hline & $\begin{array}{c}(1) \\
\text { Mortality } \\
(\text { Stay }+90 \text { Days })\end{array}$ & $\begin{array}{c}(2) \\
\text { Log Amount Billed } \\
\text { Per Patient Stay }\end{array}$ & $\begin{array}{c}(3) \\
\text { Log Amount Billed } \\
\text { Per Patient Stay + 90 Days }\end{array}$ \\
\hline $1(\mathrm{PE})$ & $\begin{array}{c}0.006 \\
(0.004)\end{array}$ & $\begin{array}{l}-0.015 \\
(0.018)\end{array}$ & $\begin{array}{l}-0.016 \\
(0.016)\end{array}$ \\
\hline $\begin{array}{l}\text { Observations } \\
\text { Y-Mean } \\
\text { F-Stat }\end{array}$ & $\begin{array}{c}7,159,535 \\
0.18 \\
441\end{array}$ & $\begin{array}{c}7,159,535 \\
9.01 \\
441\end{array}$ & $\begin{array}{c}7,159,535 \\
9.51 \\
441\end{array}$ \\
\hline
\end{tabular}

Note: This table presents estimates of the relationship between PE ownership and patient health and spending. In Panel $\mathrm{A}$, each cell presents the coefficient $\beta$ obtained by estimating Equation (2) by 2 SLS. The independent variable is an indicator for the patient being admitted to a PE nursing home, instrumented by differences in distance to the nearest PE and non-PE facility. Panel B presents results from a placebo analysis of the relationship between private equity ownership and patient health and spending. For this analysis, we use data over 2002-07, a period with very little actual PE ownership and which has little overlap with the main analysis sample. We assign placebo PE acquisition in 2004 to facilities that were eventually acquired before 2008 and 2005 to facilities acquired in and post 2008 by PE firms. Accordingly we re-compute differential distance values taking into account these placebo acquisitions. We present effects for claimsbased patient quality outcomes - patient death within 90 days of discharge from the index stay, and total amount billed (2016\$). All regressions include facility and patient HRR x Year fixed effects, and patient risk controls. Patient risk controls include age, race, gender, marital status, indicators for 17 pre-existing conditions used to compute the Charlson Index, and an indicator if patients are dual eligible. Standard errors are clustered by facility. 
Table 5: Heterogeneity in Patient Mortality

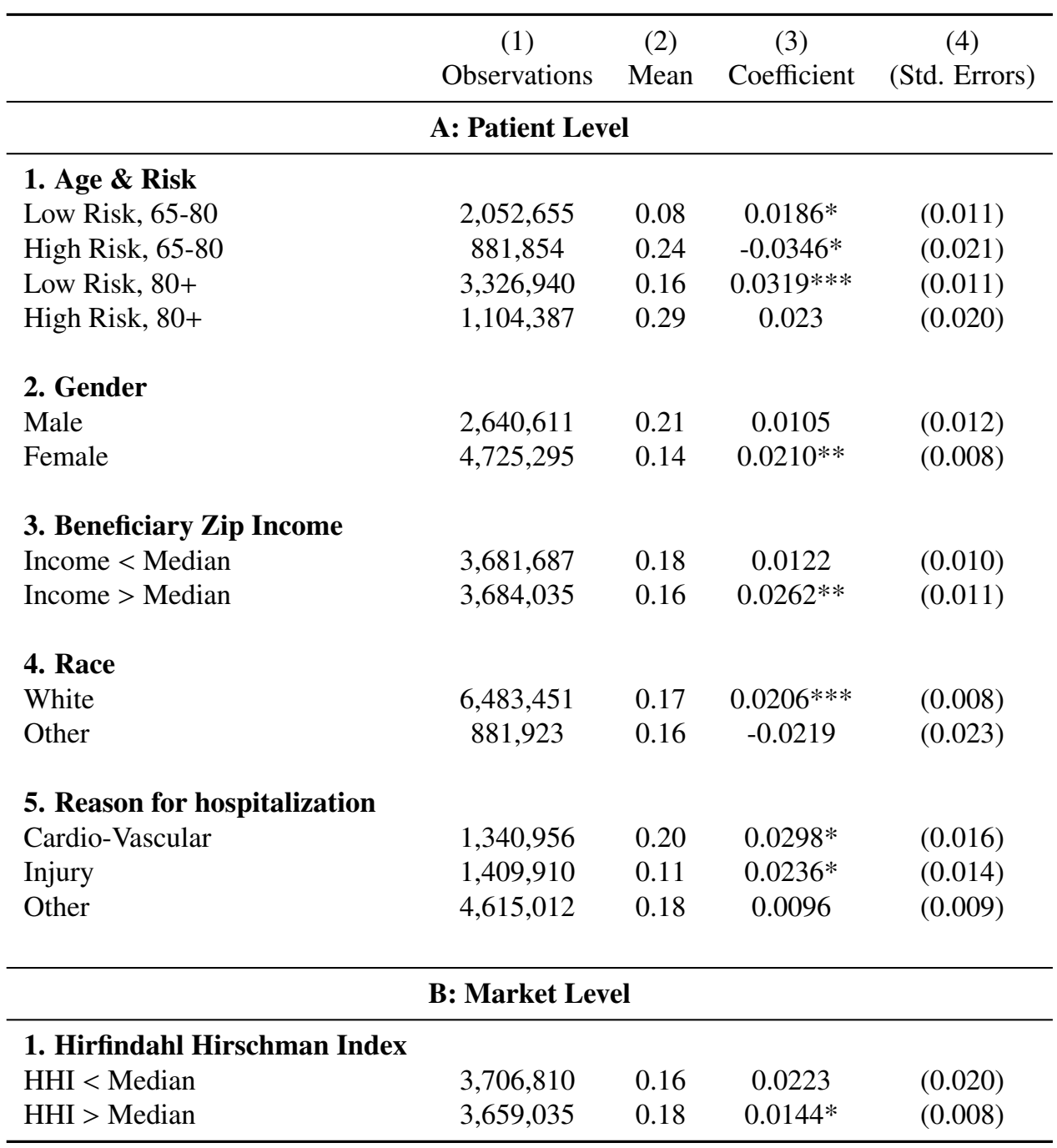

Note: This table presents heterogeneity in the effects of PE ownership on patient mortality. Column 1 presents the sample size and Column 2 presents the mean. Columns 3 and 4 present the corresponding coefficient $\beta$ and its standard error obtained by estimating Equation (2) by 2SLS. The independent variable is the indicator for a patient being admitted to a PE nursing home, instrumented by differences in distance to the nearest non-PE and PE nursing home. The outcome variable is an indicator for patient death within 90 days of discharge from the index stay. Panel A explores heterogeneity on patient level factors - by dividing patients into 4 groups based on severity of pre-existing co-morbidities (high risk $=$ Charlson Index greater than 2) and age (greater than 80) in row 1 , gender in row 2, median income in the patient's zipcode in row 3 , race in 4 , and the reason for hospitalization prior to the nursing home stay in row 5. Panel B explores heterogeneity based on market factors - dividing markets below and above the median Hirfindahl Hirschman Index (HHI). We computed the HHI using market shares in terms of beds as observed in 2003-04, where the HRR in which the nursing home is located is considered its market. All models include facility and patient HRR $x$ year fixed effects. We additionally control for the usual patient risk controls as in the main regression. Standard errors are clustered by facility. 
Table 6: Patient wellbeing

\begin{tabular}{lcccc}
\hline & $(1)$ & $(2)$ & $(3)$ & $(4)$ \\
& $\begin{array}{c}\text { 1(Starts Anti- } \\
\text { Psychotics) }\end{array}$ & $\begin{array}{c}\text { 1(Mobility } \\
\text { Decreases) }\end{array}$ & $\begin{array}{c}\text { 1(Develops } \\
\text { Ulcers) }\end{array}$ & $\begin{array}{c}\text { 1(Pain Intensity } \\
\text { Increases) }\end{array}$ \\
\hline $1(\mathrm{PE})$ & $0.0297 * * *$ & $0.0425 * * *$ & 0.0065 & $0.0273 *$ \\
& $(0.006)$ & $(0.011)$ & $(0.008)$ & $(0.016)$ \\
Observations & $7,365,934$ & $7,365,934$ & $7,365,934$ & $7,365,934$ \\
Y-Mean & 0.06 & 0.53 & 0.09 & 0.27 \\
\hline
\end{tabular}

Note: This table presents estimates of the relationship between PE ownership and measures of patient wellbeing obtained from clinical assessments. Each cell in the first row presents the coefficient $\beta$ obtained by estimating Equation (2). The independent variable is an indicator for the patient being admitted to a PE nursing home, instrumented by differences in distance to the nearest PE and non-PE facility. All models include facility and patient HRR x Year fixed effects. We additionally control for the usual patient risk controls as in the main regression. The independent variable is an indicator for whether a nursing home is private equity-owned (=1 if PE-owned, 0 otherwise) starting in the next year from the deal announcement date. We present results for patient level outcomes - an indicator for patient starting anti- psychotics, decrease in patient mobility, developing/worsening pressure ulcers, and increase in pain intensity. These variables take value one if this condition is not flagged for the patient in the initial assessment, but is flagged at some point during the stay. Standard errors are clustered by facility. 
Table 7: Patient-Level Analysis: Robustness

\begin{tabular}{|c|c|c|c|}
\hline & $\begin{array}{c}(1) \\
\text { Mortality } \\
(\text { Stay }+90 \text { Days })\end{array}$ & $\begin{array}{c}(2) \\
\text { Log Amount Billed } \\
\text { Per Patient Stay }\end{array}$ & $\begin{array}{c}(3) \\
\text { Log Amount Billed } \\
\text { Per Patient Stay + } 90 \text { Days }\end{array}$ \\
\hline $\begin{array}{l}\text { 1. Base Specification } \\
1(\mathrm{PE})\end{array}$ & $\begin{array}{c}0.0168 * * \\
(0.007)\end{array}$ & $\begin{array}{c}0.1777 * * * \\
(0.028)\end{array}$ & $\begin{array}{l}0.1054 * * * \\
(0.024)\end{array}$ \\
\hline $\begin{array}{l}\text { 2. Chain Controls } \\
1(\mathrm{PE})\end{array}$ & $\begin{array}{l}0.0169 * * \\
(0.007)\end{array}$ & $\begin{array}{c}0.1777 * * * \\
(0.028)\end{array}$ & $\begin{array}{l}0.1055^{* * * *} \\
(0.024)\end{array}$ \\
\hline $\begin{array}{l}\text { 3. W/O Top } 2 \text { Deals } \\
1(\mathrm{PE})\end{array}$ & $\begin{array}{c}0.0309 * * * \\
(0.011)\end{array}$ & $\begin{array}{c}0.2309 * * * \\
(0.045)\end{array}$ & $\begin{array}{l}0.1429 * * * \\
(0.037)\end{array}$ \\
\hline $\begin{array}{l}\text { 4. Top } 5 \text { Deals Only } \\
1(\mathrm{PE})\end{array}$ & $\begin{array}{c}0.0349 * * * \\
(0.012)\end{array}$ & $\begin{array}{c}0.2469 * * * \\
(0.046)\end{array}$ & $\begin{array}{l}0.1510 * * * \\
(0.039)\end{array}$ \\
\hline $\begin{array}{l}\text { 5. Only For Profits } \\
1(\mathrm{PE})\end{array}$ & $\begin{array}{c}0.0138 * * \\
(0.007)\end{array}$ & $\begin{array}{l}0.1474 * * * \\
(0.026)\end{array}$ & $\begin{array}{l}0.0836 * * * \\
(0.021)\end{array}$ \\
\hline $\begin{array}{l}\text { 6. Zip-Year Controls } \\
1(\mathrm{PE})\end{array}$ & $\begin{array}{l}0.0150 * * \\
(0.007)\end{array}$ & $\begin{array}{l}0.1760 * * * \\
(0.028)\end{array}$ & $\begin{array}{l}0.1029 * * * \\
(0.024)\end{array}$ \\
\hline $\begin{array}{l}\text { 7. HSA-Year FEs } \\
1(\mathrm{PE})\end{array}$ & $\begin{array}{l}0.0211 * * * \\
(0.008)\end{array}$ & $\begin{array}{l}0.1800 * * * \\
(0.030)\end{array}$ & $\begin{array}{l}0.1130 * * * \\
(0.025)\end{array}$ \\
\hline $\begin{array}{l}\text { 8. County-Year FEs } \\
1(\mathrm{PE})\end{array}$ & $\begin{array}{l}0.0221 * * \\
(0.010)\end{array}$ & $\begin{array}{l}0.1430 * * * \\
(0.034)\end{array}$ & $\begin{array}{l}0.0832 * * * \\
(0.029)\end{array}$ \\
\hline $\begin{array}{l}\text { 9. No Controls } \\
1(\mathrm{PE})\end{array}$ & $\begin{array}{l}0.0296 * * * \\
(0.008)\end{array}$ & $\begin{array}{l}0.2391 * * * \\
(0.030)\end{array}$ & $\begin{array}{l}0.1131 * * * \\
(0.024)\end{array}$ \\
\hline $\begin{array}{l}\text { Observations } \\
\text { Y-Mean }\end{array}$ & $\begin{array}{c}7,365,934 \\
0.17\end{array}$ & $\begin{array}{c}7,365,934 \\
9.07\end{array}$ & $\begin{array}{c}7,365,934 \\
9.57\end{array}$ \\
\hline
\end{tabular}

Note: This table presents results from specification checks on the relationship between PE ownership and patient health and spending. Each cell presents the coefficient $\beta$ obtained by estimating Equation (2) by 2SLS. The independent variable is an indicator for the patient being admitted to a PE nursing home, instrumented by differences in distance to the nearest PE and non-PE facility. We present effects for patient death within 90 days of discharge from the index stay, the log of the total amount billed for the stay and the log of the amount billed for the stay and across hospital inpatient, outpatient and nursing home over the 90 days following the stay (2016\$). All models include facility fixed effects. The first six rows include HRR x year fixed effects, the seventh row uses Health Service Areas (HSA), and the eighth row uses county to define patient market instead of HRR. The second row controls for facility being part of a chain. The third row calculates the results excluding all data for chains involved in the 2 largest PE deals. The fourth row limits the PE group to only the facilities bought in the 5 largest PE deals. The fifth row limits the sample only to for-profit facilities. The sixth row includes patient zip controls: median household income, the shares of the population that are white, that are renters rather than home-owners, that are below the federal poverty level, and that are enrolled in Medicare Advantage program. The first eight rows includes patient risk controls: age, race, gender, marital status, indicators for 17 pre-existing conditions used to compute the Charlson score, and an indicator if patients are dual eligible. The ninth row presents coefficients from a model with fixed effects only. Standard errors are clustered by facility. 
Table 8: Mechanisms and Operational Changes

\begin{tabular}{|c|c|c|c|c|}
\hline & \multicolumn{4}{|c|}{ A: Five Star Rating } \\
\hline & $\begin{array}{c}(1) \\
\text { Deficiency } \\
\text { Rating }\end{array}$ & $\begin{array}{c}(2) \\
\text { Overall } \\
\text { Rating }\end{array}$ & & \\
\hline $\begin{array}{l}1(\mathrm{PE}) \\
\text { (No Control) }\end{array}$ & $\begin{array}{c}-0.075 * * \\
(0.037)\end{array}$ & $\begin{array}{c}-0.079 * * \\
(0.036)\end{array}$ & & \\
\hline $\begin{array}{l}1(\mathrm{PE}) \\
\text { (With Control) }\end{array}$ & $\begin{array}{c}-0.077 * * \\
(0.037)\end{array}$ & $\begin{array}{c}-0.082 * * \\
(0.036)\end{array}$ & & \\
\hline \multirow[t]{3}{*}{ Y-Mean } & $\begin{array}{c}138,051 \\
2.9\end{array}$ & $\begin{array}{c}138,051 \\
3.2\end{array}$ & & \\
\hline & \multicolumn{4}{|c|}{ B: Staff Per Patient Day } \\
\hline & $\begin{array}{c}\text { (1) } \\
\text { All Staff }\end{array}$ & $\begin{array}{c}(2) \\
\text { Nurse Assistant }\end{array}$ & $\begin{array}{c}(3) \\
\text { Licensed Nurse }\end{array}$ & $\begin{array}{c}\text { (4) } \\
\text { Registered Nurse }\end{array}$ \\
\hline $\begin{array}{l}\text { (PE) } \\
\text { (No Control) }\end{array}$ & $\begin{array}{c}-0.050 * * * \\
(0.017)\end{array}$ & $\begin{array}{c}-0.068 * * * \\
(0.010)\end{array}$ & $\begin{array}{c}-0.019 * * * \\
(0.006)\end{array}$ & $\begin{array}{c}0.037 * * * \\
(0.005)\end{array}$ \\
\hline $\begin{array}{l}\text { 1(PE) } \\
\text { (With Control) }\end{array}$ & $\begin{array}{c}-0.048 * * * \\
(0.016)\end{array}$ & $\begin{array}{c}-0.066 * * * \\
(0.010)\end{array}$ & $\begin{array}{c}-0.019 * * * \\
(0.006)\end{array}$ & $\begin{array}{l}0.037 * * * \\
(0.005)\end{array}$ \\
\hline $\begin{array}{l}\text { Observations } \\
\text { Y-Mean }\end{array}$ & $\begin{array}{c}283,767 \\
3.6\end{array}$ & $\begin{array}{c}283,767 \\
2.3\end{array}$ & $\begin{array}{c}283,767 \\
0.8\end{array}$ & $\begin{array}{c}283,767 \\
0.5\end{array}$ \\
\hline \multirow{2}{*}{ Y-Mean } & \multicolumn{4}{|c|}{ C: Log Financials } \\
\hline & $\begin{array}{c}(1) \\
\text { Management Fee }\end{array}$ & $\begin{array}{c}\text { (2) } \\
\text { Building Lease }\end{array}$ & $\begin{array}{c}\text { (3) } \\
\text { Interest Expense }\end{array}$ & $\begin{array}{c}\text { (4) } \\
\text { Cash on Hand }\end{array}$ \\
\hline $\begin{array}{l}1(\mathrm{PE}) \\
\text { (No Control) }\end{array}$ & $\begin{array}{l}0.074 * * \\
(0.032)\end{array}$ & $\begin{array}{c}0.564 * * * \\
(0.061)\end{array}$ & $\begin{array}{c}1.181 * * * \\
(0.096)\end{array}$ & $\begin{array}{c}-0.322 * * * \\
(0.042)\end{array}$ \\
\hline $\begin{array}{l}\text { 1(PE) } \\
\text { (With Control) }\end{array}$ & $\begin{array}{c}0.074 * * \\
(0.032)\end{array}$ & $\begin{array}{c}0.560 * * * \\
(0.061)\end{array}$ & $\begin{array}{l}1.175^{* * * *} \\
(0.096)\end{array}$ & $\begin{array}{c}-0.318 * * * \\
(0.042)\end{array}$ \\
\hline $\begin{array}{l}\text { Observations } \\
\text { Y-Mean }\end{array}$ & $\begin{array}{c}231,556 \\
0.2\end{array}$ & $\begin{array}{c}231,584 \\
0.4\end{array}$ & $\begin{array}{c}231,613 \\
0.3\end{array}$ & $\begin{array}{c}231,569 \\
11.2\end{array}$ \\
\hline
\end{tabular}

Note: This table presents estimates of the relationship between PE ownership and nursing home outcomes. Each cell presents the coefficient $\beta$ obtained by estimating equation 9 with a different outcome. The independent variable is an indicator for whether a nursing home is PE-owned (=1 if PE-owned, 0 otherwise) starting in the next year from the deal announcement date. Panel A presents results for quality outcomes as measured by Five-star rating awarded by CMS - overall rating and deficiencies identified by independent contractors in audits, respectively. A negative effect on ratings implies a decline in quality. Panel B presents results on per patient nurse availability for all nurses, nurse assistants, licensed nurses, and registered nurses. Panel C presents results on the log of management fees, building lease cost, interest expenses, and cash on hand. The top row presents results with no controls. The bottom row presents the results including controls, which consist of market-level and patient mix controls, as described in Section 6.1. All models include facility and year fixed effects. All variables are winsorized at $1 \%$ and $99 \%$ levels. Standard errors are clustered by facility. 


\section{Appendix: For Online Publication}

\section{A Data appendix}

This paper uses three primary data sources. We use (1) publicly available nursing homelevel data, (2) patient-level administrative claims data, both obtained from CMS, and (3) Pitchbook data on PE deals. This section provides a detailed explanation of these data sources and how we arrived at our analysis samples.

\section{A.1 Nursing Home Data}

Our data source on nursing home-level operations and performance is a compilation of information obtained during annual surprise CMS inspector audits and data on nursing home attributes and patient characteristics reported by the facilities themselves. ${ }^{33}$ The data span 2000 through 2017. In each year we observe about 15,000 unique nursing homes, for a total of approximately 280,000 observations. Of these, about 29,000 observations represent facilities acquired by PE firms. The aggregate files provide annual data on basic facility attributes, patient volume and case mix, nurse availability, and various components of the Five Star ratings. ${ }^{34}$ These ratings started in 2009, so we cannot observe ratings pre-buyout for deals before 2010. Fortunately, half of the PE deals in our sample, accounting for 365 nursing homes, occurred post-2009.

Table 1 Panel A presents summary statistics on the Overall Five Star rating as well as the other key nursing home-level variables used in the analysis. We first present the mean and standard deviation for the whole sample (columns 1-2), then divide observations into two groups-for facilities that are not PE-owned (columns 4-5) and for those that are (columns 6-7). We observe clear differences between PE-owned facilities and those not owned (all statistically significant at the $1 \%$ level except where noted). PE targets are slightly larger, have fewer staff hours per resident, and a lower Overall Five Star rating. There have been secular increases for the whole sector in both ratings and staffing over time. For staffing, this reflects more stringent standards from regulators over time. Average staff hours per patient day increased from 3.5 in 2000 to 3.7 in 2017. Similarly, overall average Five Star ratings increased from 2.9 in 2009 to 3.25 in 2017 . As the PE deals occurred primarily later in the sample, it is therefore remarkable that they have lower measures of quality on average.

\section{A.2 Patient Data}

Our second data source consists of patient-level billing claims and assessment data for Medicare fee-for-service beneficiaries from 2004 to 2016. We observe the universe of billing data for hospital care (inpatient and outpatient) and nursing homes for these beneficiaries, as well as detailed patient assessments recorded in the Minimum Data Set (MDS). ${ }^{35}$ We use these files to track beneficiaries' demographics, spending, and health

\footnotetext{
${ }^{33}$ These files were organized and made available for research by the Long Term Care Focus research center at Brown University. See www.ltcfocus.org for more details.

${ }^{34}$ For more details on how the ratings are produced, see Rating Guide.

${ }^{35}$ Specifically, we use $100 \%$ samples of the following: Medicare Beneficiary Summary File (MBSF), Hospital inpatient and outpatient, and Skilled Nursing Facility claims files. These were obtained through a reuse DUA with CMS and accessed through the NBER.
} 
outcomes such as mortality. The MDS helps observe clinical assessments such as mobility and the use of antipsychotic drugs.

The unit of observation is a nursing home stay for a Medicare beneficiary that begins during our sample period, which we begin in 2005 in order to have at least one look-back year. Our main sample restriction is to identify index nursing home stays for patients, defined as stays that begin at least a year after discharge from a previous nursing home stay. This helps avoid mis-attributing adverse effects to the wrong nursing home. To further avoid attribution error, we consider only the patient's first index stay in our entire sample period. Hence, each patient appears only once in our sample. Using this approach, we settle on a sample of more than seven million patients over 12 years. For each of these patients, we also observe clinical assessments from the MDS, which we successfully match to the claims files. Following the prior literature (Grabowski, Feng, Hirth, Rahman and Mor, 2013), we use some other restrictions to arrive at our sample. We restrict to patients over 65 years of age who are enrolled in Medicare parts A and B for at least 12 months before the start of the nursing home stay. This restriction ensures that we observe prior medical care history and pre-existing conditions. We also restrict to stays associated with a hospital visit in the previous month, so that all patients are admitted after a hospital-based procedure and are relatively homogeneous. We drop patients who went to a nursing home in a state other than their state of residence as recorded in the Medicare master beneficiary summary file. This drops a small fraction of patients (less than 5\%) and is meant to exclude patients who may be traveling when admitted to a nursing home. We match the index nursing home stays to the MDS sample on beneficiary ID, facility ID, and admission date. We achieve a match rate of $94 \%$ and drop unmatched patients. We drop facilities with fewer than 100 patients over the entire sample period to avoid special facilities and mitigate noise.

Table 1 Panel B presents summary statistics on the final patient-level sample. We use an indicator for death within 90 days following discharge (including during the stay), based on death dates recorded in the Medicare master beneficiary summary file. We use two measures of spending. The first is the total amount that the nursing home bills to Medicare and the patient for the index stay in 2016 dollars. Medicare covers the entire cost until the 21 st day of stay, at which point the patient begins paying a coinsurance, which has risen somewhat over time and is now $\$ 170.5$ per day. ${ }^{36}$ In our data, about $90 \%$ of total payments are by Medicare. PE-owned facilities charge about $10 \%$ more than other facilities. The second measure is the total amount paid for the stay and the 90 days following discharge. This captures any subsequent hospital inpatient or outpatient care, and it provides a more holistic picture of patient care.

Demographic measures associated with risk are quite similar across the types of facilities, including patient age, the share of patients who are black and married, and the Charlson Comorbidity Index, a standard measure of patient mortality risk based on co-morbidities (Charlson, Szatrowski, Peterson and Gold, 1994). ${ }^{37}$ We create a high-risk indicator that is one if the previous-quarter Charlson score is greater than two. According to this definition, about $30 \%$ of patients are high-risk. The difference between facility types is not significant.

Finally, we examine four measures of patient well-being which comprise inputs to the

\footnotetext{
${ }^{36}$ See https://www.resdac.org/cms-data/files/ip-ffs/data-documentation and https://www.medicare.gov/Pubs/pdf/10153-Medicare-Skilled-Nursing-Facility-Care.pdf.

${ }^{37}$ The "Charlson score" assigns a point score to each of 17 disease categories recorded during the 3 months before the index stay and sums them to create an overall disease burden score.
} 
quality portion of CMS' Five Star ratings. The first is an indicator for the patient starting antipsychotic medication during the stay. The second is an indicator for the patient's selfreported mobility score declining during the stay. The third is an indicator for developing a pressure ulcer. The fourth is an indicator for the patient's self-reported pain intensity score increasing during the stay.

\section{A.3 PE Deal Data}

Our primary source of data on PE transactions is a proprietary list of deals in the "Elder and disabled care" sector compiled by Pitchbook Inc., a leading market intelligence firm in this space. The deals span 2004 to 2015 . We match the target names to individual nursing facilities using name (facility or corporate owner) and address as recorded in CMS data. ${ }^{38}$ Target names in these deals typically refer to holding companies, which often do not reflect the names of individual facilities. The matching process required manual Internet searches to confirm chain affiliations. We supplement the Pitchbook data in two ways. First, we conduct additional Internet searches that yielded a small number of PE deals not reported by Pitchbook. Second, we obtain a list of merger and acquisition deals from 2005 to 2016 from Levin Associates, a market intelligence firm that tracks the healthcare sector. This helps us to identify facilities that did not experience a new PE deal, but were acquired by an existing PE-owned chain. ${ }^{39}$

This process yielded 128 deals, which correspond to a change in ownership to PE for 1,674 facilities. The deals are spread over time (no particular year or part of the business cycle dominates) and across PE firms. Figure B.1 shows the number of deals in each year. In total, our data contain 136 unique PE firms that acquired nursing homes. Most deals are syndicated and involve multiple PE firms. Table B.1 presents the top 10 deals by number of facilities acquired. Deal sizes are skewed, with the top 10 deals accounting for about $80 \%$ of all facilities acquired. On average, we observe PE-owned facilities for eight years post-acquisition. ${ }^{40}$

It is difficult to ascertain whether we comprehensively capture PE activity in this sector. While there is no 'official' tally of PE-owned nursing homes to benchmark against, our sample size compares favorably against an estimate of 1,876 nursing homes reportedly acquired by PE firms over a similar duration, 1998-2008 (GAO, 2010). Nonetheless, our analysis likely underestimates the extent of PE activity in nursing homes, as matching between Pitchbook deals and individual facilities is very challenging.

To understand whether deals are concentrated in particular regions, we plot the location of PE-owned facilities across the U.S. in Figure B.2. PE firms appear to be more active in large metropolitan markets, and in certain states such as Florida, Texas, New York, Pennsylvania and Massachusetts. However, there is no obvious concentration, and we do not find systematic variation with local measures of income, age, elder population, or share

\footnotetext{
${ }^{38}$ We obtain data on nursing home attributes (name, address, city, owner name and type, number of beds) and quality measures (deficiencies) from Nursing Home Compare. See https://data.medicare.gov/data/ nursing-home-compare for more details.

${ }^{39}$ We matched approximately 290 additional facilities using information from the Levin files to the CMS data. Of these, about 40 were PE-owned.

${ }^{40}$ A likely source of measurement error is not capturing PE disinvestment from facility ownership. For the top 10 deals ( $80 \%$ of facilities) we verified PE exit via manual internet searches and incorporated it in the analysis. The main results are robust to dropping observations of facilities that have been owned by PEs for 10 years or more. As expected, the coefficients modestly increase in magnitude when we do so.
} 
of patients eligible for Medicare Advantage.

\section{A.4 Targeting}

This paper does not address why nursing homes may or may not be profitable acquisition targets, and does not assess returns from investing. However, exploring what types of facilities are targeted can help to interpret the effects of buyouts on patient welfare and is also useful for identifying the most relevant control variables for our empirical analysis. We describe which characteristics are robustly associated with buyouts in Table A.1, which presents estimates of Equation (11):

$$
P E_{j, t}=\alpha_{s}+\alpha_{t}+X_{j, t}^{\prime} \beta+\epsilon_{j, t}
$$

Here, $P E_{j, t}$ is set to 100 if the facility $j$ is acquired in a PE deal in year $t$ (we drop all years post-deal, and multiply by 100 for ease of reading). $P E_{j, t}$ is zero for never-PE and PE-owned facilities before the deal. We include state and year fixed effects.

We report models including variables known to be central to nursing home quality of care and economics or that are potentially important and robustly predict buyouts. In column 1, we find that facilities in more urban counties are more likely to be targeted. ${ }^{41}$ Urban nursing homes tend to be closer to hospitals and likely enjoy thicker labor markets. Facilities in a state with a higher ratio of elderly people are also more likely to be targeted. County-level income, race, and home ownership do not predict buyouts. Results for these covariates are not presented.

In column 2, we turn to facility characteristics. Chains are more likely to be acquired than independent facilities, likely reflecting substantial fixed costs in deal-making. Hospitalowned facilities are less likely to be targeted. PE firms also tend to target larger and higheroccupancy facilities. We consider patient-level characteristics in column 3: the share of the nursing home's patients covered by Medicaid, the share on private insurance, and the share who are Black. The first two are strongly negatively associated with buyouts, meaning that a higher share of Medicare patients (the omitted group) is positively associated with being targeted. In column 4, we assess two facility-level quality measures we employ in the analysis: Five Star overall rating and staff hours per patient day. Both are negatively associated with buyouts, but once we control for rating, staffing is not significant. These results indicate that PE firms target relatively low-performing nursing homes.

Finally, in column 5 we include simultaneously all of the variables from the previous models that had predictive power. Some, such as admits per bed and hospital ownership, become small and insignificant after controlling for the other variables. Notably, the state elder ratio, chain indicator, and Five star rating retain their magnitudes and precision.

\footnotetext{
${ }^{41}$ We define urban as being in the top 2 out of 9 county groups classified as urban based on a Department of Housing and Urban Development 2003 rural-urban classification.
} 
Table A.1: Targeting

\begin{tabular}{|c|c|c|c|c|c|c|}
\hline & Mean & (1) & (2) & (3) & (4) & $(5)$ \\
\hline Urban Indicator & 0.56 & $\begin{array}{c}0.193 * * * \\
(0.037)\end{array}$ & & & & $\begin{array}{c}0.105 * * \\
(0.041)\end{array}$ \\
\hline State Elder Ratio & 0.24 & $\begin{array}{c}4.340 * * * \\
(1.328)\end{array}$ & & & & $\begin{array}{c}18.819 * * * \\
(3.906)\end{array}$ \\
\hline 1(Chain) & 0.53 & & $\begin{array}{c}0.835 * * * \\
(0.033)\end{array}$ & & & $\begin{array}{c}0.367 * * * \\
(0.029)\end{array}$ \\
\hline Hospital-Owned & 0.07 & & $\begin{array}{c}-0.221 * * * \\
(0.053)\end{array}$ & & & $\begin{array}{c}-0.003 \\
(0.067)\end{array}$ \\
\hline $\log ($ Beds $)$ & 4.5 & & $\begin{array}{c}0.287 * * * \\
(0.030)\end{array}$ & & & $\begin{array}{c}0.086 * * * \\
(0.032)\end{array}$ \\
\hline Admits Per Bed & 2.08 & & $\begin{array}{c}0.051 * * * \\
(0.007)\end{array}$ & & & $\begin{array}{c}0.009 \\
(0.015)\end{array}$ \\
\hline Ratio Medicaid & 0.60 & & & $\begin{array}{c}-0.879 * * * \\
(0.117)\end{array}$ & & $\begin{array}{c}-0.434 * \\
(0.229)\end{array}$ \\
\hline Ratio Private & 0.25 & & & $\begin{array}{c}-1.441 * * * \\
(0.144)\end{array}$ & & $\begin{array}{c}-0.422 * \\
(0.236)\end{array}$ \\
\hline Ratio Black & 0.10 & & & $\begin{array}{c}0.002 \\
(0.099)\end{array}$ & & \\
\hline Overall Rating & 3.15 & & & & $\begin{array}{c}-0.075 * * * \\
(0.015)\end{array}$ & $\begin{array}{c}-0.066 * * * \\
(0.015)\end{array}$ \\
\hline Staff Hr per Patient Day & 3.55 & & & & $\begin{array}{l}-0.022 \\
(0.018)\end{array}$ & \\
\hline Observations & & 235,670 & 218,592 & 218,592 & 103,831 & 103,831 \\
\hline Y-Mean (pp) & & 0.6 & 0.6 & 0.6 & 0.6 & 0.6 \\
\hline
\end{tabular}

Note: This table shows estimates of the relationship between pre-existing nursing home characteristics and whether a nursing home is a target of a PE buyout. Column 1 presents market-level attributes: an indicator for urban and the share of state population which is elderly. Column 2 presents facility-level attributes: indicator for being member of a chain, indicator for the nursing home being hospital-based, the log number of beds, and admits per bed. Column 3 presents patient mix controls: share of patients covered by Medicaid, share of patients who pay privately, and the share of patients who are black. Column 4 presents quality metrics such as Five-star ratings awarded by CMS and staff hours per patient day. We re-run the regression on all variables which appear significant in Columns 1 to 4 in Column 5. The dependent variable is 100 if the nursing home was acquired by $\mathrm{PE}$ in that year and 0 otherwise. We remove all observations of private equity-owned facilities in years following the take-over by PE. We control for state and year FEs. Standard errors are clustered by facility. 


\section{B Supplementary Figures and Tables}

Figure B.1: PE deals for Nursing Homes by Year

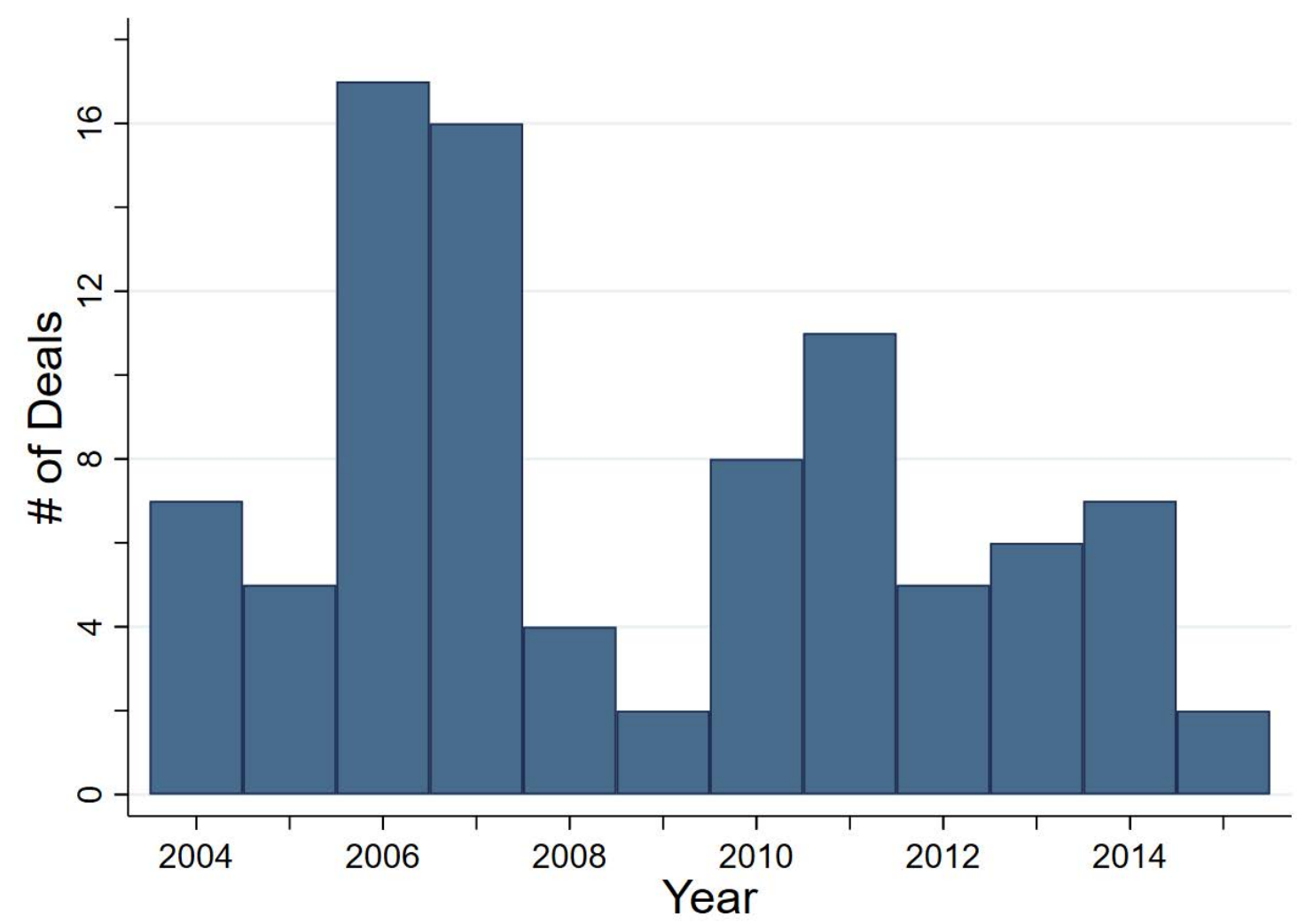

Note: This figure presents the number of unique deals for active nursing homes by PE firms for each year over the period 2004-2015. 
Figure B.2: Location of Private Equity Targets

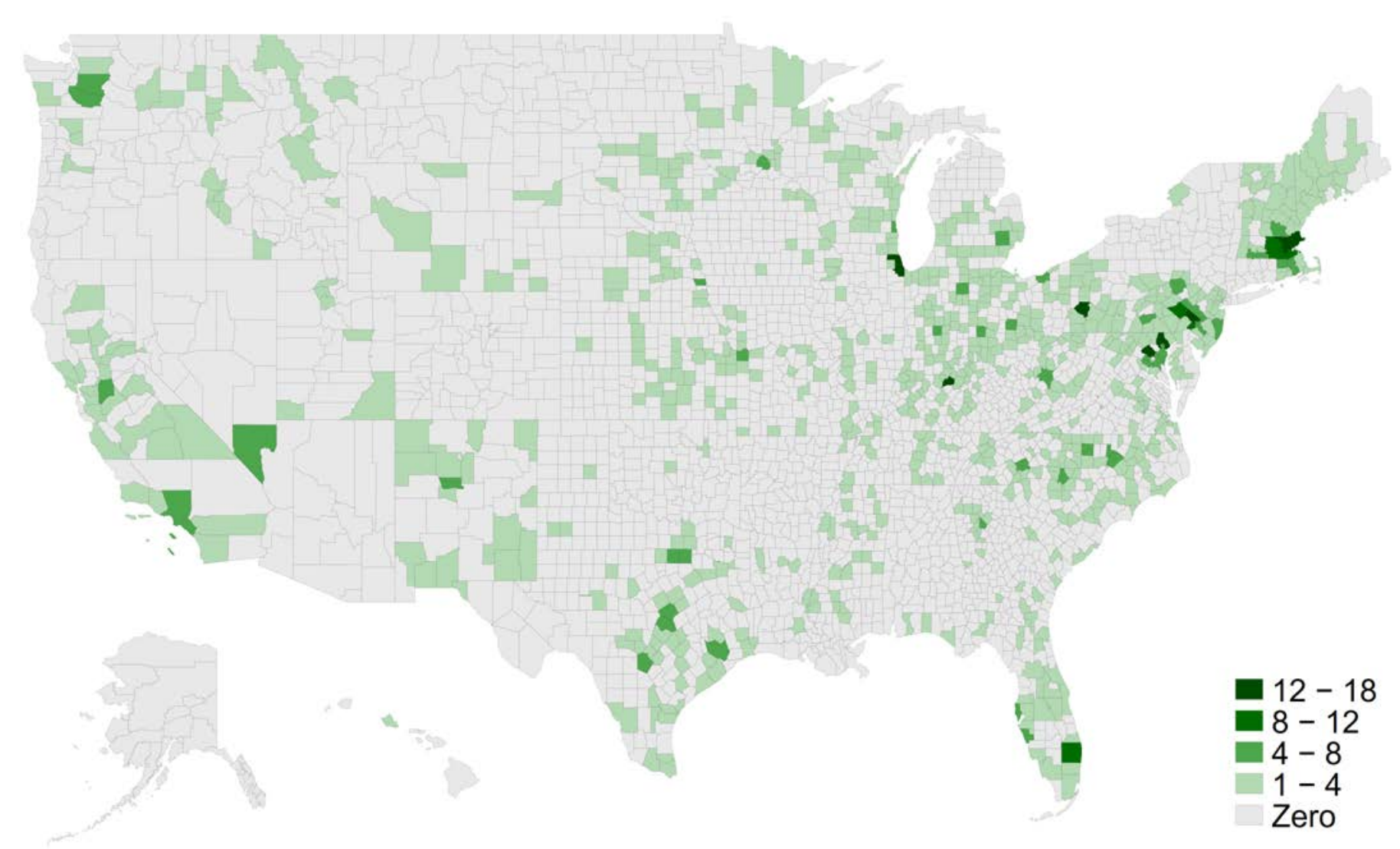

Note: This figure presents the number of facilities bought by PE firms in each county over the period 20042015. We identified 1,674 such facilities. 
Figure B.3: Initial Patient Assesments

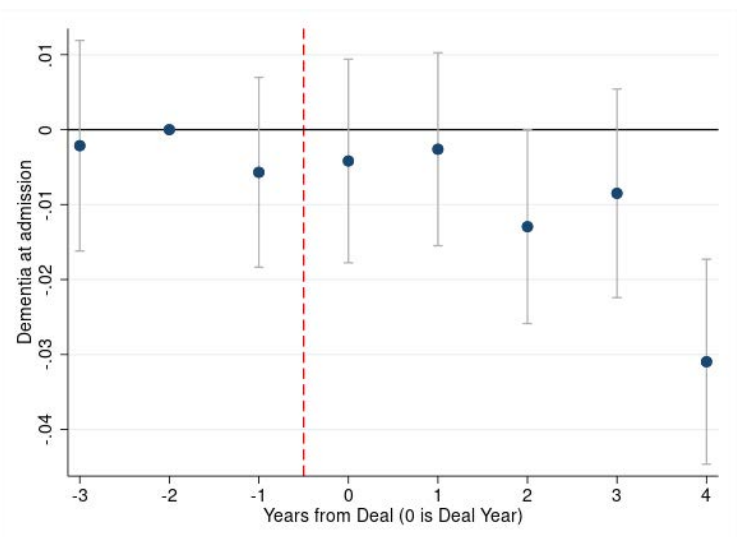

A: Dementia

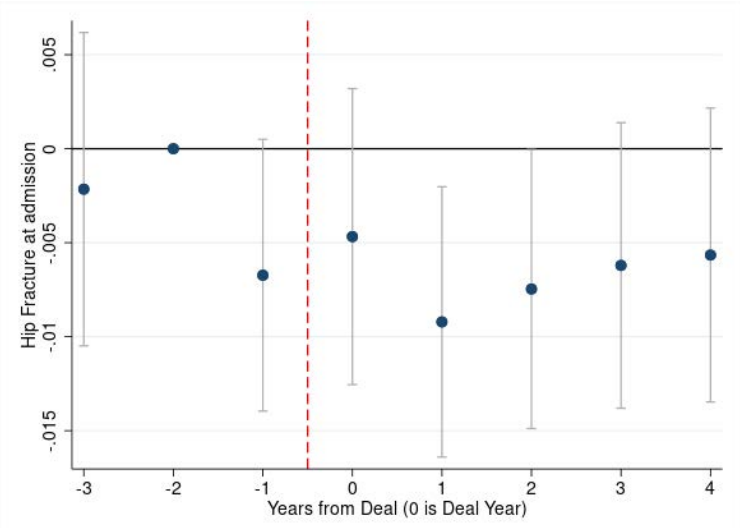

C: Hip Fracture

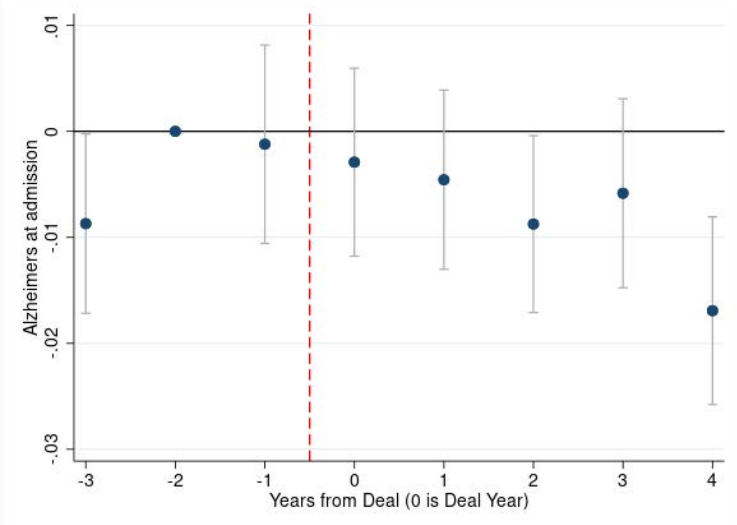

B: Alzheimers

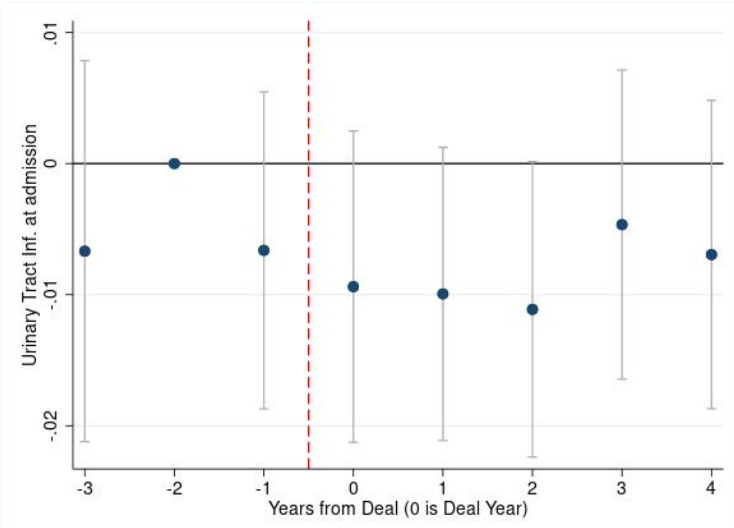

D: Urinary Tract Infection

Note: This figure presents event studies on initial patient assessments around the time a nursing home experiences a PE buyout. To match the event study plots presented in the main text, we estimate these models on collapsed facility-year level data and use the same specification, i.e., facility and year fixed effects, patient mix, and market controls, as described in Section 6.1. Each point in the figures represents the coefficient $\beta_{s}$ obtained by estimating Equation (10) as discussed in Section 6. Year $=-2$ is the omitted point. Panel A presents results on the share of patients diagnosed with Dementia, Panel B on Alzheimers, Panel C on Hip Fractures, and Panel D on Urinary Tract Infections, respectively, at admission to the index nursing home stay. Standard errors are clustered by facility. 
Figure B.4: Patient distance to Nursing Home

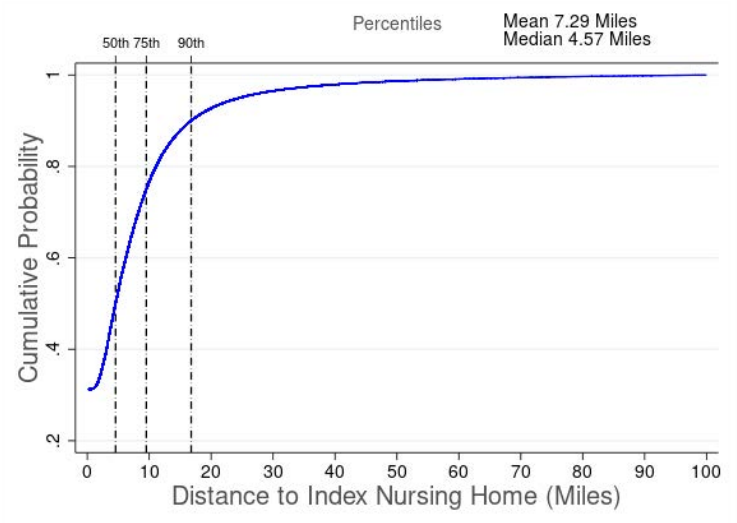

A: CDF: All Patients

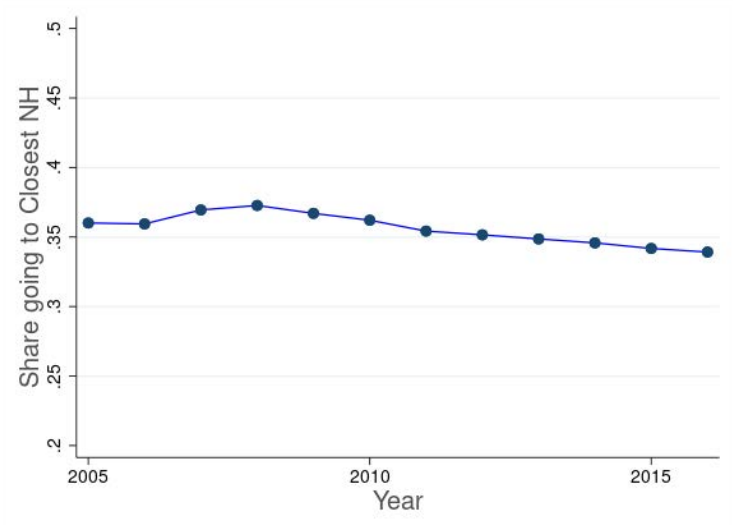

C: Trendline: Share going to Closest Nursing Home

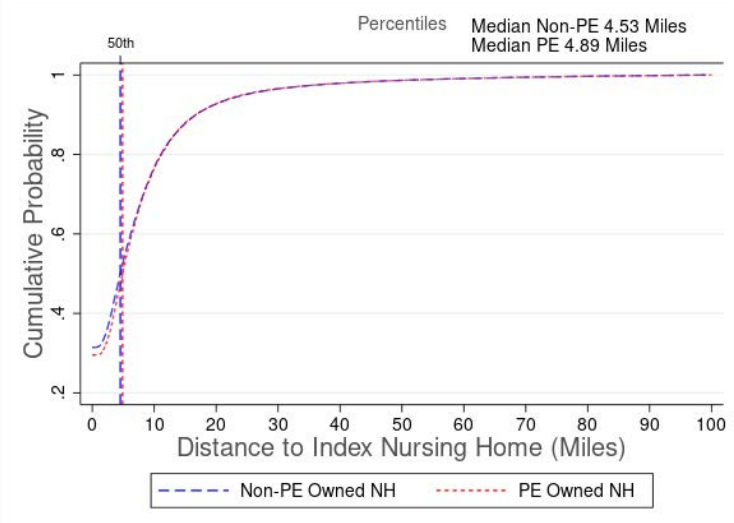

B: CDF: PE vs. Non-PE Patients



D: Event Study: PE Acquisition

Note: This figure provides descriptes on patient zip code distance to index nursing home zip code. Panels A and $\mathrm{B}$ present CDFs of the distance from patient zip code to index nursing home zip code. Panel A presents the CDF pooling PE and non-PE patients together. It also identifies the median, 75th and 90th percentile values. Panel B presents the CDFs separately for PE and non-PE patients, and their respective median values. Panel $\mathrm{C}$ presents the annual trendline for the share of patients going to their closest nursing home. Panel D presents the event study of the mean patient distance around a PE acquisition. Each point in the figure represents the coefficient $\beta_{s}$ obtained by estimating Equation (10) as discussed in Section 6. Year $=-2$ is the omitted point. The model includes facility and HRR x year fixed effects, patient mix, and market controls. Standard errors are clustered by facility. 
Figure B.5: Patient Outcome Measures

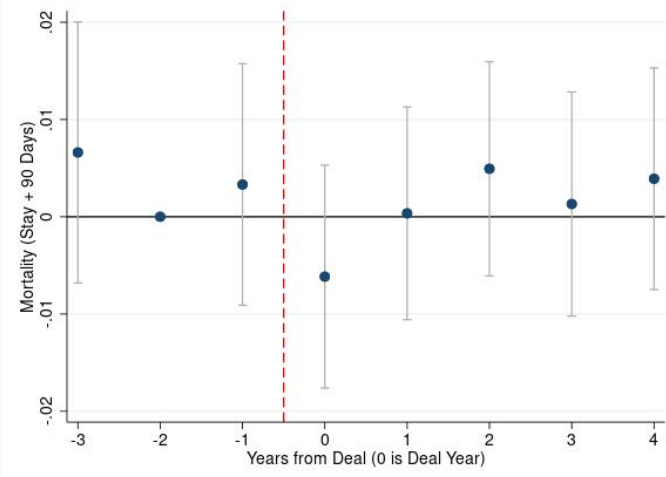

A: Mortality (Stay + 90 Days)

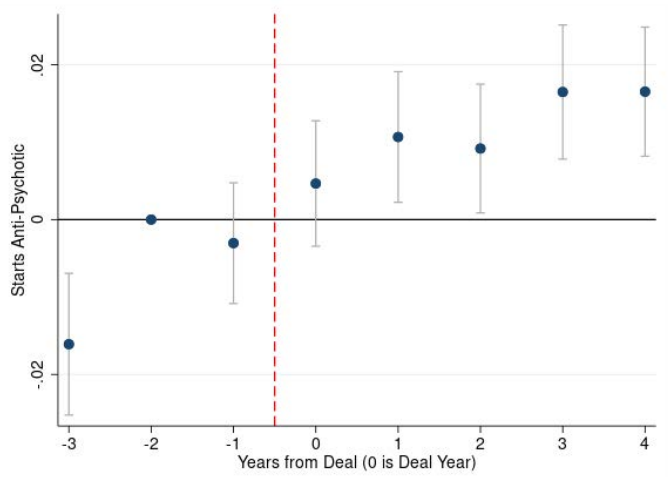

C: 1(Starts Antipsychotic Medications)

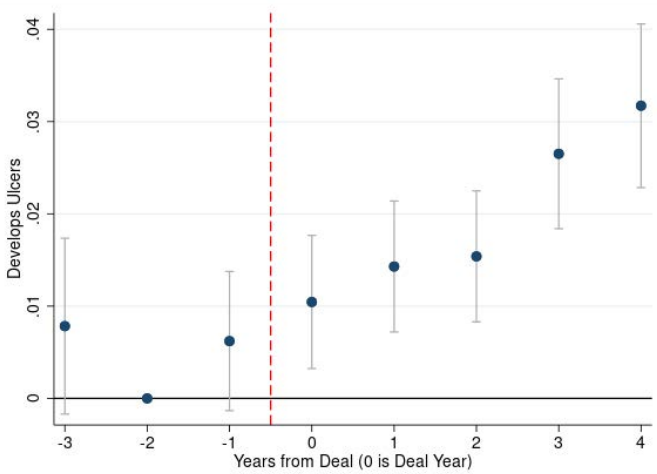

E: 1(Develops Ulcers)

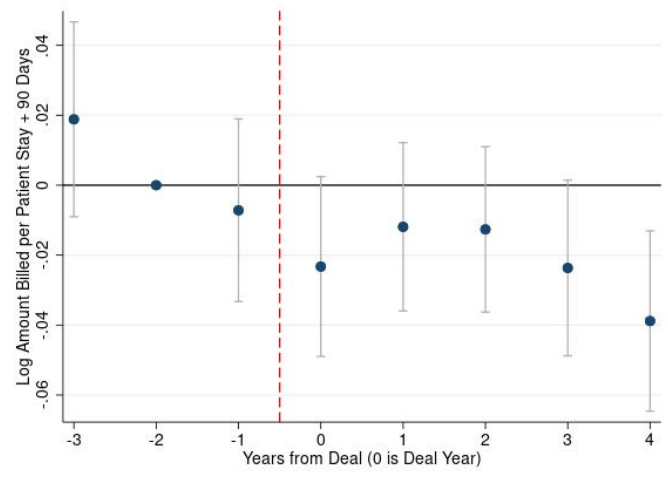

B: Log Amount Billed (Patient Stay + 90 Days)

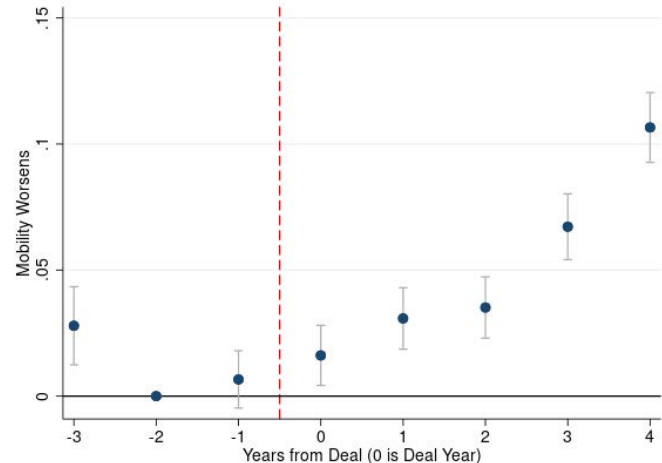

D: 1(Mobility Decreases)

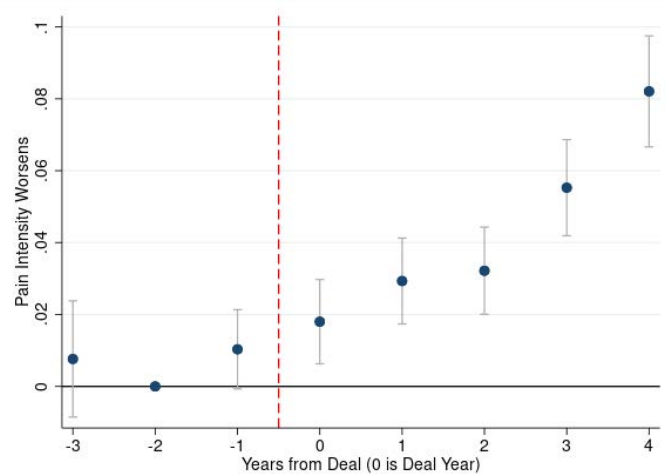

F: 1(Pain Intensity Increases)

Note: This figure presents event studies on patient outcome measures around the time a nursing home experiences a PE buyout. To match the event study plots presented in the main text, we estimate these models on collapsed facility-year level data and use the same specification, i.e., facility and year fixed effects, patient mix, and market controls, as described in Section 6.1. Each point in the figures represents the coefficient $\beta_{s}$ obtained by estimating Equation (10) as discussed in Section 6. Year $=-2$ is the omitted point. Panels A and $\mathrm{B}$ present results on the share of patients dying within 90 days of discharge from the index stay, and total amount billed over the 90-day episode including the index stay (2016\$). Panels $\mathrm{C}$ to F present results for MDS assessment based outcomes - the facility level mean for indicators for patient starting antipyschotics, decrease in patient mobility, developing/worsening pressure ulcers, and increase in pain intensity respectively. Spending is winsorized at the $1 \%$ and $99 \%$ level. Standard errors are clustered by facility. 
Figure B.6: MTE: Additional figures

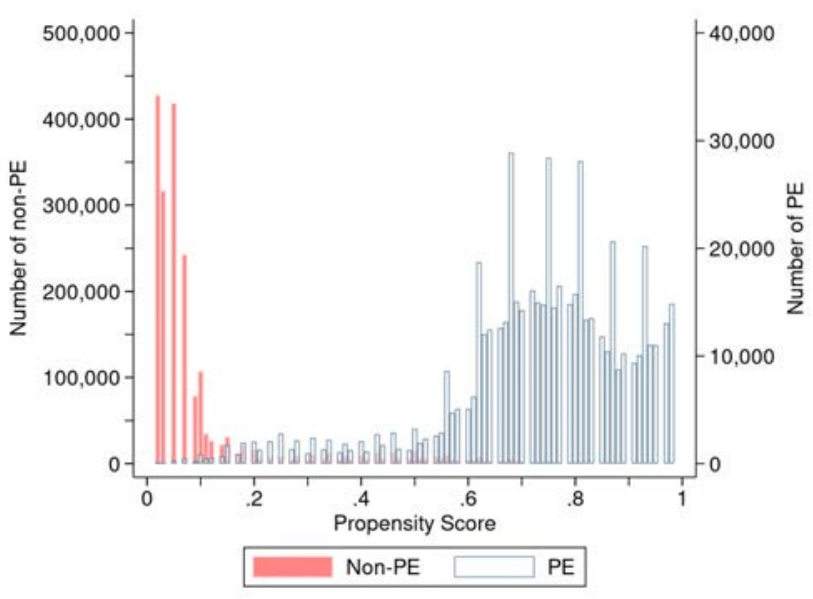

A: Common Support

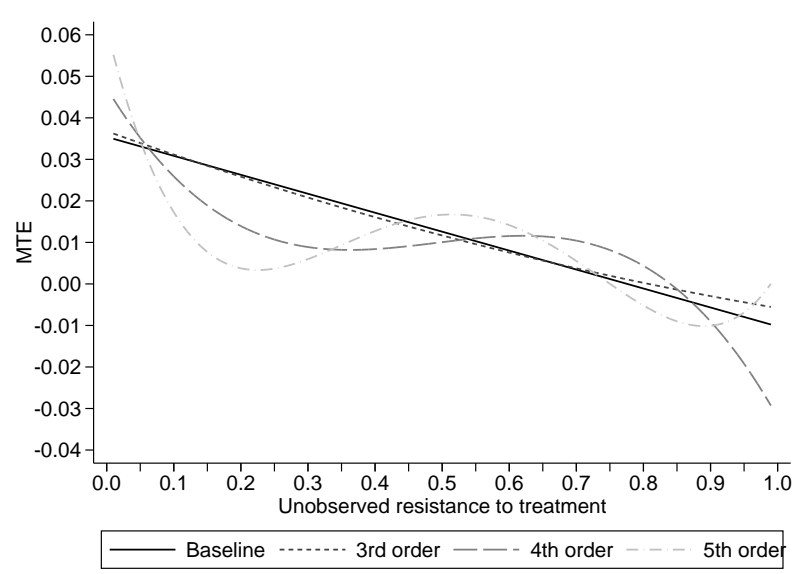

B: Order of polynomial

Note: This figure presents additional plots pertaining to Marginal Treatment Effects (MTE) analysis using the Medicare patient-level data. Panel A presents the overlap in distributions of PE and non-PE groups by propensity score, using a linear scale for the Y-axis. Panel B demonstrates robustness of the slope of the MTE curve to using different orders of polynomials. Section 5.2.2 presents details of the MTE estimation. 
Figure B.7: Staff Availability and Five Star Ratings

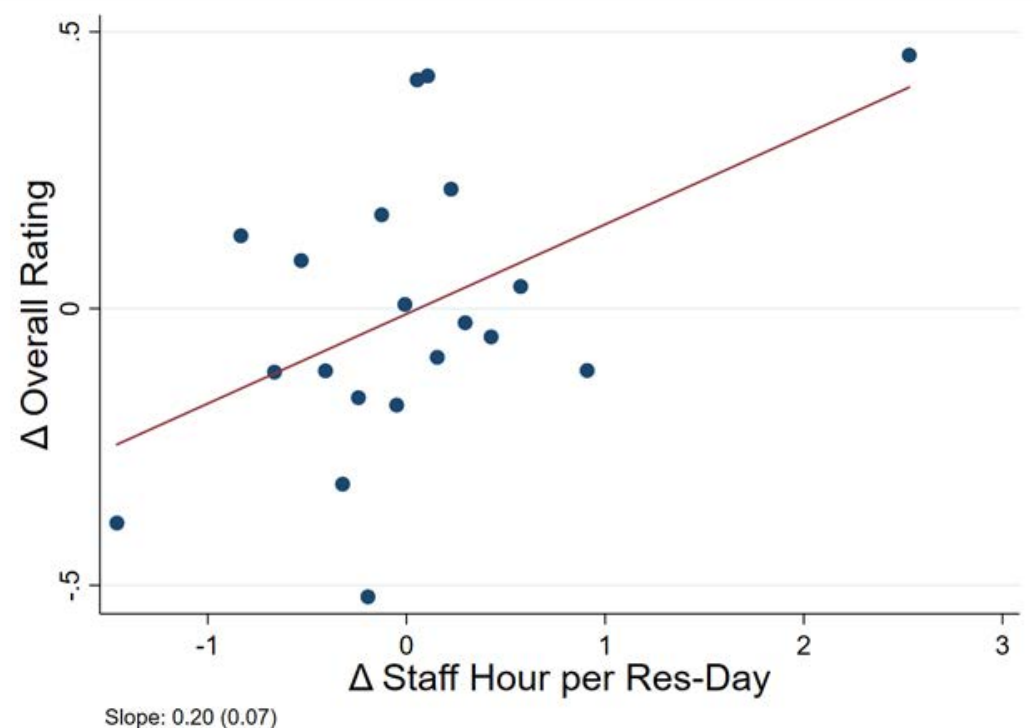

A: Overall Rating

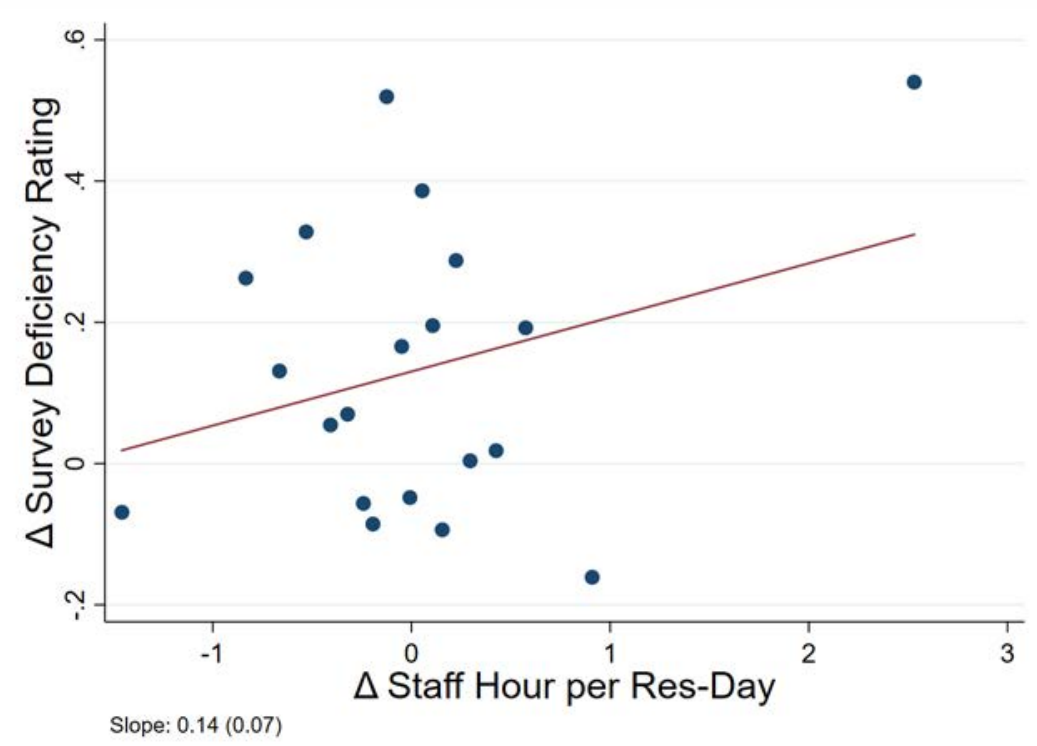

B: Deficiency Rating

Note: This figure presents scatter plots of changes in total staff hours available per patient day in the three years post-PE buyout versus three years pre-buyout on the X-axis, against changes in CMS Five-star rating over the same period on the Y-axis. Panel A presents overall rating, and Panel B presents survey based deficiency ratings. The data was collapsed into 20 equal sized bins and we plot the means in each bin. The figures also present fitted lines for these plots obtained using linear regressions on the underlying data. Each plot also presents the slope coefficient with standard error. 
Figure B.8: Patient Volume

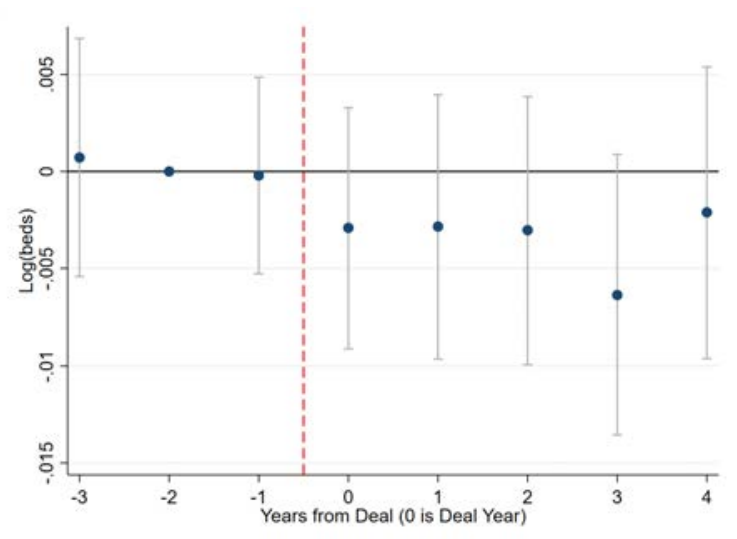

A: Log Beds - Facility

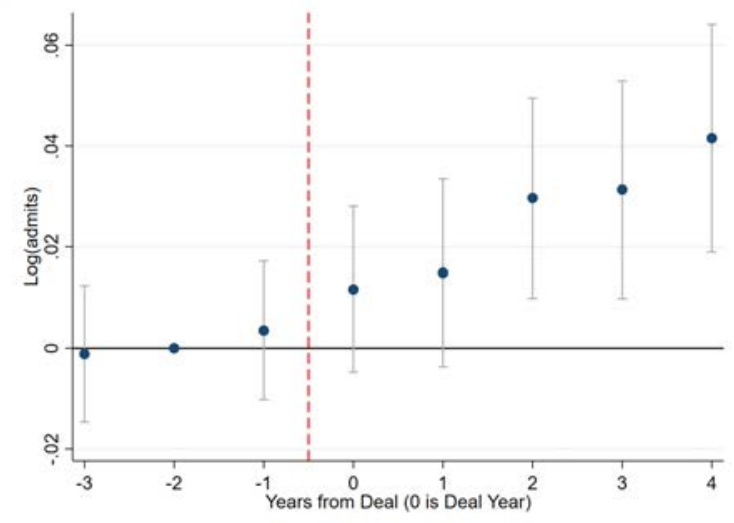

B: Log Admissions - Facility



C: Log Admissions - Market (HRR)

Note: This figure presents event studies on facility characteristics around the time a nursing home experiences a PE buyout. Each point in the figures represents the coefficient $\beta_{s}$ obtained by estimating Equation (10) as discussed in Section 6. Year $=-2$ is the omitted point. Panels A and B present results on the log of beds and admissions at the facility level, and Panel C on log admissions at the market level (HRR). All models - except when studying market-level volume - include facility and year fixed effects, patient mix, and market controls, as described in Section 6.1. All dependent variables are winsorized at 1\% and 99\% levels. Standard errors are clustered by facility. 
Table B.1: Top 10 Private Equity Deals

\begin{tabular}{|c|c|c|c|c|}
\hline $\begin{array}{l}\text { Sr. } \\
\text { No. }\end{array}$ & $\begin{array}{l}\text { Target } \\
\text { Name }\end{array}$ & $\begin{array}{l}\text { Private Equity } \\
\text { Firm(s) }\end{array}$ & $\begin{array}{l}\text { Deal } \\
\text { Year }\end{array}$ & $\begin{array}{c}\text { Number of } \\
\text { Facilities }\end{array}$ \\
\hline 1 & Genesis Healthcare & Formation Capital, JER Partners & $2007-15$ & 327 \\
\hline 2 & Golden Living & Fillmore Capital Partners & 2006 & 321 \\
\hline 3 & Kindred Healthcare & Signature Healthcare, Hillview Capital & 2014 & 150 \\
\hline 4 & HCR Manorcare & Stockwell Capital, The Carlyle Group & $2007-18$ & 145 \\
\hline 5 & Mariner Healthcare & Fillmore Capital Partners & 2004 & 95 \\
\hline 6 & Skilled Healthcare Group & Onex, Heritage Partners & $2005-07$ & 76 \\
\hline 7 & Trilogy Investors & Lydian Capital Partners & $2007-15$ & 65 \\
\hline 8 & Lavie Care Centers & Formation Capital, Senior Care Development & 2011 & 61 \\
\hline 9 & Laurel Health Care Company & Formation Capital, Longwing Real Estate Ventures & $2006-16$ & 41 \\
\hline 10 & Harden Healthcare & NXT Capital, Oaktree Speciality Lending & 2013 & 35 \\
\hline
\end{tabular}

Note: This table presents some details on the top 10 PE deals in our sample, ordered by the number of unique nursing home facilities involved in the deal. This represents the number of facilities we were able to identify and match in our administrative data, the actual number of facilities in the deal may have been different. We set the PE indicator to turn on in the year following the deal year. If a closing year is mentioned, it implies the PE investors exited or went public in that year. Accordingly, we turn off the PE indicator in the closing year. 
Table B.2: Complier Characteristics

\begin{tabular}{|c|c|c|c|c|}
\hline & Observations & Coefficient & (Std. Errors) & Ratio \\
\hline Full Sample & $7,365,934$ & $-0.0445 * * *$ & $(0.003)$ & \\
\hline \multicolumn{5}{|l|}{ A. Age \& Risk } \\
\hline Low Risk, 65-80 & $2,052,655$ & $-0.0405 * * *$ & $(0.002)$ & 0.91 \\
\hline High Risk, 65-80 & 881,854 & $-0.0471 * * *$ & $(0.003)$ & 1.06 \\
\hline Low Risk, 80+ & $3,326,940$ & $-0.0451 * * *$ & $(0.003)$ & 1.01 \\
\hline High Risk, 80+ & $1,104,387$ & $-0.0478 * * *$ & $(0.003)$ & 1.07 \\
\hline \multicolumn{5}{|l|}{ B. Gender } \\
\hline Male & $2,640,611$ & $-0.0456^{* * *}$ & $(0.003)$ & 1.02 \\
\hline Female & $4,725,295$ & $-0.0439 * * *$ & $(0.003)$ & 0.99 \\
\hline \multicolumn{5}{|l|}{ C. Marital Status } \\
\hline Unmarried & $4,838,365$ & $-0.0446 * * *$ & $(0.003)$ & 1.00 \\
\hline Married & $2,527,548$ & $-0.0439 * * *$ & $(0.003)$ & 0.99 \\
\hline \multicolumn{5}{|c|}{ D. Beneficiary Zip Income } \\
\hline Income $<$ Median & $3,681,687$ & $-0.0554 * * *$ & $(0.004)$ & 1.24 \\
\hline Income $>$ Median & $3,684,035$ & $-0.0353 * * *$ & $(0.003)$ & 0.79 \\
\hline \multicolumn{5}{|l|}{ E. Race } \\
\hline White & $6,483,451$ & $-0.0451 * * *$ & $(0.003)$ & 1.01 \\
\hline Other & 881,923 & $-0.0380 * * *$ & $(0.003)$ & 0.85 \\
\hline
\end{tabular}

Note: This table presents first stage equivalent estimates of the 2SLS for various patient subsamples. We present the coefficient $\beta$, obtained by estimating the equation $P E_{i}=$ $\alpha_{j}+\alpha_{m, t}+\beta 1\left(D D_{i}>\right.$ Median $)+\epsilon_{i} .1\left(D D_{i}>\right.$ Median $)$ is an indicator for patient $i$ 's differential distance to the nearest PE-owned facility being greater than the median value. The model includes facility $j$ and patient HRR $x$ year fixed effects, but no other controls. We divide the sample by age and risk, gender, marital status, income in patient zip code, and race. Details are available in Section 4.2. We also present the ratio of the coefficient obtained for each subsample to that for the full sample. Standard errors are clustered by facilities. 
Table B.3: Mortality Effects by Duration

\begin{tabular}{lcccc}
\hline & $(1)$ & $(2)$ & $(3)$ & $(4)$ \\
& (Stay + 30 Days) & $($ Stay +60 Days) & $($ Stay +90 Days) & $($ Stay + 365 Days) \\
\hline $1(\mathrm{PE})$ & 0.009 & $0.0148^{* *}$ & $0.0169 * *$ & $0.0239 * * *$ \\
& $(0.006)$ & $(0.007)$ & $(0.007)$ & $(0.008)$ \\
& & & & \\
Observations & $7,365,934$ & $7,365,934$ & $7,365,934$ & $7,365,934$ \\
Y-Mean & 0.12 & 0.15 & 0.17 & 0.24 \\
F-Stat & 223.9 & 223.9 & 223.9 & 223.9 \\
Coefficient/ Y-Mean & $8 \%$ & $10 \%$ & $10 \%$ & $10 \%$ \\
\hline
\end{tabular}

Note: This table presents estimates of the relationship between PE ownership and patient mortality. Each cell presents the coefficient $\beta$ obtained by estimating Equation (2) by 2SLS. The independent variable is an indicator for the patient being admitted to a PE nursing home, instrumented by differences in distance to the nearest PE and non-PE facility. We present effects for mortality at different durations - patient death within 30,60, 90, and 365 days of discharge from the index stay. All regressions include facility and patient HRR x year fixed effects, and patient risk controls. Patient risk controls include age, race, gender, marital status, indicators for 17 pre-existing conditions used to compute the Charlson Index, and an indicator for dual eligibility. Standard errors are clustered by facility. 
Table B.4: Mortality Costs

\begin{tabular}{|c|c|c|}
\hline & $\begin{array}{c}(1) \\
\text { Male }\end{array}$ & $\begin{array}{c}(2) \\
\text { Female }\end{array}$ \\
\hline \multicolumn{3}{|l|}{ A: IV estimates } \\
\hline $1(\mathrm{PE})$ & $\begin{array}{l}0.0105 \\
(0.012)\end{array}$ & $\begin{array}{c}0.0210 * * \\
(0.008)\end{array}$ \\
\hline Observations & $2,640,611$ & $4,725,295$ \\
\hline Y-Mean & 0.21 & 0.14 \\
\hline F-Stat & 221 & 221 \\
\hline \multicolumn{3}{|l|}{ B: Placebo } \\
\hline $1(\mathrm{PE})$ & $\begin{array}{l}0.0091 \\
(0.006)\end{array}$ & $\begin{array}{l}0.0044 \\
(0.005)\end{array}$ \\
\hline Observations & $2,497,830$ & $4,661,700$ \\
\hline Y-Mean & 0.23 & 0.15 \\
\hline F-Stat & 431 & 440 \\
\hline \multicolumn{3}{|l|}{ C: Calculations } \\
\hline Number of Patients in PE Facilities & 435,035 & 741,838 \\
\hline Additional Deaths & 4,568 & 15,579 \\
\hline Total Lives Lost & \multicolumn{2}{|c|}{20,146} \\
\hline Mean Life Expectancy & 6.7 & 8.2 \\
\hline Additional Loss in Person Years & 30,814 & 128,384 \\
\hline Total Person Years Lost & \multicolumn{2}{|c|}{159,198} \\
\hline Value of Life Year (2016\$) & \multicolumn{2}{|c|}{130,000} \\
\hline Total Cost $(2016 \$)$ & \multicolumn{2}{|c|}{ 20.7 Billion } \\
\hline
\end{tabular}

Note: This table presents estimates of additional deaths, life-years lost, and the associated cost using standard estimates of statistical value of a life-year due to PE ownership of nursing homes. Panel A presents the coefficient $\beta$ obtained by estimating Equation (2) by 2 SLS. The independent variable is the indicator for a patient being admitted to a PE nursing home, instrumented by differences in distance to the nearest non-PE and PE nursing home. The outcome variable is an indicator for patient death within 90 days of discharge from the index stay. Panel B presents a placebo analysis for this patient subsample using the same approach as for the whole sample, as presented in Table 4. All models include facility and patient HRR x year fixed effects and the usual patient risk controls as in the main specification. Standard errors are clustered by facility. Panel C presents calculations to estimate lives, life-years lost and total cost based on Panel A coefficients. We calculate average life expectancy at discharge (by gender) using the observed distribution of lifespans for Medicare patients. For patients still alive at the end of our sample, we assign a year of death based on patient gender and age using Social Security actuary tables. We adjust downward the resulting life expectancy to account for the fact the decedents tend to be older than the average nursing home patient (about two years). 
Table B.5: Patient-Level Analysis: OLS Results

\begin{tabular}{|c|c|c|c|c|}
\hline & \multicolumn{4}{|c|}{ A: Initial Patient Assesments } \\
\hline & (1) & (2) & (3) & (4) \\
\hline & Dementia & Alzheimers & Hip Fracture & Urinary Tract Infec. \\
\hline & At Admission & At Admission & At Admission & At Admission \\
\hline $1(\mathrm{PE})$ & $-0.0098 * * *$ & $-0.0040 * * *$ & $-0.0034 * * *$ & $0.0044 * *$ \\
\hline & $(0.002)$ & $(0.001)$ & $(0.001)$ & $(0.002)$ \\
\hline Observations & $7,365,934$ & $7,365,934$ & $7,365,934$ & $7,365,934$ \\
\hline \multirow[t]{4}{*}{ Y-Mean } & 0.16 & 0.05 & 0.09 & 0.16 \\
\hline & \multicolumn{4}{|c|}{ B: Main Outcomes } \\
\hline & (1) & (2) & (3) & \\
\hline & $\begin{array}{c}\text { Mortality } \\
\text { (Stay + } 90 \text { Days })\end{array}$ & $\begin{array}{l}\text { Log Amount Billed } \\
\text { Per Patient Stay }\end{array}$ & $\begin{array}{c}\text { Log Amount Billed } \\
\text { Per Patient Stay + } 90 \text { Days }\end{array}$ & \\
\hline $1(\mathrm{PE})$ & $0.0034 * * *$ & $-0.0221 * * *$ & $-0.0118 * *$ & \\
\hline & $(0.001)$ & $(0.006)$ & $(0.005)$ & \\
\hline Observations & $7,365,934$ & $7,365,934$ & $7,365,934$ & \\
\hline \multirow[t]{5}{*}{ Y-Mean } & 0.17 & 9.07 & 9.57 & \\
\hline & \multicolumn{4}{|c|}{ C: Assesment Based Outcomes } \\
\hline & (1) & (2) & (3) & (4) \\
\hline & 1(Starts Anti- & 1(Mobility & 1(Develops & 1(Pain Intensity \\
\hline & Psychotics) & Decreases) & Ulcers) & Increases) \\
\hline $1(\mathrm{PE})$ & $0.0115^{* * *}$ & $0.0349 * * *$ & $0.0094 * * *$ & $0.0266 * * *$ \\
\hline & $(0.001)$ & $(0.003)$ & $(0.003)$ & $(0.005)$ \\
\hline Observations & $7,365,934$ & $7,365,934$ & $7,365,934$ & $7,365,934$ \\
\hline Y-Mean & 0.06 & 0.53 & 0.09 & 0.27 \\
\hline
\end{tabular}

Note: This table presents OLS estimates of the relationship between PE ownership and patient health and spending. Each cell presents the coefficient $\beta$ obtained by estimating Equation (2) by OLS. The independent variable is an indicator for the patient being admitted to a PE nursing home. In Panel A, we present effects for initial patient assessments - dementia, alzheimers, hip fracture and urinary tract infection at time of admission. In Panel B, we present effects on patient death within 90 days of discharge from the index stay and total amount billed during the stay and during the 90 day episode (2016\$). Panel C presents results for assessment based outcomes recorded in the MDS - an indicator for patient starting antipyschotics, decrease in patient mobility, developing/worsening pressure ulcers, and increase in pain intensity. All regressions include facility and patient HRR x Year fixed effects, and patient risk controls. Patient risk controls include age, race, gender, marital status, indicators for 17 pre-existing conditions used to compute the Charlson Index, and an indicator for dual eligibility. Standard errors are clustered by facility. 
Table B.6: Robustness: Facility-Level Outcomes

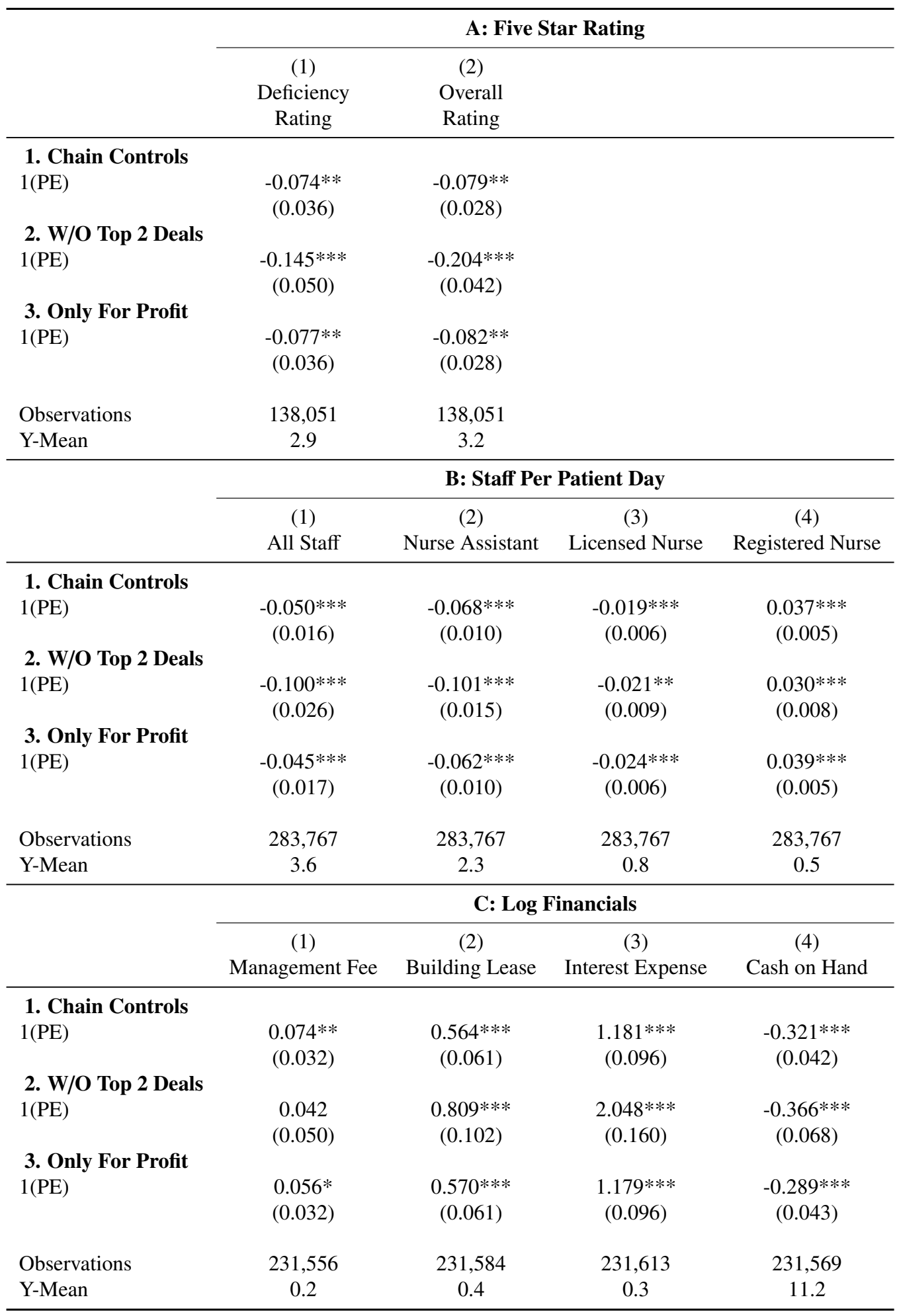

Note: This table presents robustness tests on the estimates of the relationship between PE buyouts and Five star ratings, nurse availability, and financials. The corresponding main results are presented Table 8 . Each cell presents the coefficient $\beta$ obtained by estimating Equation (9) with a different outcome. The independent variable is an indicator for whether a nursing home is PE-owned (=1 if PE-owned, 0 otherwise) starting in the next year from the deal announcement date. We control for a chain indicator in the first row, remove the top 2 deals by size in the second row, and estimate the results on a sample limited to for-profit facilities in the third row. We do not present results limiting to the Top 5 deals as Five Star ratings are only available post-2009, and 4 Top 5 deals occurred before 2009. All models include facility and year fixed effects. All variables are winsorized at $1 \%$ and $99 \%$ levels. Standard errors are clustered by facility. 
Table B.7: Patient Volume

\begin{tabular}{|c|c|c|c|}
\hline & \multicolumn{2}{|c|}{ Facility Level } & \multirow{2}{*}{$\begin{array}{c}\text { Market Level } \\
(3) \\
\text { Log } \\
\text { Admissions }\end{array}$} \\
\hline & $\begin{array}{c}(1) \\
\text { Log } \\
\text { Beds }\end{array}$ & $\begin{array}{c}\text { (2) } \\
\text { Log } \\
\text { Admissions }\end{array}$ & \\
\hline $\begin{array}{l}1(\mathrm{PE}) \\
\text { (No Control) }\end{array}$ & $\begin{array}{l}-0.002 \\
(0.003)\end{array}$ & $\begin{array}{c}0.036^{* * * *} \\
(0.009)\end{array}$ & $\begin{array}{c}0.014 \\
(0.014)\end{array}$ \\
\hline $\begin{array}{l}1(\mathrm{PE}) \\
\text { (With Control) }\end{array}$ & $\begin{array}{l}-0.003 \\
(0.003)\end{array}$ & $\begin{array}{c}0.035 * * * \\
(0.009)\end{array}$ & $\begin{array}{c}0.007 \\
(0.011)\end{array}$ \\
\hline Observations & 283,767 & 283,767 & 5,364 \\
\hline Y-Mean & 4.5 & 4.8 & 12.7 \\
\hline
\end{tabular}

Note: This table presents estimates of the relationship between PE ownership and patient volume. Each cell presents the coefficient $\beta$ obtained by estimating Equation (9) with a different outcome. The independent variable is an indicator for whether a nursing home is PE-owned (=1 if PE-owned, 0 otherwise) starting in the next year from the deal announcement date. We present results on the log number of beds, log number of admissions in facility, and log number of admissions at HRR level. The bottom row presents the results including controls, which consist of market-level and patient mix controls, as described in Section 6.1. All models include facility and year fixed effects. All variables are winsorized at $1 \%$ and $99 \%$ levels. Standard errors are clustered by facility. 